Florida International University FIU Digital Commons

$3-27-2012$

\title{
A Hermeneutic Phenomenology of Graduate Education Students' Understandings of Instructor Power in a Higher Education Classroom
}

Antonio Delgado

Florida International University, adelg009@fiu.edu

DOI: $10.25148 /$ etd.FI12041113

Follow this and additional works at: https://digitalcommons.fiu.edu/etd

\section{Recommended Citation}

Delgado, Antonio, "A Hermeneutic Phenomenology of Graduate Education Students' Understandings of Instructor Power in a Higher Education Classroom" (2012). FIU Electronic Theses and Dissertations. 562.

https://digitalcommons.fiu.edu/etd/562 


\section{FLORIDA INTERNATIONAL UNIVERSITY}

Miami, Florida

\section{A HERMENEUTIC PHENOMENOLOGY OF GRADUATE EDUCATION STUDENTS' UNDERSTANDINGS OF INSTRUCTOR POWER IN \\ A HIGHER EDUCATION CLASSROOM}

A dissertation submitted in partial fulfillment of

the requirements for the degree of

DOCTOR OF EDUCATION

in

ADULT EDUCATION AND HUMAN RESOURCE DEVELOPMENT

by

Antonio Delgado

2012 
To: Dean Delia C. Garcia

College of Education

This dissertation, written by Antonio Delgado, and entitled A Hermeneutic Phenomenology of Graduate Education Students' Understandings of Instructor Power in a Higher Education Classroom, having been approved in respect to style and intellectual content, is referred to you for judgment.

We have read this dissertation and recommend that it be approved.

Benjamin Baez

Hilary Landorf

Thomas G. Reio, Jr.

Tonette S. Rocco, Major Professor

Date of Defense: March 27, 2012

The dissertation of Antonio Delgado is approved.

Dean Delia C. Garcia

College of Education

Dean Lakshmi N. Reddi

University Graduate School

Florida International University, 2012 
(C) Copyright 2012 by Antonio Delgado

All rights reserved. 


\section{DEDICATION}

I dedicate this dissertation to my mother, Mirtha Delgado, and my late father, Leonardo Delgado, for their love and support. Without their courage and conviction to leave everyone and everything behind in their native Cuba, neither I nor this dissertation would have been possible. 


\section{ACKNOWLEDGMENTS}

I wish to express my deepest appreciation to the members of my dissertation committee, Drs. Tonette S. Rocco, Hilary Landorf, Thomas G. Reio, and Benjamin Baez for their guidance and support. Special gratitude is extended to my major professor, Dr. Tonette S. Rocco, whose guidance was crucial for developing my dissertation and my personal metamorphosis into a scholar and writer.

I also wish to thank my peer review group and the rest of my dissertation group members for their invaluable time and support throughout the years we have worked together. I am particularly indebted to Ms. Rehana Seepersad for being such a supportive friend and colleague every step of the way. I extend a special thanks to my friend, Dr. Masha Plakhotnik, for her patience, encouragement, advice, and willingness to share a drink (or two) when I needed it the most.

To the wonderful faculty librarian, Ms. Patricia Pereira-Pujol, thank you for listening to me all these years and providing me support when I felt buried in information.

Thank you to my employer, Miami Dade College, for being so good to me for 8 years now. I am particularly thankful to my supervisor and friend, Ms. Cecilia Bermudez, for her understanding and support every time I needed to put my doctoral studies ahead of work and also helping me keep the big picture in perspective. I also want to thank my friend and colleague, Ms. Yoly Rebollida, for being one of my biggest cheerleaders. 
ABSTRACT OF THE DISSERTATION

A HERMENEUTIC PHENOMENOLOGY OF GRADUATE EDUCATION STUDENTS' UNDERSTANDINGS OF INSTRUCTOR POWER IN A HIGHER EDUCATION CLASSROOM by

Antonio Delgado

Florida International University, 2012

Miami, Florida

Professor Tonette S. Rocco, Major Professor

Higher education is a distribution center of knowledge and economic, social, and cultural power (Cervero \& Wilson, 2001). A critical approach to understanding a higher education classroom begins with recognizing the instructor's position of power and authority (Tisdell, Hanley, \& Taylor, 2000). The power instructors wield exists mostly unquestioned, allowing for teaching practices that reproduce the existing societal patterns of inequity in the classroom (Brookfield, 2000).

The purpose of this hermeneutic phenomenological study was to explore students' experiences with the power of their instructors in a higher education classroom. A hermeneutic phenomenological study intertwines the interpretations of both the participants and the researcher about a lived experience to uncover layers of meaning because the meanings of lived experiences are usually not readily apparent (van Manen, 1990). Fifteen participants were selected using criterion, convenience, and snowball sampling. The primary data gathering method were semi-structured interviews guided by 
an interview protocol (Creswell, 2003). Data were interpreted using thematic reflection (van Manen, 1990).

Three themes emerged from data interpretation: (a) structuring of instructorstudent relationships, (b) connecting power to instructor personality, and (c) learning to navigate the terrains of higher education. How interpersonal relationships were structured in a higher education classroom shaped how students perceived power in that higher education classroom. Positive relationships were described using the metaphor of family and a perceived ethic of caring and nurturing by the instructor. As participants were consistently exposed to exercises of instructor power in a higher education classroom, they attributed those exercises of power to particular instructor traits rather than systemic exercises of power. As participants progressed from undergraduate to graduate studies, they perceived the benefits of expertise in content or knowledge development as secondary to expertise in successfully navigating the social, cultural, political, and interpersonal terrains of higher education. Ultimately, participants expressed that higher education is not about what you know; it is about learning how to play the game. Implications for teaching in higher education and considerations for future research conclude the study. 


\section{TABLE OF CONTENTS}

CHAPTER

PAGE

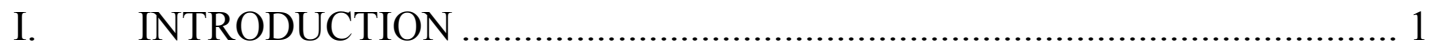

Background of the Problem ....................................................................

Problem Statement ................................................................................5

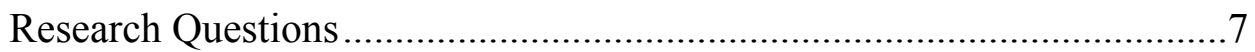

Conceptual Framework ..........................................................................

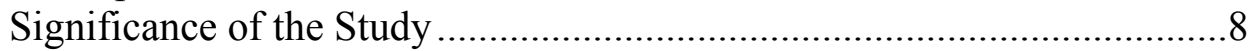

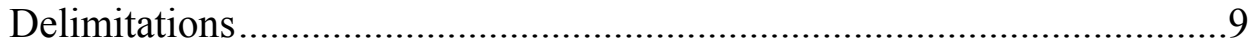

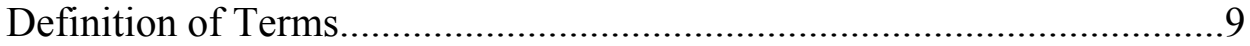

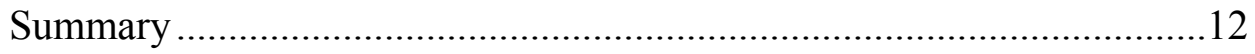

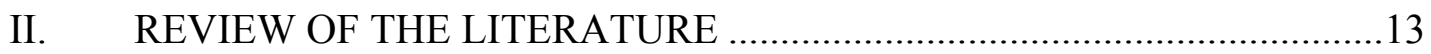

Emotions as a Context for Understanding Power ......................................13

The Higher Education Classroom as a Context for Understanding Power........................................................................18

The Higher Education System as a Context for Understanding Power ....24

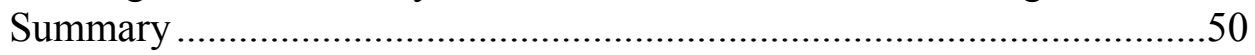

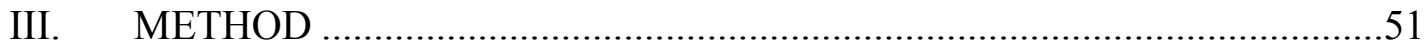

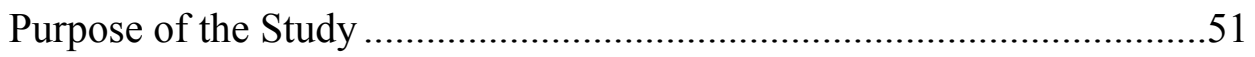

Research Questions .................................................................................51

Hermeneutic Phenomenology as a Research Design.................................52

Pre-understandings to This Study ..........................................................53

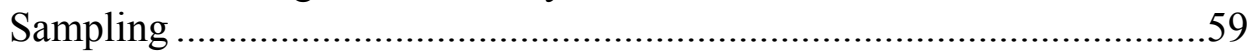

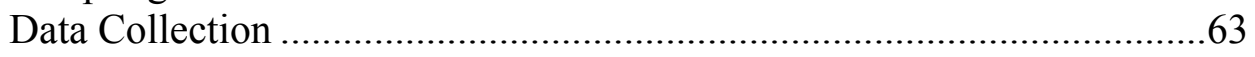

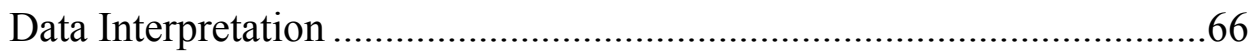

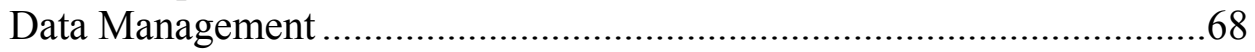

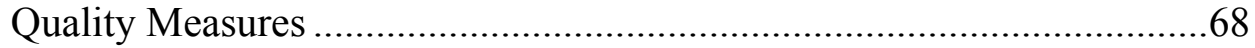

Ethical Issues ...................................................................................

Limitations of the Study....................................................................

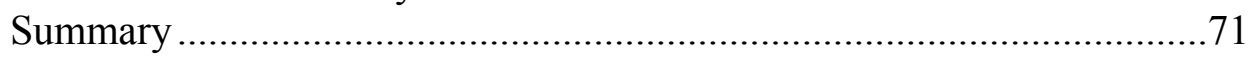

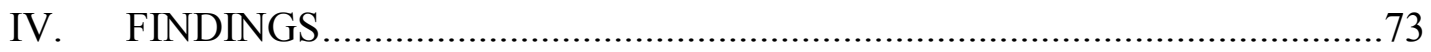

Structuring of Instructor-Student Relationships .......................................73

Connecting Power to Instructor Personality ……………..........................84

Learning to Navigate the Field of Higher Education..................................89

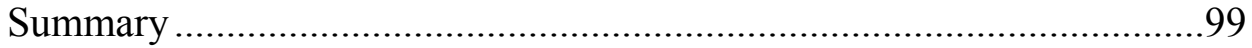




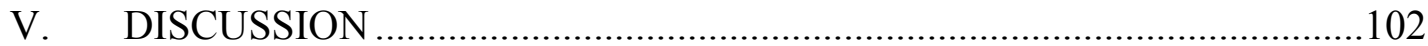

Responses to the Research Questions ................................................102

Implications for Students and Instructors in Higher Education..............113

Recommendations for Future Research ..........................................119

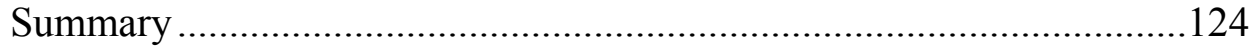

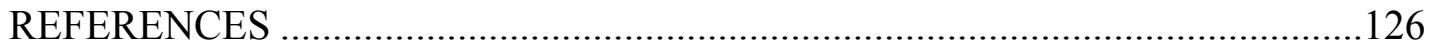

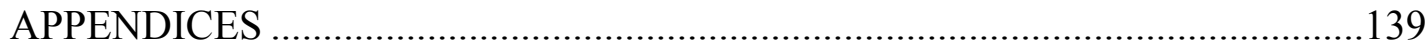

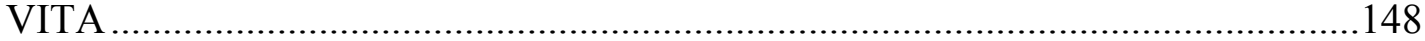




\section{CHAPTER I}

\section{Introduction}

Sometimes a simple, almost insignificant gesture on the part of a teacher can have a profound formative effect on the life of a student.

(Freire, 1998, p. 46)

This hermeneutic phenomenological study explored students' experiences involving instructor power in a higher education classroom. The background of the problem, problem statement, research questions, and conceptual framework are presented in this chapter. Significance of the study, delimitations of the study, and definition of terms are also addressed.

\section{Background of the Problem}

Higher education is a distribution center of knowledge and economic, social, and cultural power (Cervero \& Wilson, 2001). The distribution of knowledge and power occurs primarily in a higher education classroom. Power, associated with the position of the educator, consists of "formal authority, control over resources and rewards, control over punishment, control over information, and ecological or environmental control" (Cranton, 2006, p. 108). Regardless of instructors' views on power in practice, intentions during practice, or self-awareness about their practice, their power shapes adult learning and the result can damage and alienate a student during the learning process (Brookfield, 2000). Students may be alienated if they perceive themselves as experiencing powerlessness, meaninglessness, isolation, and/or self-estrangement (Blauner, 1964).

A personal story of mine shared below illustrates how one simple action by an instructor can alienate a student from learning as a result of her power as an instructor in the classroom. This personal account will elucidate how I became interested in exploring 
students' experiences involving the power of instructors in a higher education classroom and sensitized to issues of student power and voice.

In a graduate course, a classmate (referred to here as Joe) was sharing results from an interview he conducted as part of a class assignment on a particular company. During his presentation, Joe stated that $80 \%$ of the employees in the customer service department of the company he studied were women. Another classmate (referred to here as Jan) interjected with a chuckle and remarked that most likely the other $20 \%$ were gay men. Joe proceeded with his presentation as I sat in my chair in disbelief and questioned myself, wondering whether I had heard Jan's comment correctly.

The class continued and nobody, except for one other student, appeared to have caught the comment that Jan made. I interrupted the class and asked Jan to restate what she had said. She repeated the same information and explained her position. Jan's rationale was that since gay men are very friendly, social, and fun, they would most likely be in customer service. I replied that I did not agree with her comment because I thought it was based on stereotypes and false assumptions.

The instructor, who was standing at the back of the classroom, jumped in the developing discussion and stated we should refrain from these stereotypes, and now that she had addressed the issue we should move on. I felt that my concerns were insufficiently addressed and that the instructor was more concerned about getting the class back on task and avoiding the tension bubbling in the room rather than using the situation as a learning opportunity. It appeared to me the instructor was uncomfortable facilitating such a dialogue in the classroom. Addressing biased comments and emotionally charged tension in the classroom may be difficult for instructors (Bell, 
Washington, Weinstein, \& Love, 1997). However, the instructor was a self-proclaimed critical theorist and social justice educator. I was disappointed by this shortcoming and the apparent dichotomy and lack of congruence between the instructor's espoused theories and theories-in-use (Argyris \& Schön, 1974). When there is lack of congruence between words and actions, students' trust in an instructor may be broken and may lead to students feeling manipulated (Brookfield, 2006).

The murmurs grew as classmates began to talk about the confrontation developing between the instructor and myself in the classroom. The instructor then walked to the front of the classroom and asked me what I would like to see happen in a tone I perceived to be condescending. I replied that because we were in a graduate course, we should discuss the comments that were made and explore what was happening. This physical confrontation by my instructor of posturing directly in front of me made me feel very uneasy. Although I felt I was being dismissed and unheard, I decided against risking my sense of feeling academically safe in the course and decided not to beleaguer the subject; it was easier to give in to the powers of my instructor rather than jeopardize my chances of satisfactorily completing the course (Brookfield, 2006; Johnson-Bailey \& Cervero, 1996). With a clearly dismissive tone I stated we should just move on with the class. The class continued. The instructor missed the opportunity to help us as students understand our emotional responses and develop our ability to engage in difficult intercultural interactions (Spelman, 2010).

I was still very upset and, as a result, I emotionally and mentally withdrew myself from the rest of the class session. I closed my books and looked out the window next to me hoping time would fly by so that I could escape the environment. The instructor 
never approached me to talk about what had occurred. This experience of alienation impacted my future relationship with her. I avoided, as much as I could, any conversations or interactions with her because I continued to be upset. I perceived that she was avoiding me as well. It became for me an uncomfortable and severed relationship characterized by mutual avoidance. For me, the "do as I say, not as I do" approach does not work and damages the way I view the credibility and integrity of an instructor. My focus was on finishing the course and never having to deal with her again rather than continuing to learn by fully engaging myself in the course.

In the scenario above, learning and participation in the classroom were hampered as a result of the power dynamics inherent in a higher education classroom. Power, which is present in all adult classrooms, may "undergird, frame, and distort so many adult learning processes and interactions" (Brookfield, 2000, p. 33). My experience is similar to ways other students have been alienated and silenced such as when students' raised hands and opinions are ignored or not taken seriously (Johnson-Bailey, 2001).

Not only was I rattled by the sudden deterioration and disconnect in my relationship with the instructor, I also felt a disconnect within myself (Case, 2008). I began to question why I felt so alienated. Why did I back down from the instructor that day? Am I not as strong a person as I thought myself to be? Why didn't I speak out further to make the instructor and other students more aware of the impact these prejudicial ideas and remarks have in the workplace or society at-large? I am writing about this experience of alienation in my classroom years ago because it still impacts and haunts me today. My biggest regret from all of my higher education experiences was repressing my will and succumbing to the power tactics of my instructor. I willingly gave 
in to her sophisticated effort to restore a "poisonous pedagogy" designed to instill obedience, eliminate independent action, and remove critical thought from the classroom (Macedo, 1994, p. 67).

\section{Problem Statement}

A critical approach to understanding adult learning involves identifying and critiquing concepts relating to power such as hegemonic ideology and practice, knowledge construction, systems of power and oppression, and barriers limiting liberation and the practice of democracy (Brookfield \& Preskill, 2005; Merriam, Caffarella, \& Baumgartner, 2007). Higher education, as a setting for adult education, is an institution where these concepts exist and intersect (Wilson \& Cervero, 2001). A critical approach to understanding a higher education classroom begins with recognizing the instructor's position of power and authority (Tisdell et al., 2000). An instructor's position of authority and power may negate learners' abilities and beliefs and ultimately alienate and silence learners (Sheared \& Sissel, 2001).

Understanding alienation in a higher education classroom illuminates the ways power influences educational transactions and the interests of both students and instructors (Brookfield, 1995). Alienation is a subjective experience of powerlessness, meaninglessness, normlessness, isolation, and/or self-estrangement resulting from a given relationship such as an instructor-student relationship (Seeman, 1959). Understanding alienation in a higher education classroom may further understanding of how instructors reproduce the social inequities of society in the classroom, disempower students, and impact student learning (Bounous, 2001). 
The purpose of education by means of the instructor-student relationship is to develop the whole person cognitively (e.g., knowledge and intellectual powers), affectively (e.g., emotional, moral, and ethical capacities), and practically (e.g., functioning as a citizen or in family, work, and society (Bowen, 1999). Instructors who alienate students risk severing the instructor-student relationship and the opportunity to further develop students cognitively, affectively, and practically.

Literature on student alienation in higher education has primarily focused on depersonalized theoretical treatises (Brookfield, 2002; Case, 2008; Mann, 2001) or studies on persistence and retention (Cooke, Sims, \& Peyrefite, 1995; Huffman, 2001; Loo \& Rolison, 1986; Mohr, Eiche, \& Sedlacek, 1998; Quarterman, 2008; Schram \& Lauver, 1988; Sellers, Kuperminc, \& Damas, 1997; Steward, Germain, \& Jackson, 1992; Steward, Jackson, \& Bartell, 1993; Steward, Jackson, \& Jackson, 1990; Suen, 1983; Tomlinson-Clarke \& Clarke, 1996) that avoid the central and most basic unit of the system which is the instructor-student relationship. As a result, the power instructors wield exists mostly unquestioned, allowing for teaching practices that reproduce the existing societal patterns of inequity in the classroom (Brookfield, 2000; Johnson-Bailey \& Cervero, 1996; Tisdell, 1993). To understand alienation in a higher education classroom, the ways instructors' power influences educational transactions must first be illuminated (Brookfield, 1995). Therefore, the purpose of this hermeneutic phenomenological study was to explore students' experiences with the power of their instructors in a higher education classroom. The goal of this study was to provide a deeper understanding of instructor power in higher education classrooms in order to inform teaching in higher education. 


\section{Research Questions}

This study addressed the following question: What are students' understandings of their experiences with the power of their instructors in a higher education classroom? The following subsidiary questions also guided the study:

1. How do students become aware of the power of their instructors?

2. How do students relate their particular experiences to the power of their instructors?

3. What do students perceive as the consequences of the power of their instructors?

\section{Conceptual Framework}

The conceptual framework for this study emerged from the literature on using a critical approach to understanding adult learning. Critical theory is one of the more recent contributions to the field of adult education and higher education. According to Brookfield (2005), "a critical approach to understanding adult learning sees it as comprising a number of crucial tasks such as learning how to perceive and challenge dominant ideology, unmask power, contest hegemony, overcome alienation, pursue liberation, reclaim reason, and practice democracy" (p. 2). Using a critical approach involves questioning the normalcy and exercising of such power and the practice of alienation, particularly by those who are alienated and disadvantaged as a result. This study was an exercise between researcher and participants to discuss and understand how instructors in higher education, who are in positions of power and privilege, have exercised their power, positively or negatively, during our higher education classroom 
experiences. It was a dialogic process grounded in the discussion and analysis of our own experiences (Brookfield, 2000).

\section{Significance of the Study}

Although the field of adult education has long claimed social justice as a central tenet, there is little evidence in practice to support this claim (Bierema, 2010). This study addressed this shortcoming by facilitating an opportunity for students and instructors alike to see the position of an instructor exposed as an agent of the power system embedded in higher education. Inglis (1997) pinpoints the dilemma instructors face:

If we want students to analyze the social and political structures that constitute their lives, we have to begin with those which are socially and politically the closest. In effect, this means that teachers must enable students to understand what power they, the teachers, have over them; the strategies and tactics by which this power is operated; and, paradoxically, the strategies and tactics by which they could be empowered to take control of their own learning. This involves enabling students to recognize and challenge the structures, hierarchies, privileges, rhetoric, rules and regulations of the educational institution within which they operate. (p. 14)

This study was an exercise for students to engage in an analysis of instructor power from their own points of view.

This study informs higher education instructors on how to become more critical of their teaching practices. Instructors will gain a better understanding of how students perceive power in the classroom, the ways in which this power manifests itself, and consequently, how students perceive the impact of power in their learning. Instructors will also gain a better understanding of how their teaching practices may not have impacted students in the ways intended and how they may adapt their pedagogical practices to better support a relationship of equality between instructor and student. 


\section{Delimitations of the Study}

Although the higher education student population may be segmented in numerous ways (e.g., undergraduate, graduate, college, age, race, gender, major, etc.), this study focused on graduate students. Graduate students have many years of undergraduate and graduate studies that serve as a frame of reference when reflecting on experiences of being alienated in their classrooms. Additionally, this study was delimited to graduate students majoring in education because they were assumed to be more sensitive to concepts involving teaching and learning in an educational setting and would, thereby, facilitate dialogue and reflection about an area in which they were familiar (King \& Kitchener, 2002).

\section{Definition of Terms}

The following definitions are provided for clarity concerning terms used by the researcher throughout the study.

\section{Alienation}

Alienation is a general subjective condition emerging from a relationship in which a person experiences powerlessness, meaninglessness, normlessness, isolation, and/or self-estrangement (Seeman, 1959). "Alienation is the degree to which man feels powerless to achieve the role he has determined to be rightfully his in specific situations" (Clark, 1959, p. 849).

\section{Critical Pedagogy}

Critical pedagogy places politics and ethics at the center of educational theory and practice by recognizing the role educational institutions play in the production of dominant societal identities and cultural practices (Giroux, 2006). 


\section{Hermeneutic Phenomenology}

As a research approach, hermeneutic phenomenology combines understanding and interpretation (Richards \& Morse, 2007) in the process of arriving at the essence of an experience, which is a person's perceptions about his/her presence in the world at the time the experience took place (van Manen, 1990).

\section{Instructor}

Instructor is any person who teaches in a higher education institution such as a college or university. The term instructor is used as an inclusive term without any reference to status (tenure or non-tenure track) or other classification.

\section{Isolation}

Isolation is a person's sense of disintegration or social distancing from belonging and membership in a society or a specific community (Seeman, 1959).

\section{Meaninglessness}

Meaninglessness is the absence of a person's sense of purpose in his/her relationship to a product, process, and/or organization of work (Seeman, 1959).

\section{Mentor}

A mentor is an instructor who is committed to a relationship with a student which is student-centered and characterized by open and genuine dialogue to foster student learning (Mandell \& Herman, 2009).

\section{Normlessness}

Normlessness is a situation in which a person feels the norms that govern behavior or relationships are no longer effective (Seeman, 1959). It may also involve a 
feeling that the relationship is no longer effective due to a breakdown of standards, values, or expectations.

\section{Power}

Power is any advantage one person has over another person (Rocco \& West, 1998).

\section{Powerlessness}

A person is in a state of powerlessness when s/he perceives being controlled or manipulated by others and is not able to modify or escape from the dominating circumstances (Seeman, 1959).

\section{Privilege}

Privilege is any unearned asset or benefit received by virtue of being born with a particular characteristic or status due to membership in a particular group (Rocco \& West, 1998).

\section{Self-estrangement}

A person experiences self-estrangement when s/he feels detached from his/her inner self as a result of an external circumstance that inhibits self-expression or selfactualization (Seeman, 1959).

\section{Silencing}

Silencing is the opposite of giving voice. It is a metaphor for powerlessness (Reinharz, 1994).

\section{Voice}

Voice is a metaphor for power, presence, freedom, and identity (Reinharz, 1994). When instructors allow space for student voice, instructors provide students the right or 
opportunity to express their choices or opinions and share power and control in the learning environment (Sheared, 1999). Those choices and opinions are related to affirming students' experiences and unique identity characteristics such as race, gender, class, and sexual orientation (Giroux, 1988; Sheared, 1999).

\section{Summary}

This chapter presented my personal story of being alienated in a higher education classroom. This experience sparked my interest in and sensitized me to issues of power in a higher education classroom. My experience was the background to this hermeneutic phenomenology study. This chapter included the background of the problem, the problem statement, and the research questions. Alienation and power were introduced as concepts shaping the framework for this study. The significance and delimitations of the study were also discussed. Key terms were listed and defined to provide a reference for their use throughout the study. Chapter 2 provides a review of the literature on emotions as a context for understanding power, the higher education classroom and system as contexts for understanding power, and theoretical and empirical literature on power and alienation in a higher education setting. The hermeneutic phenomenological research design and procedures are explained in Chapter 3. The findings of this study are discussed in Chapter 4. Conclusions and implications to inform teaching and learning in higher education are provided in Chapter 5. 


\section{CHAPTER II}

\section{Review of the Literature}

This study explored how students perceive their experiences with the power of their instructors in a higher education classroom. This chapter is divided into three main sections: (a) emotions as a context for understanding power, (b) the higher education classroom as a context for understanding power, and (c) the higher education system as a context for understanding power. The literature review in this chapter, based on the background to this study as presented in Chapter 1, is an overview of work that informs this study, which includes the role of emotions in learning, theoretical literature regarding the concepts of power and alienation, and empirical research on power and alienation in a higher education setting. The purpose of this review of the literature is to provide a context and language for this study.

\section{Emotions as a Context for Understanding Power}

By viewing emotions as part of the learning process, emotions are placed at the nexus of a critical understanding of education. Emotion is also commonly referred to as affect or feeling (Dirkx, 2008). "Within Western patriarchal culture, emotions are a primary site of social control; emotions are also a site of political resistance and can mobilize social movements of liberation" (Boler, 1999, p. xiii). Emotions are political because they can trigger social and political movements that seek to counter or change existing systems and mechanisms of control. "The personal is also political" and instructors should consider the "political, economic, and cultural conditions" under which adult learning occurs (Clark \& Dirkx, 2008, p. 91). 
Emotions play a role in why "adults show up for educational programs, their interest in the subject matter, and the processes by which they engage the material, their experiences, the teacher, and one another" (Dirkx, 2006, pp. 15-16). Recognizing how emotions are connected to learning and the meaning-making process (Dirkx, 2006) enhances the way we understand how meaning is constructed (Clark \& Dirkx, 2008; Spelman, 2010). Furthermore, being open to the emotional component of learning helps to illuminate how learners perceive reality (Dirkx, 2006; Mezirow, 2009). Clark and Dirkx (2008) asserted that much work and understanding is needed before instructors move away from the negative perceptions surrounding the concept of emotions in the learning experience.

A higher education classroom, as a learning environment, can be an emotional space (Spelman, 2010). The classroom presents students with a multitude of experiences that trigger emotional reactions ranging from fear, embarrassment, and anger to pride, excitement, and joy. These strong emotions are evoked as students worry about performance on a test, complain about the structure and direction provided by their instructors, or are already overwhelmed with other demands in their personal lives (Dirkx, 2008).

To deny the importance of emotions in the way we construct and understand our experiences "flies in the face of our socially accepted definition of what it means to be human" (Clark \& Dirkx, 2008, p. 90). However, most dominant educational approaches hinge on rationalist perspectives that place on emphasis on facts and reason in the learning process (Dirkx, 2001). Emotions are then seen as intrapersonal obstacles that can either impede learning or internal motivators that enhance learning (Dirkx, 2001; 
Wolfe, 2006). These educational approaches assert that "students who are anxious, angry, or depressed don't learn; people who are caught in these states do not take in information efficiently or deal with it well" (Goleman, 2006, p. 78).

Dirkx (2006) presented two approaches, literal and symbolic, by which to understand learner's emotions in the classroom. The literal approach involved making explicit connections regarding the emotional response of a student. For example, a math instructor may look to interpret a student's emotional response of anger as a sign that the student is not happy with the way the instructor is teaching the course. This approach to thinking about emotions will lead the instructor to possibly seek other ways by which to deliver the course content. The other approach was a symbolic approach where the instructor seeks for deeply-rooted layers of meaning that are connected to the emotional response. For example, a math instructor may choose to talk to the student and, in doing so, learns that the student has always been told that as a woman she will never do well in math. The instructor may then choose to see the emotions exhibited in the course as a product of the messages the student has internalized over the years. This approach then leads the instructor to seek possible way to empower the student to learn and succeed in math. "Depending on which perspective we take, we will adopt quite different pedagogical strategies to address the anger with instructional process" (Dirkx, 2006, p. 17).

One of the most challenging tasks for instructors is to understand the emotional component to learning within the classroom and the curriculum and help students understand the same (Dirkx, 2008). Part of the reason is that instructors themselves learned that there is no room for emotions in scholarly pursuits, which has mostly been 
dominated by positivist notions that equate emotions to a lack of rationalism and reason (Dirkx, 2001). This disregard for the role emotions play in the learning process, and consequently its avoidance and mitigation of expression, are products of the Enlightenment and scientific revolution (Dirkx, 2008).

Personal reasons why instructors may have difficulty understanding the emotional component to learning are that instructors have emotional responses of their own. For instance, when delivering course content and the curriculum, instructors may feel as the targets of students' emotional responses to the content and attacked by students (Dirkx, 2008). Instructors can sense the presence of emotionally-charged issues in a course by "a tightening in [the] stomach or an increased sense of anxiety" (Dirkx, 2006, p. 22). These sensations are just as real for instructors as they are for students who experience them.

Higher education is an environment that governed by complex rules of power and authority (Boler, 1999). On a broader scale, higher education is a social institution that not only consists of the transmission of information, but it also serves as an additional source of indoctrination to hegemonic values and beliefs (Boler, 1999). Part of this indoctrination is the control of emotions, particularly when these emotions drive students to question authority such as instructors and administrators. For example, instructors will attempt to silence students, particularly if their own class and privileged positions of authority are questioned, by "labeling the expression of anger an inappropriate act" (Macedo, 2006, p. 4). Most students are generally taught that emotions are personal problems rather than indications that there are things "wrong with the outside world" (Boler, 1999, p. xiv). 
Students are also generally less exposed to critical perspectives that "challenge and resist this privatization and pathologizing of emotions" (Boler, 1999, p. xiv). But when instructors do decide to employ critical perspectives in the classroom, they are "likely to experience anticipation and fear" as making change in the classroom may require educators to "overcome the fear that makes it difficult for them to change the way they approach the learning situation" or face the "many parties affected by the existence of a critical class" (Callahan, 2004, p. 79). For example, there may be emotional responses by faculty members in choosing whether or not to permit certain dissertation questions from being explored; confronting other professors who they disagree with epistemologically, ontologically, or pedagogically; or guiding research activities on topics or viewpoints that instructors are not comfortable in discussing. And in employing critical perspectives in the classroom, instructors should be open to the idea that critical pedagogy may place them in an actual location of student resistance.

"Oppression, silencing, inequality, and injustice can also occur in any learning context" (Callahan, 2004, p. 76). Emotions are most commonly expressed when there is conflict resulting from the disagreement of values or interests (Dirkx, 2008). Emotional responses can be cues for instructors on the matters that have a personal significance for their students (Spelman, 2010). The classroom is a place that provides an environment where students can both validate their sense of self or be potentially challenged with respect to value systems and other worldviews (Kasworm, 2008). But this should be done when the classroom is both a physically and psychologically safe environment where learners feel they can experiment with and test new perspectives without punishment or judgment (Wolfe, 2006). Students generally remember learning 
experiences that have a "strong, positive, emotional, or affective dimension" that involved "a caring teacher who listens to us [students] as individuals, a teacher who respects us [students] as persons, or a teacher who involves the whole person in the learning experience" (Dirkx, 2001, p. 67).

\section{The Higher Education Classroom as a Context for Understanding Power}

The center of educational activity in higher education lies in the higher education classroom (Tinto, 1997). A critical examination of the phenomenon of instructor power in a higher education classroom starts with recognizing instructor power and authority (Tisdell et al., 2000). Instructors as agents of the higher education system wield a great amount of economic, political, and social power and control over the lives of their students. Power is associated with the instructor's formal position, which consists of "formal authority, control over resources and rewards, control over punishment, control over information, and ecological or environmental control" (Cranton, 2006, p. 108). An instructor generally has the power to make decisions on course content, which means s/he controls what information will be made available to students, sometimes without regard of students' specific needs (as is the case of liberal education). An educator has the ability to evaluate student learning and performance by assigning a grade at the end of a course (Tisdell, 1993). This evaluation is then used for the purpose of credentialing or the awarding of a degree, which then leads the student to additional resources and other opportunities.

A college degree is attractive because it is viewed as a key to open the doors to socioeconomic growth, self-sufficiency, and a better future (Buttaro, 2004; Zalaquett, 2006). Inglis (1997) believes that: 
The individual who can personally transform him or herself, who can obtain new knowledge or skills (cultural capital), who can adopt and fulfill the ethos and objectives of the organization (social capital) can attain a higher position (political capital) and better pay (economic capital). (p. 13)

But to then say that students have a choice of whether or not to participate in this system is a skewed assumption made by people in positions of privilege. Instructors have access to resources that students do not. In other words, students must unconditionally learn and adapt to the structures of power within the culture of higher education, especially if students need a college degree to be in a better position for upward socioeconomic mobility in their chosen career path (Inglis, 1997).

An aspect of the political practice of education is the discourse in the classroom as students and instructors interact with one another (Shor, 1992). Power is behaviorally manifested in the classroom as instructors exercise the power to control the dynamics of the classroom. Manifestations of power can include "talking down to students, allowing no interruptions or questions, and maintaining complete control over resources, information, and rewards" (Cranton, 2006, p. 122). Students are taught about the power relations in higher education through physical arrangements such as seating of the classroom (e.g., sitting in rows versus a large circle) or the instructor sitting or standing during group discussions. Students learn about power relations through language such as the use of inclusive language and how students address the instructor (e.g., inviting students to address the instructor by his/her first name instead of using titles and last name). Although students are generally told that they live in a free and democratic society, traditional classroom practices teach students to become obedient to unilateral authority (Macedo, 1994, 2006; Shor, 1992). 
Traditional classrooms employ a banking system of education (Freire, 2000). A banking system of education exists when education is a one-way method of communication with students playing the role of passive receivers of knowledge that is transmitted by the instructor (Macedo, 1994). The banking system of education mirrors the functioning of an oppressive society and is built on practices that generate passivity to protect the oppressive system itself (Freire, 2000). The instructor's power is usually unquestioned, particularly by students who must comply with instructors who are the gatekeepers to the resources they need. Consequently, students are alienated when instructors dominate the dialogue (Shor, 1992).

Cranton (2006) made several suggestions about exercising power responsibly in the classroom. The term responsibly here is important because by virtue of their positions in higher education, instructors will always have power regardless of the critical pedagogies adopted by the instructor. Cranton (2006) suggested the following strategies: reduce formal authority by minimizing time spent standing in front of the class; do not provide all the answers or make all of the decisions in the classroom; make resources available for students; use different strategies for grading and evaluation (e.g., peer evaluations, learning contracts, self-evaluations); and develop open and authentic connections with students.

Although many relationships exist in a higher education classroom, the primary relationship is the instructor-student relationship. And within those instructor-student relationships, it is the instructor that inarguably holds the position of power and authority (Tisdell et al., 2000). When examining that instructor power, it is important to consider 
where that instructor power comes from and how it exercised in the instructor-student relationship. The sources of instructor power are discussed below.

French and Raven (1959) identified five sources (or bases) of power to explain how social agents (i.e., person, role, norm, and group) influence psychological, social, and behavioral change of a person. This theory of power explains power in dyadic relationships from the perceptions of a target (Aguinis, Nesler, Quigley, Lee Suk, \& Tedeschi, 1996). When this framework is applied to a higher education classroom, the five sources of power facilitate the process of identifying and labeling the exercises of power and influence by an instructor toward his/her student. The five sources are reward power, coercive power, legitimate power, referent power, and expert power.

Reward power is based on a person's perception that the social agent has the ability to provide or facilitate the individual's perceived rewards (French \& Raven, 1959). Reward power is greatest when a student believes the instructor "possesses the ability to distribute or withhold rewards not obtainable elsewhere" (Tauber, 1985, p. 3). For example, an instructor may be perceived as having reward power if a student requires rewards from the instructor such as letters of reference/recommendation, referrals to jobs or research opportunities, or even an extra credit point that will result in a positive grade change.

Coercive power is based on a person's perceptions that the social agent has the ability to assign perceived punishments (French \& Raven, 1959). For example, an instructor may be perceived to have coercive powers if a student is afraid of being continuously picked on during class or that the instructor will grade his/her work more stringently if not well-liked by the instructor. Coercive power also involves punishments 
such as instilling fear, boredom, discomfort, or creating embarrassment and humiliation for the student (Tauber, 1985).

Legitimate power is based on a person's perception that the social agent has the right or authority to dictate the individual's behavior (French \& Raven, 1959). A student may perceive that an instructor has power by virtue of their job, title, or rank. For example, legitimate power is maintained when a student is expected, whether perceived or expressed, to address their instructors by titles such as doctor or professor preceding the instructor's surname. When legitimate power is involved, students show respect for the instructor based on their position, not necessarily who that instructor is as a person (Tauber, 1985).

Referent power is the ability of social agents to influence others by persuasive interpersonal skills (e.g., charisma, charm) that build the loyalty of individuals and attraction to a social agent (French \& Raven, 1959). A student will be influenced more by an instructor that the student admires or is interpersonally attracted to that an instructor the student does not like or admire. Referent power is the opposite of legitimate power; students respect the instructor as an individual, not necessarily the instructor's formal role or position of authority (Tauber, 1985).

Lastly, expert power is the ability of social agents to influence change on a person based on the perceived knowledge or skills of the social agent (French \& Raven, 1959). If a student perceives an instructor to be an expert in a given field, the student is more likely to be influenced by that instructor. Expert power increases the likelihood that whatever the instructor communicates will be unquestioned and more readily accepted by 
a student. Expert power is increased when students perceive instructors' knowledge as important to accomplishing a needed task (Tauber, 1985).

Jamieson and Thomas (1974) researched power and conflict in the higher education classroom, particularly the bases of instructor power and how students handled conflict with instructors. Results highlighted that coercion, the power to facilitate punishment in order to enforce compliance, was particularly prevalent. There was an overall negative relationship between coercive power and student satisfaction, learning, and the extent to which students perceived their instructors influence beyond the scope of the course. The study also reported that students were predominantly passive when it came to them attempting to change the dynamics in the classroom.

Aguinis et al. (1996) used the French and Raven (1959) power taxonomy to investigate graduate students' perceptions of their graduate advisor's power. The results of the study showed that when participants perceived their graduate advisor as having high referent, expert, and reward power, participants reported more positive relationships with their advisor. As the degree of coercive power perceived increased, participants increasingly reported negative relationships with the advisor. The results of the study also showed that participants' perception of their advisor's trustworthiness was related to coercive and with referent power as a mediator. When there was high coercive power and low referent power, participants reported lower levels of trustworthiness. When participants reported high referent power, there was no difference between high and low coercive ratings on trustworthiness. The other important finding was that legitimate power had an impact on participants' compliance with their advisor's requests. The 
combination of high legitimate power and high coercive power were associated with the highest participant compliance ratings.

\section{The Higher Education System as a Context for Understanding Power}

A critical approach to understanding power requires exploring not only how institutions work, but also how the institutions create problems relating to social inequality and injustice (Popkewitz, 1999). This section discusses various conceptualizations of power from a systemic perspective. Specifically this section touches on the three central figures of critical theory - Marx, Bourdieu, and Foucault and how their philosophies involving power provide a foundation to critical inquiry in higher education (Popkewitz, 1999). The sections below discuss power as alienation (Marx), reproduction of capital (Bourdieu), and production of knowledge (Foucault).

\section{Power as Alienation}

Alienation is about perceived powerlessness in a situation (Clark, 1959). The concept of alienation, which originated from the writings of Hegel, Rousseau, Locke, Smith, and Feuerbach, was cultivated into modern philosophy by Karl Marx (Wendling, 2009). This section briefly introduces the theory of alienation as developed by Marx followed by additional conceptualizations of alienation that developed in sociology and then applied in education. This section also provides a context for the research literature on student alienation as an outcome of power as alienation.

Marx and alienation. Marx's (1964) theory of alienation was embedded in the material world of labor where alienation was an objective and observable feature of capitalism such that workers were estranged, or alienated, from the products and the nature of their labor. This is because workers were not owners of their labor or the 
products of their labor in capitalism. Laborer, labor, and the product produced were all commodities.

Marx (1964) posited that alienation in labor under a capitalist system occurred in four different ways. The first type was the alienation of the worker from his/her product (Marx, 1964). Both the product that was produced and the process by which the product was made was out of the worker's control and owned by capitalists. Secondly, the worker was alienated from the act of production itself (Marx, 1964). This meant that labor "does not belong to his essential being," it is "coerced," and that it is "merely a means to satisfy needs external to it" (Marx, 1964, pp. 110-111). Third, the worker was alienated from his/her species as a human being (Marx, 1964). Labor did not serve personal or collective interests as a species, but rather became a means to individual existence. Lastly, as a result of the worker being alienated from the product of his/her labor, from his/her life activity (which is labor), and from the nature of his/her species, the worker was alienated from other workers (Marx, 1964). "The alien being, to whom labor and the product of labor belongs, in whose service labor is done and for whose benefit the product of labor is provided, can only be man himself" (Marx, 1964, p. 115). Therefore, people related to each other based on the commodities they own. The concept of alienation can be applied to instructors and learners in a higher education setting. Mann (2001) articulated the connection:

The work that is undertaken by students is not usually done for the good of the group of learners or other community, but in order to satisfy the requirements of the teacher and the institution, and for the mark that may be obtained. (p.13) 
Students will relate to each other based on the grades they receive based on instructors' valuation of student labor, not necessarily based on the value students think their labor is worth.

Fromm and alienation. To Fromm (1955), alienation was an experience where a person experienced him/herself as an alien, estranged from him/herself. Alienation was a central concept to understanding the "modern personality" involving the "interaction between the contemporary socio-economic structure and the character structure of the average individual" (Fromm, 1955, p. 103). Building on Marxian analysis of capitalism, Fromm tied alienation to the quantification and abstraction that takes place in economies of mass production and their subsequent impact on personality (Fromm, 1955). Fromm compared alienation to idolatry, which is the "worship of something into which man has put his own creative powers, and to which he now submits, instead of experiencing himself in his creative act" (Fromm \& Marx, 1966, p. 45). For example, production is alienating because as human we no longer control the entire creation of object; rather, because of the ever-increasing division of labor, we are never connected to the finished product of our labor. Production and consumption are abstract in a "world of things" and "our only connection with them is that we know how to manipulate or to consume them" (Fromm, 1955, p. 122).

Seeman and alienation. Seeman (1959) presented a practical view of five forms of alienation based on his analysis of contemporary literature and history of sociological thought. The five forms of alienation were powerlessness, meaninglessness, normlessness, isolation, and self-estrangement. 
Powerlessness referred to a person's sense of control or lack of control in circumstances involving the self (Seeman, 1959, 1983). Powerlessness was experienced when a person believed that no matter what $\mathrm{s} /$ he does, there will be no difference in the outcome the person sought.

Meaninglessness indicated a lack of understanding that resulted in a perceived inability to predict outcomes (Seeman, 1959). In other words, a person was unable to make a connection between his/her role and behavior in a given situation and how s/he related to a desired outcome.

Normlessness was a sense that socially accepted standards for behavior and/or interaction were no longer effective to reach a desired outcome (Seeman, 1959). In other words, normlessness involved the belief that the "rules" must be broken if a desired outcome were to be reached.

Isolation referred to a sense of emotional or intellectual detachment due to differential values placed on goals and beliefs by an individual and the group or society to which they belonged (Seeman, 1959). Isolation related to individuals' perceptions that they just did not "fit in."

Lastly, self-estrangement was experienced when an individual did not find their behavior or activities as self-rewarding and engaging (Seeman, 1959), but rather that their activities were a means to desired ends. Self-estrangement may exist as: incongruence between an ideal self and perceived actual self; a sense of failure to achieve one's perceived capabilities or interests; and not finding one's activities as rewarding in and of themselves (Seeman, 1983). 
Blauner and alienation. Blauner's (1964) conceptualization of alienation, based on his studies on different environments of factory workers, built on the Marxist notion of alienation and was an adaptation of the forms of alienation proposed by Seeman (1959). According to Blauner (1964), alienation was a "general syndrome made up of a number of different objective conditions and subjective feeling-states which emerge from certain relationships between workers and the sociotechnical settings of employment" ( $p$. 15). The four states of alienation were powerlessness, meaninglessness, isolation, and self-estrangement. A person experienced powerlessness when s/he perceived themselves to be an object that was controlled and manipulated by others and was unable to escape to change or escape the situation (Blauner, 1964). Meaninglessness is propagated in bureaucratic structures because individuals may become "lost" in its intricacies and, as a result, lose a sense of purpose in their work (Blauner, 1964). Isolation was a sense of social distancing from specific communities or the larger social order (Blauner, 1964). Self-estrangement was a "rupture in the temporal continuity of experience" such that there was a "split between present engagement and future considerations" (Blauner, 1964, p. 32). The situation or activity was the source of self-estrangement conflicted with a person's identity and sense of self.

The four states of alienation had corresponding non-alienated states as follows: powerlessness versus freedom and control; meaninglessness versus understanding of a life-plan (self) or an organization's activities as purposeful; isolation versus belonging and membership in society or defined communities through a sharing of norms; and selfestrangement versus self-expression and self-actualization (Blauner, 1964). 
Although Blauner (1964) acknowledged Emile Durkheim's concept of anomie (normlessness) as a distinguishing feature of modern society as did Seeman $(1959,1983)$, he chose not to build on that notion due to his observations in the industries he studied. Blauner (1964) asserted that normlessness is less of a distinguishing feature in advanced industrial settings because organizations tended to be "normatively integrated" by having a "consensus between the work force and management on standards of behavior, expectations of rewards, and definitions of fair play and justice" (Blauner, 1964, p. 25). In other words, organizations imposed universal norms and procedures that were agreed upon in collective bargaining agreements and, thus, a sense of equity was created. However, Blauner (1964) viewed this establishment of a normative system as a greater divide between management and the labor work force and as such was another form of isolation.

Student alienation in higher education. In the literature on alienation in higher education, two primary research models, Dean (1961) and Burbach (1972), were identitified as springboards for other studies. Each primary research model is reviewed below along with the research studies that stemmed from it. Additional research related to alienation in higher education, but not based on the research of Dean (1961) or Burbach (1972), are also discussed below.

Research based on Dean (1961). Dean (1961) sought to develop an instrument to measure the social phenomenon of alienation based on Seeman (1959). Dean (1961) hypothesized that there was a negative correlation between social status and alienation, a positive correlation between advancing age and alienation, and a negative correlation between rural background and alienation. The results of the empirical study showed a 
low statistically significant negative correlation between alienation and the components of occupational prestige, education, income, and rural background as well as a small positive correlation between alienation and advancing age. Dean (1961) suggested that alienation may not be "a unitary phenomenon, but a syndrome" and "more research is required before the alienation concept can be empirically validated" (p. 758). The studies identified below were based on Dean's (1961) research on alienation. The studies largely involve research on racial and ethnic minority student populations.

Tobacyk (1985) looked at the relationship between supernatural beliefs and feelings of alienation of college students. The researcher hypothesized that the greater traditional religious beliefs held, the less alienation would be reported. This hypothesis was based on the assumption that traditional belief systems provide: "(1) clear values governing conduct, reducing normlessness, (2) social support systems, reducing social isolation, and (3) methods of communicating with the deity, reducing experiences of powerlessness and social isolation" (p. 844). However, no significant relationship was found.

Toth (1996) explored the effect of cluster course teaching on student academic achievement, self-esteem, sense of alienation, and perceived meaningfulness of students' college experience. No benefit was found from the cluster teacher model as results showed the teaching method may have had a negative effect on students' grade point averages and reported self-esteem.

Suarez, Fowers, Garwood, and Szapocznik (1997) used a multivariate framework to explore relationships among biculturalism, differentness, loneliness, and alienation in Hispanic college students. The researchers found an inverse relationship between 
biculturalism and the degree of loneliness and alienation reported by students. The results indicated a positive relationship between perceived differences in value orientations from family and students' reported feelings of loneliness and alienation. However, there was no significant relationship found between loneliness or alienation and perceived difference from peers.

Asamen and Berry (1987) studied how Chinese and Japanese Americans perceived being affected by prejudice directed toward them by the majority culture as well as how feelings of alienation affect the development of self-concept in these groups. There were no significant relationships identified in this study between perceived prejudice or self-concept in both groups. In the Japanese American sample, a negative relationship was found between how they perceived their physical self and their perceived racial prejudice. Lastly, the results of the study indicated that higher perceived alienation is tied to lower self-concepts for both Chinese and Japanese Americans. The results of this study indicated that Japanese and Chinese Americans who feel more alienated will have lower self-concepts than do Japanese Americans and Chinese Americans who feel less alienated.

Cabrera and Nora (1994) focused on examining the relationship between students' perceptions of prejudice and discriminiation and their subsequent perceptions of alienation from the institution. Discrimination and prejudice were measured using three factors: racial and ethnic climate on campus, faculty and staff prejudice, and in-class discriminatory experiences. However, alienation was not measured using any specific theoretical model of alienation, but rather by guaging students' sense of belonging and whether they were enjoying their college experience. The results of the study showed 
that African Americans perceived the most prejudice and discrimination followed by Asian and Hispanic Americans and then by Whites. All minorities felt isolated in class, but African Americans also had many experiences of discrimination and perceived prejudice outside of class. One important finding of this study was that across all racial/ethnic groups, in-class discriminatory experiences were the only factor that affected feelings of alienation.

Mohr, Eiche, and Sedlacek (1998) examined the issues relating to nontransfer college seniors who decide to withdraw from their academic programs prior to completion. The most reported reasons for withdrawal are economic reasons (e.g., finding a new job, debt), academic problems (e.g., low grades, too many incomplete grades), or other school problems (e.g., enrollment in another school). However, students reported feelings of alienation in the form of lack of personal attention from advisors and instructors as an additional reason for withdrawal from their academic program.

Research based on Burbach (1972). Burbach (1972) based his research on Seeman's (1959) work to develop a measure for components of alienation within the specific context of a university. Burbach (1972) argued that alienating characteristics of society-at-large are also found within the context of the university. The findings of this study showed powerlessness, meaninglessness, and social estrangement as components of alienation were measurable and supported the validation of the University Alienation Scale (Burbach, 1972). The studies identified below were based on Burbach's (1972) research on alienation. The studies largely involved research on racial and ethnic minority student populations and their retention and persistence in college. 
Suen (1983) examined the differences between alienation and attrition among Black students within a predominantly White university environment. Black students scored higher than White students on all dimensions of alienation measured (meaninglessness, powerlessness, and social estrangement). Social estrangement was the most statistically significantly form of alienation reported by Black students. It was also found that Black students dropped out at double the rate of White students.

Schram and Lauver (1988) examined nine possible predictors of international student alienation: social contact, age, sex, presence of a spouse, geographical home region, length of time in the United States, length of time in the university town, urban or suburban versus rural background, and graduate versus undergraduate academic status. The results of the study indicated a negative correlation between alienation and the constructs of social contact, graduate status, and being from European origins.

Steward, Jackson, and Jackson (1990) examined the relationship between Black students' feelings of alienation and interaction style at a predominantly White university in either a mostly White campus situation or an all-Black campus situation. Students reported higher feelings of alienation from predominantly White campus situations. During follow-up discussions, researchers learned that Black students expressed a desire for more inclusion and affection in a predominantly White campus situation because they perceived their interaction in this setting as critical to their academic and professional success. The researchers found that successful Black students changed their interaction styles in order to accomodate the racial makeup of the specific campus situation in which they were. Interaction in all-Black situations were primarily social interactions in which they already perceived themsleves to be accepted. 
Steward, Gennain, and Jackson (1992) partly replicated Steward et al. (1990) by examining the interactional style and reported feelings of alienation among successful Anglo [sic], Asian, and Hispanic students within a predominantly Anglo university setting. Both within race/ethnicity and between race/ethnicity interactional styles were compared with reported feelings of alienation. No significant differences were found in the degree to which alienation was experienced by all three groups. Asian and Hispanic students exhibited stable interactional styles regardless of the racial or ethnic composition of the campus situation. The researchers discussed that alienation may have less to do with interactional style and more with internalized processes.

Nottingham, Rosen, and Parks (1992) examined the risk of psychological dysfunctions and psychosocial stressors of African American students at a predominantly White university as compared to African American students attending a predominantly African American university. Psychological dysfunctions included depression, suicidal ideation, and hopelessness. Psychosocial stressors included life events, ethnocentrism, institutional satisfaction, and feelings of alienation. The findings included that feelings of alienation were a significant predictor of depression, hopelessness, and poor self-esteem at both campuses. However, there were no significant differences between both educational settings.

Steward, Jackson, and Bartell (1993) sought to understand within-group diffences of reported levels of alienation among Black students on a predominantly White campus. Specifically, the study focused on examinining if Black students who held a just world view, which was reinforced on predominantly White campuses, reported a lower level of alienation than Black students who did not adopt such a worldview. A just world view is 
the perception that the world is indeed just and that people get what they deserve. Although there was a negative correlation found between adoption of a just world view and reported levels of alienation, the results only accounted for $15 \%$ of the variance.

Cooke, Sims, and Peyrefite (1995) examined personal variables (e.g., alienation, locus of control, need for achievement, social support, and stress) to predict graduate student attrition. Alienation was not found to be predictive of attrition with graduate students.

Delphin and Rollock (1995) examined university alienation and African American ethnic identity as predictors of attitudes towards the knowledge and use of both formal and informal mental health services. The researchers hypothesized that if students reported alienation from the university environment, they would be less knowledgable of mental health services on campus and would, therefore, seek informal sources for help. However, the study did not find that the use of either formal or informal mental health resources were significantly influenced by alienation.

Tomlinson-Clarke and Clarke (1996) examined the relationship between alienation and three different campus settings (a research university, a comprehensive college, and a 2-year college). The study found a direct relationship between institution size and alienation. The study also found that men were more likely to feel alienated than women on all three subscales of the University Alienation Scale (Burbach, 1972).

James (1998) conducted a descriptive-correlation research study designed to identify and describe the relationship between African American students' levels of social alienation and how those feelings of alienation affected their college performance. The study found that racially biased standardized tests, lower socioeconomic status, large 
class sizes, and lack of respect from peers and instructors contributed to African American students' feelings of social alienation.

Additional studies on alienation. Smith (2000) examined how instructors were able to be more effective by developing a sense of spirit in their classrooms. Spirit in this study referred to a disposition that was animating to individuals and/or a group. The researcher interviewed instructors the researcher perceived as having a "breath of life" ( $p$. 58) and their students at both a community college and a university. The researcher found that instructors who cared for their students, formed communities in their classroom, and made their subject matter interesting created the most spirit. The researcher suggested caring, community, and developing a sense of human transcendence as remedies to the alienation, isolation, and fear commonly experienced by students.

Huffman (2001) explored the cultural conflict experienced by culturally traditional American Indian students to understand why some successfully completed their academic goals and others did not. The researcher identified those students who performed poorly academically as those who experienced alienation and estrangement and who exhibited resistance towards any ideas that threaten their sense of culture, heritage, or identity. Those who performed well were able to transcend the initial alienation they experienced and underwent a process of transculturation so that they were then able to use their cultural heritage and identity as a source of strength while operating in two distinctly different cultural settings.

Quarterman (2008) sought to describe the perceptions of program coordinators and directors regarding barriers to the recruitment and retention of a diverse graduate student population at a predominantly White university in the midwest United States. 
The most dominant barriers identified for the retention of a diverse student population included students' feelings of alienation, isolation, and loneliness as well as perceptions of a non-supportive environment.

Lane and Daugherty (1999) examined gender and membership in a collegiate Greek social organization as correlates of social alienation among college students. The study found that women reported significantly less social alienation than men and that members of collegiate Greek social organizations reported significantly less social alienation than students who were not members of such organizations. Interaction between gender and membership in a Greek social organization was not found to be significant.

Loo and Rolison (1986) explored the extent and nature of alienation and academic satisfaction among ethnic minority students and whether there were significant differences between alienation and satisfaction of minority students as compared to White students. Findings showed that sociocultural alienation of minority students was significantly greater than that of White students due to the cultural dominance of White, middle-class values and the ethnic and cultural isolation that results from being a small proportion of the student body. The study also found that sociocultural alienation is not necessarily tied to academic satisfaction for ethnic minority students. Loo and Rolison (1986) implied that although minority students may feel alienated, they may perceive positive characteristics and benefits from any number of factors such as the curriculum, programs, or supportive instructors.

Sellers, Kuperminc, and Damas (1997) examined the college life experiences of African American women athletes, specifically as they relate to academic performance, 
alienation and abuse, perceptions of social advantage as an athlete, and satisfaction. The results showed that African American women athletes reported almost never feeling alienated or abused, which was possibly linked to their status of student athlete.

Researchers speculated on the possibility that African American women athletes may have reported lower levels of alienation because African American males posed a larger threat to the current male-dominated society than their female counterparts.

Wells and Daly (1992) looked at whether there was a relationship between alienation and prejudicial attitudes toward African Americans, women, and homosexuals. Using Seeman's (1959) model of alienation, the researchers hypothesized that individuals who were less prejudiced would express greater anomie (normlessness) on a measure of alienation. "Normlessness or a lack of guidelines to regulate behavior, feeling powerless to change the status quo, and feelings of isolation from the predominant culture as well as from other people characterize alienation" (Wells \& Daly, 1992, p. 623). The study found that when students held more positive attitudes toward women and homosexuals, they felt greater alienation from society-at-large. The study also found that gender and religiosity did not influence alienation and attitudes toward African Americans, women, and homosexuals.

Klomegah (2006) explored whether alienation as experienced by international students was significantly different from the alienation experienced by American students in the context of a small minority-serving institution. The study showed no evidence to support the idea that international students experienced more alienation than American students in the context of the study. The researcher attributed the lack of differences in 
reported alienation due to the smaller campus environment that was easier for students to navigate.

\section{Power as Reproduction of Capital}

Rather than focusing on economic factors commonly associated with Marxist perspectives, Bourdieu and Passeron (1977) highlighted the capacity for social actors to actively reproduce social structures of domination based on an economy of cultural capital. Bourdieu proposed a model of symbolic power that placed power in the center of social life and how social distinctions based on cultural capital facilitated and legitimated access to power (Swartz, 1997). Bourdieu and Passeron (1977) discussed the role that education, as a social system, played in the reproduction of the social structure. Formal education not only reproduced culture, but it also became a selective filter through which individuals were positioned into the various segments of the social order (Beder, 1989; Rubenson, 1989). And since education credentials have increasingly become a requirement for entry to desirable positions in the job market, the higher education system and the role it plays in access to those positions has grown (Swartz, 1997).

Cultural capital "exists in three distinct forms: connected to individuals in the general educated character - accent, dispositions, learning, etc.; connected to objects books, qualifications, machines, dictionaries, etc.; and connected to institutions - places of learning, universities, libraries, etc.” (Grenfell \& James, 1998, p. 21). In other words, cultural capital consists of the behaviors such as language, organizational skills, resources, and social rules required to function at a specific place in the social hierarchy (Beder, 1989). The assumption is that more cultural capital is needed as movement is made up the social hierarchy. People with more cultural capital are at a better advantage 
to compete for spaces at the top of the social hierarchy while those with little cultural capital face more struggles to climb the ranks of the hierarchy (Beder, 1989). In addition to cultural capital, economic capital (e.g., money and property), social capital (e.g., personal and business connections and networks), and symbolic capital (e.g., legitimation) enables access to the top spaces of the social hierarchy (Swartz, 1997).

Participation in education can become a habitus, or a form of cultural consumption, that is self-perpetuating and internalized so that the social order itself is legitimized and unquestioned (Bourdieu \& Passeron, 1977). Habitus functions within a field, which is a social setting that "denotes arenas of production, circulation, and appropriation of goods, services, knowledge, or status, and the competitive positions held by actors in their struggle to accumulate and monopolize these different kinds of capital" (Swartz, 1997, p. 117). The higher education market is a field of cultural consumption. Entering a field of cultural consumption "requires the tacit acceptance of the rules of the game, meaning that specific forms of struggle are legitimated whereas others are excluded" (Swartz, 1997, p. 125).

Education is a political practice that socializes students to the values, norms, power, and discourses in society (Shor, 1992). One aspect of this political practice is the selection of curriculum and subject matter. Through the political practice of education, students learn what is accepted as legitimate knowledge and culture in their society (Darder, 1995). For example, what histories will be acknowledged and which ones will be ignored? Which perspectives will be highlighted and reinforced and which ones will be dismissed or undermined? By ignoring community traditions, histories, and forms of knowledge within the dominant school culture and curricula, the conditions are being 
created to weaken the possibilities for students to undertake active citizenship (Giroux, 1988). By failing to "critique, expose, and challenge the manner in which schools impact upon the political and cultural life of students," instructors "thwart the formation of critically thinking and socially active individuals" (Darder, 1995, p. 329).

\section{Power as Production of Knowledge}

Foucault (1980a, 1980b) presented a conceptual change and described a new exercise of power in contemporary society. According to Foucault (1980a), this change was a movement from a clearly hierarchical sovereign power that used "exemplary penalty" (p. 38) to a "synaptic regime of power, a regime of its exercise within the social body, rather than from above it" (p. 39). Foucault (1980a) has stated:

But in thinking of the mechanisms of power, I am thinking rather of its capillary form of existence, the point where power reaches into the very grain of individuals, touches their bodies and inserts itself into their actions and attitudes, their discourses, learning processes and everyday lives. (p. 39)

A micro-physics of power was then produced (Lukes, 2004). According to Foucault (1980a), power has changed from a sovereign form of power to a form of surveillance as social control. The exercise of power through the mechanism of surveillance of both the mind and body of the individual in contemporary society was such that individuals learned over time to police or discipline their own behavior (Foucault, 1980a).

Foucault's analysis of power moved away from looking at power from traditional perspectives on power, including Marxist influenced perspectives, as if power was something that may be possessed and used by an individual or group to dominate others (Olssen, 1999). "Power is not primarily the maintenance and reproduction of economic relations, but is above all a relation of force" (Foucault, 1980b, p. 89). Power should be 
viewed as a web that circulates among all individuals and works through them. Power is productive because it exists only when it is put into action (Peters \& Burbules, 2004).

Therefore, power should be examined "at the point where its intention, if it has one, is completely invested in its real and effective practices" (Foucault, 1980b, p. 97). For example, an understanding of schooling from this perspective goes beyond looking at how power is wielded over for repression and control. For example:

A long analysis of how the division of the school day into periods with clear schedules and transitions not only serves the curricular and organizational purposes, but also teaches submission to a particular order that defines for the subject what can be done, where, and when. (Peters \& Burbules, 2004, pp. 63-64)

Individuals are the "vehicles of power, not its points of application" (Foucault, 1980b, p. 98). "They are not only its inert or consenting target; they are always also the elements of its articulation" (Foucault, 1980b, p. 98). If power is to be understood as something that is exercised, then the discourse on power should consider its practice such as what kind of exercise it involves, what the exercise of power consists of, and what are its mechanisms (Foucault, 1980b). When power is viewed as production of knowledge, the view shifts from pinpointing agents of power to recognizing "the systems of ideas that normalize and construct the rules through which intent and purpose are constructed in action" (Popkewitz, 1999, p. 6).

Power in the higher education system is primarily expressed through two mechanisms of power, which are examination and confession (Mann, 2001). Examination and the affixing of values and grades objectify students and places them in a hierarchy based on the grades that they earn. The process of examination is normalized and accepted as if it is based on an objective standard of truth or quantifiable amount of 
knowledge (Mann, 2001). Confession is the process of making students subjects by requiring them to participate in conversations in which students are the speaker and the instructors are the listeners and judges (Mann, 2001). Confession is put into practice through the use of journals, learning contracts, and educational plans that serve to discipline students into regulating and monitoring their own sense of limited power.

\section{Additional Conceptualizations of Power}

This section presents additional theories or conceptualizations by which power may be understood, studied, and discussed. Although these perspectives may not be dominant in discussions on power in higher education, they provide additional frameworks for a discussion involving the concept of power.

A three-dimensional model of power. Lukes (2004) presented a conceptual three-dimensional model to understand and discuss power. Lukes (2004) stated the onedimensional view is that of the pluralists, the two-dimensional view is that of the pluralists' critics, and the three-dimensional view is the view of power.

The one-dimensional view focused on situations where there is a conflict of interest and on the behaviors and outcomes involved in the decision-making (Lukes, 2004). The focus was on observable conflicts and known interests. It was an overt form of power.

The two-dimensional built on the one-dimensional view and added a new layer of understanding and critique of the behavioral focus of the one-dimensional view (Lukes, 2004). This critique considered the political structures of influence that set the parameters and preferences for agenda setting and decision-making. The two- 
dimensional view was focused on both observable and hidden behaviors and interests as well as issues of bias and control. The two-dimensional view involved covert power.

Lastly, the three-dimensional view of power built on both the one- and twodimensional views of power by examining how power shapes ideologies, norms, values, and preferences (Lukes, 2004). This view involved looking at how power can influence the ideas and behavior of individuals even if it is against their best interests. This form of power may be invisible to both the powerful and the powerless.

Understanding power from these three dimensions may facilitate different perspectives of the transactions that take place in a higher education classroom. A onedimensional view of power in a higher education classroom will focus on the behavioral or interpersonal aspects of the exercise of power between teachers and students or between students and their peers. Moving to the other end of the spectrum, a threedimensional view of power will provide a context for understanding the pervasiveness of cultural systems and power structures that configure the social environment in the higher education classroom resulting in the behaviors and outcomes observed from a onedimensional view.

Forms of power. Russell (1986) defined power as the "production of intended effects" (p. 19). Individuals may be influenced by organizations through three different forms of power: physical power, rewards and punishments, and influence on opinion. Physical power, which Russell (1986) related to military and police power, was physical power over the body. For example, the use of corporal punishment via excessive physical exercise is a commonplace occurrence in military academies. Fraternity and sorority social organizations on college campuses use hazing as a form of physical power 
to indoctrinate new members and instill obedience to organizational rituals and standards of secrecy.

The use of rewards as incentives and the use of punishments as deterrents, as a form of behavioral conditioning, are commonly attributed to economic organizations (Russell, 1986). Higher education may be considered an economic organization due to its role in workforce and career development.

Lastly, power over individuals through the influence of opinion was related to organizations such as schools, churches, propaganda, and political parties (Russell, 1986). Higher education from this perspective has the power to shape a student's personal ideology and behaviors through by socializing the student into the academic and institutional culture. Although organizations may be perceived as using one of these forms of power, organizations typically use a combination of them to influence power over individuals.

Similarly, Russell (1986) made distinctions between three different forms of psychological power: traditional, revolutionary, and naked. Traditional power relied on the force of habit, customs, and conformity. By the time a student reached a higher education classroom, s/he had already been socialized into the habits of schooling such as siting in rows, only speaking when acknowledged, and how to properly address instructors. Revolutionary power relied on a new group formed by new ideals or sentiments that lied in conflict with traditional power. An example of revolutionary power was what Freire (2000) referred to as conscientization, or the process achieving a critical consciousness of social and political sources of oppression and then taking action to overcome them. Lastly, naked power was the physical exercise of force. Instructors 
and administrators in institutions of higher education weree able to exercise naked power in certain circumstances such as using campus police officers to remove any student who is deemed unruly or incitant from educational forums and classrooms.

\section{Additional Research on Power in Higher Education}

This section reviews and discusses additional existing research involving instructor power in the higher education. Some of the research pertained to instructor power and how it related to students' experiences. Other research focused on instructors' perspectives on power and their own struggles with power in the academy.

Rouse (1983) studied the effect of instructor's social power on graduate students' mood and moral in the higher education classroom. Social power was defined as the instructor's control of resources (e.g., expertise, authority, rewards, and punishments) and students' desire for the resources the instructor has to offer. The results of the study found that low student satisfaction, moral, and overall mood were correlated with instructor's manipulation of punishing or negative resources. Inversely, high student satisfaction, moral, and overall mood was correlated with instructor manipulation of rewarding or positive resources.

Heinrich (1991) conducted a phenomenological study that explored women doctoral recipients' perceptions of power and sexual issues in their relationships with male advisors. The results of the study indicated that the most personally and professionally supportive relationships between female advisees and male doctoral advisors were the ones where the advisor adopted an androgynous mentoring style. An androgynous approach was described as balanced between task-oriented and 
interpersonal dimensions and in which the advisor used their legitimate power in the interest of the advisee (Heinrich, 1991).

Romer and Whipple (1991) examined how professors' roles of authority and power can be a barrier to engaging in collaborative education with students. They discussed how even though a professor may invite a student to engage in collaboration, the structures that reinforce the professor's authority remain. These structures may include tangible signs of authority (e.g., academic regalia in ceremonies), body language, forms of address, or subtle forms (e.g., arrangement of furniture).

Tisdell $(1992,1993)$ studied how power relationships based on gender, intersected with race, class, and age, were exhibited in the higher education classrooms of nontraditional age adult students. Using a comparative case study, the findings showed that both the male and female professor in the study reproduced controlling power structures in the classroom, although the female professor was less controlling. The study also found that students maintained the power differential in the relationships with the professors by conceding to their professors, but they were also more willing to argue with the female professor than the male professor. Overall, Tisdell $(1992,1993)$ reported that students who benefit from interlocking systems of privilege have more power in the higher education classroom.

Johnson-Bailey and Cervero (1996) examined how the dynamics of larger society (examples) impacted nontraditional age Black women in the higher education classroom. The findings showed that it was common for the participants to face issues involving power because of the dynamics of race, gender, and class. The participants in the study responded to the issues of power and oppression by using strategies of silence, 
negotiation, and resistance. Silence was a coping strategy adopted to feel psychologically safe (internal strategy) or to feel safer during activities or discussions (external strategy). Negotiation involved finding the best course of action that would produce the least amount of conflict in any given situation. Resistance only occurred in rare occasions when participants felt particularly conflicted in situations that were perceived as unfair or biased against them or their backgrounds.

Johnson-Bailey and Cervero (1998) explored the ways in which power relations found in society-at-large occurred within higher education classrooms. Using a comparative case study of two graduate classrooms, Johnson-Bailey and Cervero (1998) found that the complexity that race, class, gender, disability, and sexual orientation brought to power relations affected the teaching and learning process in the classroom. However, the strongest intervening characteristic in the classroom power dynamics was the racial distinction of being White.

Maxham-Kastrinos (1998) explored how critical feminist pedagogy could influence nontraditional college age adults' learning in her writing classroom. The findings suggested that engaging adult students in a critical writing classroom helped move students from alienation to activism. This was done by fostering peer collaboration, engaging students with their writing and their community, and promoting student activism.

Golish (1999) researched students' perceptions of the power and credibility of professors versus graduate teaching assistants. Golish (1999) identified 19 compliancegaining strategies students use to influence their graduate teaching assistants, which included honesty, blame, begging, complaining, guilt, emotional displays, and flattery. 
This research was later expanded to instructors by examining students' use of power and behavior alternation techniques to gain compliance from their instructors (Golish \& Olson, 2000). Specifically, students reported using prosocial strategies (e.g., honesty, flattery, private persuasion) most frequently and antisocial techniques (e.g., blame, negative course evaluation, emotional displays) least frequently.

Tai (1999) explored how students and instructors experienced and made sense of power in the higher education instructor-student relationship through constructions of the self and other. The study found that a lack of trust and inability to identify with the other, for both students and instructors, influenced the way that power was perceived. When there was strong mutual identification between student and teacher, less emphasis was placed on instructors' institutional powers such as grades, recommendations, etc.

Hackman (2000) examined instructor power in the classroom and suggested two models instructors can use to reflect on their power use and develop a deeper consciousness of power in their teaching. The Spheres of Educator Power model was an organizational schema that groups educator power into three primary spheres, which weree the public, private, and intimate. The Sites of Educator Power model identified seven fundamental sites of educator power in the classroom: social identity, teacher education programs, educational biography, personal history, content mastery, student abdication, and institutional conference.

Graf (2001) explored college students' understanding of the relationship between knowledge, power, and social change using a social reconstructionist approach. Specifically, Graf (2001) examined how students in his “Alienation and Powerlessness" course struggled with the concept of power while incorporating Freirian liberation 
pedagogy in the classroom. The findings from the study showed that participants changed their perceptions of power from negative to more positive as they learned ways to create social change. However, students resisted engaging in collective social action to create change despite new awareness of systemic factors that contributed to social injustices.

\section{Summary}

In this chapter, the literature relating to the context of this study was reviewed. The literature included reviewed discussed emotions as a context for understanding power in the higher education classroom as well as literature on the concept of power both in the higher education classroom and the higher education system. In Chapter 3, the phenomenological research methodology and procedures used to conduct this study are discussed. Chapter 4 contains data acquired in the study and relevant findings. A summary of the study in addition to conclusions, recommendations, and implications for teaching and learning in a higher education setting are included in Chapter 5. 


\section{CHAPTER III}

\section{Method}

This chapter begins with the purpose of the study and research questions as presented in Chapter 1. The framework for a hermeneutic phenomenological research design and its appropriateness to this study is then discussed. Following the framework for the research design, my autobiography and assumptions are presented as they relate to the purpose of the study. The remainder of this chapter outlines the procedures for the study, which includes a description of the participants and research setting, and procedures for collecting, managing, and analyzing data.

\section{Purpose of the Study}

The purpose of this hermeneutic phenomenological study was to explore students' experiences with the power of their instructors in a higher education classroom. Specifically, this study focused on how power impacts student learning to inform teaching and learning in higher education.

\section{Research Questions}

This study addressed the following question: What are students' understandings of their experiences with the power of their instructors in a higher education classroom? The following subsidiary questions also guided the study:

1. How do students become aware of the power of their instructors?

2. How do students relate their particular experiences to the power of their instructors?

3. What do students perceive as the consequences of the power of their instructors? 


\section{Hermeneutic Phenomenology as a Research Design}

The research questions in this study were designed to explore student experiences involving the power of their instructors in a higher education classroom. The classroom is a common setting where transactions of knowledge and power frequently take place between students and instructors. Phenomenology is an appropriate qualitative research design for exploring how people describe and make meaning of a phenomenon experienced by them directly (Patton, 2002). In this study, the phenomenon of interest is students' perceptions of their experiences involving instructor power in a higher education classroom. This research design was also appropriate because this study is exploratory. There has been little research on this topic and, therefore, it is not well understood.

A hermeneutic phenomenological study intertwines the interpretations of both the participants and the researcher about a lived experience to uncover layers of details and to identify the core essence of that lived experience (van Manen, 1990). By using hermeneutic phenomenology, it was my role as the researcher to collect and interpret descriptions of student experiences to determine the structures or essences that comprised those experiences. The use of hermeneutic phenomenology created a space for me as a researcher to explain meanings and assumptions of participants' experiences based on my own theoretical and personal knowledge (Ajjawi \& Higgs, 2007). The aim was to illuminate lived experiences because the meanings of lived experiences are usually not readily apparent (van Manen, 1990).

Ever since I was alienated and silenced by an instructor, I have been seeking ways both to regain my voice by talking about the power dynamics inherent in the classroom 
and to share my story by highlighting what I consider a problem regarding teaching and learning in the higher education classroom. Although this research arises from my own personal experience, I aimed to create a space in my research for others to share their own stories involving the power of instructors in higher education classrooms. Because qualitative research is interpretive by nature, voices of the participants in the study are channeled through the researcher. Therefore, the voices of the participants of any study are situated in relationship to the voice(s) of the researcher(s). Qualitative researchers seek to provide a presence of the participants in their studies while acknowledging their own impact as researchers (Goodley, Lawthom, Clough, \& Moore, 2004).

Qualitative research involves the study of problems of interest to the researcher (Moustakas, 1994; van Manen, 1990). Due to my high level of interest and involvement in the study, it was important for me as the researcher to recognize all assumptions and biases as they may relate to the research questions studied (Creswell, 2003; Richards \& Morse, 2007). Therefore, when beginning a hermeneutic phenomenological study, researchers should engage in the reflective process of making explicit understandings, biases, theories, and beliefs related to the study (Laverty, 2003; van Manen, 1990). Because it is not entirely possible to set aside one's personal feelings and thoughts (van Manen, 1990), researchers need to "become aware as possible and account for these interpretive influences" (Laverty, 2003, p. 24).

\section{Pre-understandings to This Study}

This section presents a brief autobiography and my assumptions as they related to this study. The intent was to provide transparency (Flick, 2007a) as the researcher and to 
offer some context to how I may have interpreted the data based on my individual background and experiences (Laverty, 2003; van Manen, 1990).

\section{Autobiography}

My earliest memories of the presence of power in education stem back to the third grade. I clearly remember one day I was sent to the office to make the morning announcements over the public address system. The small room had a view of the principal's office. I remember seeing three wooden paddles of incremental sizes hanging on the wall. Nobody had to tell me what those paddles were used for. Although I had always been a good student, I feared that one day I would be sent to the principal's office and that my hind end would be introduced to the power of one of those paddles.

Although the threat of the paddles faded, the potential power of education to possibly transform my life became more manifest. My Cuban parents always talked about the power of education to transform lives, using themselves as examples. Both of my parents completed a grade school education and then had to work to support the family. Their lives improved here in the United States with their newfound freedoms, but their struggles continued as they worked in blue-collar jobs in the textile industry. I thought that if I were to avoid a life of economic hardship similar to what they experienced, I had to go as far as I could with my education. Through the end of high school, I was a model student and an overachiever. I thought that education was then, as it is now, a means for socioeconomic progress.

My perspective about education changed once I attended college. I enrolled at a public state university and spent a great deal of my first 2 years sitting in large impersonal auditoriums or classrooms where instructors spent most of their time 
lecturing. College was not what I expected. Because my parents had not attended college, all I really knew about college was what I had learned from watching television or movies. I expected to sit in classrooms built within ivory walls where I would spend my time engaging in philosophical debates with instructors. Instead, instructors mostly talked at us from recycled lecture notes and my learning was demonstrated by providing my best guess from a selection of multiple-choice answers. My opinion never mattered and critical thinking was never required. Learning then became a game for me. The object of the game was to figure out what the instructors wanted and then give them just that. I like to believe I played the game well.

Most of my attention in college was focused on extracurricular activities. I was involved in a social fraternity and numerous honor societies on campus. On the surface, it seemed that these extracurricular activities were merely opportunities for me to carve out a social niche for myself. But thinking back about my experiences in these activities, I realize that I was so focused on them because those activities made me feel important and that I belonged. In other words, I had a purpose. I was able to use my skills, talents, and creativity; whereas, in the classroom, I felt there was no place for them.

Extracurricular involvement provided me a space and an existence in college. My affinity for the extracurricular carved out a career path in higher education and student affairs administration.

My later perceptions of higher education have been shaped by professional experiences working in the field of higher education, specifically in student affairs administration, as an adjunct instructor, and as a graduate student for many years. These experiences have allowed me to gain different perspectives about higher education. 
As an administrator in higher education, I have had the opportunity to work in various settings such as large public state universities and a community college in South Florida. Regardless of the institutional mission or culture, I have found that higher education is highly political. All decisions involve power, whether it is the state government determining how much money will be funneled into the education budget, the instructor in a classroom determining how to grade students in a course, or any decision in between. Decisions are not always made with the best interest of students in mind.

Power is embedded everywhere in higher education. In the classroom, power begins with what the instructor decides is going to be included in the syllabus and how students will be evaluated. Deciding what will or will not be included in a course is a political act. Using professional judgment to assign students a grade is a political act. Standing in front of a classroom with students seated in rows facing the front is a political act. The idea that summative evaluations, in the form of grades, by instructors result in something called a diploma, which is a form of credentialing that either restricts or enables access to resources (e.g., jobs, money), is political. As a student, I feel I have spent over 15 years of my life in higher education learning how to maneuver political terrains.

Despite all of my years of education and professional experience, I felt that I could not overcome the power dynamics when I was silenced in my doctoral class as I described in Chapter 1. I was not prepared to handle the situation as a student. A few years later, this experience continues to circulate around in my head and has sparked my 
interest to understand it more deeply in this study by learning from others who also had experiences with the power of their instructors in a higher education classroom.

\section{Assumptions}

The following list highlights my assumptions as I entered this study:

1. It is not possible to be neutral in the research process or to fully separate oneself from it. I do not strive for this neutrality. My past experiences will shape the way I interpret the data and generate findings. I am a product of my past experiences and prior learning and there is no way to suspend these as I proceed in my study. Others may or may not find what I find using the same data.

2. People in positions of authority are not infallible. Regardless of intentionality, people in positions of authority make mistakes, abuse their power, and may harm those they intend to serve or help. More extreme cases of this abuse of power may be readily witnessed in the daily news with stories of teachers, police officers, and clergy members violating both individual and public trust. Subtle day-to-day exercises of power take place mostly unrecognized. Having a title of authority does not equate with truth or righteousness. Titles depicting varying levels of authority have been arbitrarily set and only serve to remind us of where we are located in the social order.

3. Formal education has systemically taught us not to question authority. We sit in rows and assigned desks/spaces. We raise our hands to speak and only speak when acknowledged or given permission. We stay on task and do what we are told. We learn to obey all rules, not question them. We have learned 
not to take notice when we have been silenced or marginalized in the classroom. As students, we learn how to be citizens and how not to take notice when we are marginalized.

4. Education is political. Education is driven by tiered structures of power that only work to maintain the socioeconomic hierarchy. Instructors are hand-tied to curriculums mandated by elected governing bodies such as accreditation organizations and governmental departments of education, who oftentimes have no expertise in the content areas their policies dictate. I also see education as political when it comes to credentialing. There have been movements toward professionalization in many fields with the establishment of accrediting boards and, as a result, education has become a line of demarcation between those that have access to careers and those who do not. There has also been academic inflation as jobs that formerly required only a high school degree now require a college degree and those that formerly required a college degree now require a graduate degree. Education is political because it involves issues of power, access, and control.

5. Education is subjective. My perception that education is subjective is supported by my experience as a student who has witnessed educational fads (e.g. five paragraph essays, learning styles, experiential learning, career education, phonics, emotional intelligence) come and go throughout the years.

6. There is as much to learn from human emotions as there is from logic and reason. When we act or make decisions, we largely rely on previous learning, understandings, and emotions. We generally do not act or make decisions by 
relying on positivist rationalizations in our daily lives and interactions with others. I believe a more human science is needed to uncover deeper understandings about ourselves.

7. Having been oppressed does not free you from being an oppressor. People who are marginalized for certain reasons can and do marginalize other people for other reasons. We are intersections of different groups and populations which have varying degrees of power and privilege depending on the context/environment we are in. For example, a professor who is African American and a woman may be marginalized by her White male colleagues at a university. However, when that same African American woman professor steps into the classroom, the power and privilege ascribed to her in the context of a higher education classroom enables her to marginalize a gay Latino male student.

8. Everyone has a voice. Social, cultural, economic, political, and temporal circumstances determine the presence of that voice in each context. In the context of educational research, I believe that student voices are missing. This is because scholarly research is a field controlled by academicians who set the parameters for what is considered valuable commodity in the knowledge marketplace. For me, this study is an exercise of student voice and an opportunity to inform teaching practices from a student perspective.

\section{Sampling}

All participants in this study were affiliated as graduate students at a large, urban public research university located in southeast Florida. The institution, Florida 
International University (FIU), enrolls over 46,000 students and is the largest university in South Florida (Florida International University, 2011). In terms of FIU's student demographics, $56 \%$ are women and $44 \%$ men with an ethnic breakdown of $13 \%$ African American, 4\% Asian American or Pacific Islander, 61\% Hispanic American, 15\% White non-Hispanic, and 7\% other minority groups (Florida International University, 2011). The following sections describe the sampling strategies used for this study and the participants who were included in the study.

\section{Sampling Strategies}

In this study, I sought sources of information that would provide an understanding surrounding instructor power in the higher education classroom. Purposeful sampling allows for the selection of "information-rich cases" that will produce "insight and indepth understanding rather than empirical generalizations" (Patton, 2002, p. 230). Specifically, criterion, convenience, and snowball sampling were used to recruit participants for this study (Patton, 2002).

Criterion sampling, which involves reviewing and studying all cases relevant to this study that meet a predetermined set of characteristics, was used as a purposeful sampling strategy (Patton, 2002). For the purposes of this study, the criteria for participation were defined as currently enrolled as a graduate student of education at FIU and self-disclosed as having experienced the power of an instructor in a higher education classroom. Graduate students were selected because of the large amounts of formal education they have completed in a higher education setting, thereby increasing the likelihood for the phenomenon of interest to have occurred. Also, as graduate students of education, participants were assumed to have engaged in reflective thinking and 
discussions about their experiences from a more critical perspective than perhaps other student populations. This study related to an area in which individuals were more familiar with the intricacies of issues relating to education (King \& Kitchener, 2002).

Convenience sampling involves using methods that are easily accessible and inexpensive to the study (Patton, 2002). As a form of convenience sampling, an email was sent to graduate students enrolled in the College of Education at FIU explaining the intent of my study (see Appendix A). The email was sent June 25, 2011 via the Office of Graduate Studies listserv (doctoral and masters), which reached all of the graduate students in the college. The email asked students to contact me if they have had any particular experiences involving the power of an instructor in a higher education classroom and were interested in participating in my study so that I may interview them to capture their stories. A total of 26 prospective participants responded to the email invitation. They each received a reply email from me thanking them for expressing an interest in the study and were asked to confirm they were enrolled as a graduate student of education at FIU. Three prospective participants were excluded from participation when they reported they had recently graduated. Three additional prospective participants were also excluded due to geographic distance and the inability to schedule a face-to-face interview. Seven prospective participants did not respond to the follow-up email and were excluded from the study. The remaining 13 prospective participants were selected and interviewed face-to-face at a mutually convenient time and location.

The purpose of snowball sampling was to identify prospective participants from people who know other people who may be information-rich cases (Patton, 2002). In this study, I solicited the assistance of key informants to help identify prospective participants 
for the study. Key informants were other students at FIU. Additionally, participants in the study were asked if they can recommend additional students who may provide information-rich cases for this study. Two prospective participants were identified using snowball sampling. Both met the criteria for participation and were interviewed face-toface at a mutually convenient time and location.

Phenomenological studies typically have a small number of participants. Sample sizes typically range from as little as 6 to 10 participants (Teddlie \& Tashakkori, 2009), around 12 participants (Guest, Bunce, \& Johnson, 2006), to 5 to 25 participants (Miller \& Salkind, 2002). My aim as a researcher was to have a minimum of 15 participants, which is a median of the sample size ranges indicated above. According to the approved proposal of this study, if one month after the initial email invitation there were less than 15 participants in the study, a subsequent email invitation would be sent out using the listserv and participant recruitment would then be extended for another month. Because 15 participants were selected within one month of the initial email invitation, no further participant recruitment was necessary.

\section{Participants}

The 15 participants in the study included nine women and six men. Their ages ranged from under 30 to over 60 years. In terms of racial-ethnic identification, eight selfreported as being Latino, six as White (non-Latino), and one as African American. Six of the participants were enrolled in an education master's degree program and nine were enrolled in an education doctoral degree program. With regards to occupation, seven reported employment in a non-instructional role in higher education, three were employed in an instructional role in higher education, four were teachers in grades K-12, 
one was employed in the corporate sector, and two reported other forms of employment (some participants reported more than one occupation). A summary of participant characteristics are presented in Table 1.

Table 1

Summary of Participant Characteristics

\begin{tabular}{|c|c|c|}
\hline Category & Description & Frequency \\
\hline \multirow{4}{*}{ Age } & $20-29$ & 5 \\
\hline & $30-39$ & 4 \\
\hline & $40-49$ & 2 \\
\hline & 50 and over & 4 \\
\hline \multirow[t]{2}{*}{ Gender } & Male & 6 \\
\hline & Female & 9 \\
\hline \multirow[t]{3}{*}{ Racial/Ethnic } & Latino & 8 \\
\hline & African American & 1 \\
\hline & White (non-Latino) & 6 \\
\hline Degree & Master's & 6 \\
\hline Program & Doctoral & 9 \\
\hline \multirow[t]{5}{*}{ Occupation $^{\mathrm{a}}$} & Corporate & 1 \\
\hline & Higher Education (instructional) & 3 \\
\hline & Higher Education (non-instructional) & 7 \\
\hline & K-12 Education & 4 \\
\hline & Other & 2 \\
\hline
\end{tabular}

${ }^{a}$ Some participants reported multiple occupations.

\section{Data Collection}

The primary data gathering method in this study were interviews. Interviews are appropriate when the topic of interest is focused on finding patterns between participants' experiences rather than on the particular settings in which the experience occurs (Warren, 
2002). The development of the interview protocol and procedures for conducting the interviews are described below.

\section{Interview Protocol}

The interviews were semi-structured in design. The interviews were loosely guided by an interview protocol that included main questions and possible follow-up questions in order to address the research questions of this study (Creswell, 2003; Rubin \& Rubin, 2005; Warren, 2002). Main questions provided some structure to the interview so that the main research questions are addressed. If needed, follow-up questions were used to obtain more details about the information that was shared in response to the main questions. The interview protocol was meant to be a guide as each interview took a different form from the other interviews.

The interview protocol was developed to address the research questions of this study. A peer review group of doctoral students and my dissertation committee examined the initial interview protocol to provide feedback about the questions chosen to address the research questions of this study (Flick, 2007a; Rubin \& Rubin, 2005). The present interview protocol (see Appendix B) was revised based on the feedback provided by the peer review group and dissertation committee.

\section{Interview Administration}

Participants were contacted by email to set up a mutually convenient time for a face-to-face interview. Prior to beginning the interview, participants were given an informed consent form approved by the FIU Institutional Review Board to acknowledge their voluntary participation in this study (see Appendix C). A list of all participants and 
their contact information was stored in my private home office files to protect the confidentiality of all participants.

A semi-structured interview approach was used to follow each of the participants as they share their stories. The interview protocol served as a reference tool for me to focus the interviews if participants departed greatly from the research questions (Rubin \& Rubin, 2005). Follow-up questions were not asked for all points brought up during the interviews. Rather, follow-up questions were reserved for points made that were important to the interviewee or those points that were essential to the research questions (Rubin \& Rubin, 2005). Interviews were scheduled for at least one hour each and were recorded using two digital voice recorders. Interviews ranged from 47 minutes to 90 minutes. The average length of the interviews was 66 minutes. The two digital voice recorders were used in case one of the recorders malfunctioned during any of the interviews.

Professional transcriptionists transcribed all recorded interviews. To verify accuracy of the transcriptions, I reviewed all of the transcriptions by listening to the recordings and reading the transcript simultaneously and made any corrections needed to prepare the data for analysis (Creswell, 2003).

\section{Research Journal}

Additional data was collected in the form of field notes as part of my research journal. In the journal, I recorded reflections following each of the interviews conducted. The research journal also contains correspondence between participants and me, as well as my thoughts, reflections, insights, or decisions that occurred during the study that were reviewed and considered later during thematic reflection (van Manen, 1990). 


\section{Data Interpretation}

Data were interpreted using thematic reflection (van Manen, 1990). The first step in thematic reflection was to read through all of the transcripts of interviews and research notes. The purpose of this first reading was to identify significant statements, emerging themes and concepts, to develop initial coding categories, and to get a sense of the information and its overall meaning (Braun \& Clarke, 2006; Creswell, 1998, 2003; Patton, 2002). Coding is a process of identifying and labeling data linked by a common idea or concept (Gibbs, 2007). All codes were included in a master code list. Ideas and concepts that were recurrent and emerged in the descriptions of respondents' lived experiences as they relate to the research questions were considered themes (Braun \& Clarke, 2006; Gibbs, 2007). ATLAS.ti, a qualitative data software tool, was used to facilitate coding of the data and identifying themes in the data (ATLAS.ti Scientific Software Development GmbH, 2009). When a quotation is assigned a code in ATLAS.ti by the researcher, the quotation is assigned an identifier that is composed of a primary document number to which the quotation belongs and a secondary number that identifies its location in the primary document (e.g., 30:2 corresponds to primary document number 30 and the quotation number 2 in that primary document) (Friese, 2011). All quotations from the transcripts referenced in this study will use this unique quotation ID as assigned in ATLAS.ti during the data interpretation phase of this study.

After identifying the initial coding categories and themes, all of the transcripts were reread to further code the data. New themes that emerged during subsequent readings of the transcripts were included in a master code list. The process of reading and coding data was a iterative process until I felt all codes and/or themes had been 
discovered (Braun \& Clarke, 2006). After two cycles of reading and coding of all of the transcripts, I found no further themes in the data.

Codes interpreted as being phenomenologically related were placed into sets of codes, or code families. The code families were then organized into larger units of meanings or themes (Creswell, 1998). These themes were expanded by providing textural and/or structural descriptions of the experiences as they related to the phenomenon of study. Textural descriptions included examples of what participants experienced in relation to the phenomenon and structural descriptions described how participants experienced the phenomenon (Creswell, 1998).

Textural and structural descriptions were combined to provide an overall description of the phenomenon (Creswell, 1998). This is a description of the essence or nature of the phenomenon as experienced by the participants in the study. "The essence or nature of an experience has been adequately described in language if the description reawakens or shows us the lived quality and significance of the experience in a fuller or deeper manner" (van Manen, 1990, p. 10).

Finally, themes were shared with participants in the study as a form of member checking (Flick, 2007a). After conducting interviews with the participants in this study, I emailed each participant individually to explain the process I used to interpret the data and presented my initial findings and themes. The aim was for participants to be able to recognize their experiences in the initial findings and themes and offer participants an opportunity to provide new insights to better capture and explain their experiences (Merriam, 2002). If any new insights were to arise from the member checking process, they would be incorporated into the thematic analysis. A code would then be assigned to 
each new insight provided by participants during the member checking process and the entire data set would be revisited to determine if there are any new findings. Of the 15 participants in this study, a total of nine responded to my email that presented my initial themes. All nine responded by expressing support of my findings and that my themes resonated with the experiences they shared with me during the interview process. No new insights were provided by participants during the member checking process.

\section{Data Management}

Data management refers to how the data were collected, handled, and protected (Patton, 2002). Participants chose pseudonyms that I used to protect their identity and to report all findings. The interview recordings, transcripts, and research journal were stored in a locked cabinet in my home when these materials were not in use. All electronic data files were backed up to a USB flash drive that was also stored in a locked cabinet at my home. All data will be kept for 3 years after the conclusion of this study.

\section{Quality Measures}

The words validity and reliability are terms used in order to assess the quality of any research study. Although the terms have been mostly used in the quantitative research area, these concepts have been connected to the practice of qualitative research (Merriam, 2002). Therefore, the following measures to promote quality were included in this study: peer review, member checking, and audit trail.

\section{Peer Review}

Peer review is a process of consultation with colleagues regarding the research methods and the congruency between the data collected and the findings and interpretations that emerge from the data (Merriam, 2002). For the purpose of this 
project, four colleagues from my dissertation program reviewed the research methods, interview guide, data coding, data analyses, and research findings. Peer review occurred after preparation of the research methods and initial interview guide. The research methods and interview guide included here are a product of this consultation. Additional peer review occurred after I completed preliminary data analysis and before engaging in member checking. The feedback received during the peer review at this stage was used to develop the communication to participants for the purpose of member checking, which included samples of quotations following each sub-theme to provide clarification and support (see Appendix D). Peer review was a way to verify that the project is progressing soundly (Flick, 2007b).

\section{Member Checking}

Member checking is a process of sharing data and preliminary interpretations with the participants from whom the data were obtained (Merriam, 2002). The purpose of member checking is to allow participants to review the researcher's preliminary analysis in order to verify that the analysis strikes a chord with their experiences. Because my research specifically involves understanding participants' perceptions of their experiences involving the power of an instructor in their classrooms, it was particularly important for me to engage in member checking so that extra steps were taken to verify that my interpretation of the experience resonated with participants' interpretations of their own experience. However, member checking is not about seeking unanimous approval from participants, but rather about seeking their consensus with the data and the findings (Flick, 2007a). As previously discussed in the data interpretation section, nine 
participants provided feedback during the member checking process and all expressed agreement and support with my findings.

\section{Audit Trail}

An audit trail is a collection of researcher notes of detailed information about the methods, procedures, and decisions made during the course of the study (Merriam, 2002). I kept a researcher journal to establish an audit trail that contains information about all of the activities related to the project in order to be able to account for any of the decisions made during the course of this project (Patton, 2002). This is important for several reasons. First, because the nature of the project emerged from my own experience when I was alienated in a classroom, there was a likelihood that my emotions may have come into play during the research. A researcher journal provided a space to park and deal with any emotionality that arose and potentially shaped my interpretation of the data. Second, an audit trail is important when reporting findings at the end of the study. I was able to rely on the journal as a reference. Last, the researcher journal was used to record decisions made during the research process. This was important for engaging in peer review because I was be able to rely on it to share with colleagues any information or justification involving any questions about my research.

\section{Ethical Issues}

A major ethical issue involved in this study was maintaining confidentiality. It was important not to disclose names of the participants or the instructors they discussed due to potential backlash that may occur to the student. There may also be the possibility of backlash to an instructor if any information reaches a supervisor that an instructor has 
acted poorly. In order to handle this dilemma, students were asked to use pseudonyms for themselves and the instructors they discussed during the study.

\section{Limitations of the Study}

Due to the interpretive nature of this hermeneutic phenomenological study, the findings are subject to alternate interpretations. The interpretations are situated in a sociopolitical and specific historical moment of time (Creswell, 2003). Whereas participants were able to reflect on their experiences during both undergraduate and graduate studies thus far, their interpretations and experiences may continue to develop and change as they complete their graduate studies. Similarly, my interpretations may continue to evolve and result in alternate interpretations at different points in time as I progress toward completion of my studies. Additionally, this study is not empirically generalizable and does not lead to the "production of law-like statements, or the establishment of functional relationships," but rather focused on the "uniqueness of human experience" (van Manen, 1990, p. 22).

Interviews provided information filtered through the perspective of the interviewees (Creswell, 2003). This means that their respective perceptions may have been affected by factors such as history, memory, and emotions. People are also not equally articulate and perceptive, thereby influencing the way they communicated the perceptions of their experiences to me (Creswell, 2003).

\section{Summary}

In this chapter, hermeneutic phenomenology as a research design was described followed by my autobiography and assumptions as they relate to the focus of this study. The sampling strategy to identify participants in this study and the process for collecting 
and analyzing data, including interview protocol construction, interview administration, journaling, and thematic analysis, were explained. Details were also shared about how the data were managed and quality promoted in the research process. Chapter 4 includes the findings of this study and Chapter 5 includes a discussion on the implications of the findings and suggestions for further research. 


\section{CHAPTER IV}

\section{Findings}

This chapter presents the findings of this hermeneutic phenomenological study on students' experiences involving instructor power in a higher education classroom. Student perceptions of the ways instructor power influences educational transactions beg illumination because the power instructors exercise in the instructor-student relationship exists mostly unchallenged (Brookfield, 1995, 2000). Data were analyzed using thematic reflection (van Manen, 1990). Three themes emerged from this data analysis: (a) structuring of instructor-student relationships, (b) connecting power to instructor personality, and (c) learning to navigate the field of higher education.

Each of these themes and their sub-themes are presented in this chapter with excerpts in the form of quotations from participants' interview transcripts to illustrate how the themes emerged and to support the findings. When direct quotations are used, the participant's pseudonym and unique quotation ID from ATLAS.ti (see Chapter 3) are used as the citation (e.g., Hirv 37:1). An ellipsis was inserted in direct quotations to indicate omission of words from the original quotation.

\section{Structuring of Instructor-Student Relationships}

The way instructor-student relationships were structured in a higher education classroom shaped how students perceived power in that higher education classroom. Participants discussed the structuring of instructor-student relationships in terms of: (a) instructors valuing students through demonstrations of caring and nurturing, (b) use of the family metaphor for instructor-student relationships, and (c) the degree of student participation in the classroom. Participants identified the values of caring and nurturing 
as important qualities by which to understand the instructor-student relationship and frequently used the metaphor of family to explain the instructor-student relationship. The metaphor of the family as used by participants helped convey aspects of the function, values, and structure relating to instructor-student relationships. Positive instructorstudent relationships tended to include descriptions of, or relating to, a family.

Participants gauged the openness and fluidity in the instructor-student relationship based on the level of student participation in a higher education classroom.

\section{Instructors Valuing Students by Caring and Nurturing}

When participants perceived their instructors as having a positive influence on them and that their instructors valued them as students, participants identified caring and nurturing as values that defined the instructor's professional practice of teaching. Caring is an expression of concern, whether explicitly or implicitly, for another person. "He cared about me learning" (Elizabeth 35:3). "I think that she had a caring heart" (Jessica 38:4). "It's the attitude and the essence of their teaching and their presence in the classroom that makes the student say this person cares for me" (Mariana 41:10). In these instances, caring referred to the way participants perceived the interpersonal dispositions of their instructors.

A value of caring was expressed as existing when an instructor demonstrated importance or a personal interest in the particular student. "For me, a teacher shows that they care by doing more than delivering the content of the class. I knew they cared because they took a personal interest in my future" (Judy 39:1). When the instructor cares about a student, the instructor is interested in not only what students are learning in the course, but their overall personal and professional success and wellbeing. 
Accessibility, approachability, and flexibility inside and outside of the classroom were also reflective of a caring approach to teaching. "If we needed anything, personal stuff, or needed to stay after [class] because you didn't know anything, they were always there" (Hirv 37:3). Sasuke spoke about a caring instructor he had during his undergraduate studies who had really negative feedback about his writing skills. But instead of penalizing him on a paper, the instructor told him, "I want you to use the writing center and stay as much as you can with me after class" (45:1). Sasuke attributes the development of his writing skills to that instructor's caring nature exhibited by her accessibility, approachability, and flexibility.

Daniela brought up the role that non-verbal communication played in determining the approachability of an instructor. She shared, "if I sense that the professor is not approachable, not really caring, is not really interested, I generally won't either" (34:2). Daniela also went as far as to say that if instructors consistently show up to class dressed casually such as wearing jeans and t-shirts, those instructors probably do not care about their work.

Being a caring instructor was not always equated with having a personable or warm disposition. For example, Jessica referenced an economics instructor who was "very strict" and "very rigid" and yet "when I spoke to him one-to-one he was very caring, very understanding and he pushed me to study and encouraged me to even though I was not you know performing" (38:12). Hirv spoke about an instructor and how "she cared," but "still managed to give us the eye" when he and a bunch of his friends acted up in class (37:2). Gina also shared how seemingly negative feedback from an instructor could be viewed positively by a student depending on whether or not the student 
perceived the instructor as caring. Gina recalled how in one class the instructor

embarrassed her in front of everyone by saying she did not know how to write. Gina shared the following about feedback from an entirely different instructor:

"This is a piece of crap [the instructor remarked to Gina in front of the class]." I don't know why it didn't affect me like with [the other instructor]...I think the caring comes through somehow. I think it was also that you could see that she would stay after class, and she would go out of her way to help you out...In a way, I kind of like laughed. I said, "Oh my God. This is a piece of crap. I better make sure not to turn in anymore crap in the future." Then she would tell me when I did things right. Also, I think a big thing was that she was like that with everybody. She would praise you when you did things right, and then when you didn't she would tell you. She told you from the very beginning, "Hey, this is the way I am." With the other professor, I felt that it was a personal putdown. (36:9)

In essence, the act of caring as expressed by the participants involved the perception that the instructor ultimately valued the student.

Positive relationships with instructors were perceived as being nurturing. Nurturing was loosely interchanged with the concept of caring, but generally nurturing in participants' responses implied actions by instructors that were intended to support and develop the student. For example, when Elizabeth spoke about one of her instructors as being "very nurturing of my intellect" (35:4), she was referring to the way he helped her develop as a scholarly writer. She shared, "he had me publishing you know... in terms of power it was very nurturing" (35:7). Leila remembered how she struggled with her master's thesis, particularly when it came to methodology, but it was the "one-on-one guidance" she received from her instructor that really helped her get through the process (40:22). Gina remarked how one of her instructors spent time with students outside of the classroom. "She'll go out to eat with us. She'll show her other side. It's different. We're here to do work, and it's business when you're in the class" (36:13). 
Participants also provided some perspectives on what was not considered as nurturing. For example, Nicole mentioned that her instructor was not nurturing because she would confront students if they ever question her. Nicole remarked, "she was a very strong woman, you know, tough personality, she was by no means nurturing and soft hearted... I saw during that semester students never questioned her" (43:5). Caring and nurturing followed hand-in-hand when participants felt valued and supported by their instructor in both their personal and professional development.

Two participants used the term "mentor" to define the instructor they perceived as being caring and nurturing. A mentoring relationship with an instructor was perceived by participants as student-centered, caring, and characterized by a commitment to engage in genuine dialogue to foster student learning (Caffarella, 1992; Mandell \& Herman, 2009). Judy spoke about her mentor as follows:

On the other hand we had this one phenomenal professor or mentor, who would hear our stories about the other professor, and he'd try to get us to stick with the program for one thing and catch up on the content. He was teaching his courses, and he was teaching theirs too - the things that we were missing or didn't understand. He would fill in the gaps for us. And sometimes he would actually come in on a Sunday and spend all Sunday with us. If two or three of us would ask him to do that, and he would do it. He also showed a personal interest. (39:8)

Elizabeth shared that the same instructor who was nurturing of her intellect told her that he wanted to be her mentor and fostered a relationship that would develop her as a scholarly writer. Using the term mentor implied a level of commitment beyond the duration of the course into the structure of the instructor-student relationship, thereby fostering growth and progress for the mentee.

The antithesis to a caring and nurturing instructor-student relationship is one that is antagonistic. For instance, Barbara remarked: 
I never thought of a teacher-student, professor-student relationship as adversarial. My mind comes from a different perspective, not that I'll be a friend to my high school students. I can't be their friend but I'm also not their adversary. (32:5)

Participants generally perceived that it was really up to the instructor more so than the student to establish the tone for the instructor-student relationship. This is because instructors have "the power to shape the environment in the class" and "the power to lead the students in a direction that will be beneficial for that student" (Leila 40:43).

Sometimes adversarial relationships were explicit. For example, in a psychology class, Nicole completed a journal writing assignment in which she shared some personal information about her family that applied to the course content. Then, one day, the instructor's adversarial attitude showed when Nicole approached her instructor in class about something Nicole thought was unfair and the following happened:

She said, "Well you are absolutely right, I guess narcissistic personality disorder does run in your family" and this was in front of my entire class. It wasn't a small class like you find in graduate school, this was the 160 people in the auditorium and it was silent. I mean the room, everybody, was just quiet and through that whole confrontation I was doing fine and I thought I could handle it until she made that comment and that really embarrassed me, you know.... (43:4)

For others, the lack of caring and nurturing came in more subtle forms. "I remember thinking he was so absorbed in his own life and his own stuff" (Leila 40:11). "Some teachers they could listen to you and dialogue with you. But the rest, I guess, you get the feeling that you were looked down [upon], got no respect" (Roberto 44:6).

\section{Use of the Family Metaphor for Instructor-Student Relationships}

"I think classroom is largely [about] interpersonal relationships" (Leila 40:41).

Participants used the metaphor of family to describe and understand their experiences and relationships to their instructors in higher education. The family is a primary 
socialization source by which an individual learns how to participate in social life and assume the role of a learner within the context of the family unit (Mortimer \& Simmons, 1978). The qualities of caring and nurturing, which are first learned during primary socialization, form a basis on future learning and socialization. Thinking back to his undergraduate experience, Hirv recalled:

We had great instructors that we had for two or three different classes. They knew us and we knew them. It was like a big family, it really was. One of the things that I recall was that those instructors, those teachers were very sincere at not letting us fail. (37:1)

Judy also recalled feeling like a "close-knit family" (39:9) as she and a few of her friends from her undergraduate studies would invite one of their instructors to their dance performances or religious events. Judy commented, "he [the instructor] showed that he supported us. He's kept in touch with all of us. We all keep in touch with each other" (39:10).

Mariana provided some distinction between how the family metaphor used to describe the instructor-student relationship might be different prior to higher education and during higher education:

Well, in early years it's somebody that makes you feel like you are in a family, like with your mom, aunt, right? But in higher education... they are [not] going to treat you like babies or children, but it's somebody that you would like hang out with outside of the classroom, you know? Somebody that you would invite to your Christmas dinner or something. (41:2)

The distinction that Mariana provides is one that shifts the view of family from one that is hierarchical to one that is less tiered and more relational. The hierarchical perspective from earlier education experiences may be perceived and expressed by comparing instructors to more parental figures such as mother, father, uncle, or aunt. This 
perception of a familial hierarchy to understand the classroom flattens somewhat in higher education so that the instructor-student relationship is less hierarchical as there is progression from undergraduate to graduate studies. In other words, the connections remain even though the perception of the instructor as an authority figure diminishes.

In a family unit, members are generally identifiable and recognizable to each other. Members of a family who are frequently in contact know each other and address each other by name. For example, at a family gathering, I may recognize Uncle Samuel or Aunt Jacintha, but may not know the names of their grandchildren even though I am able to easily recognize them. In terms of the higher education classroom, many of the participants (Barbara, Elizabeth, Mariana, Jessica, Leila, Hirv) discussed the use of first names in the instructor-student relationship. They indicated that the mutual use of first names was an indicator of the degree of closeness that was perceived by the student as existing in the instructor-student relationship. The use of first names took shape in two different ways. The first was instructors making it evident that they knew their students' names. For example, Jessica remarked "I think she [the instructor] accumulated a lot of points because she knew everybody's name" (38:15). Jessica felt a connection with her instructor and this was reinforced by the idea that the instructor knew that Jessica was Jessica. Mariana, who equated the idea of the warmth of the family to the warmth exhibited by an instructor, brought up the notion of remembering one's name:

I want to add to my warmth notion that somebody who remembers your name and the kind of work you have, the kinds of questions you've posed. So this person is really, really warm. And I don't feel afraid of coming to him and saying "can you explain this to me again and again?" So yeah he is a great professor. (41:8) 
For Leila, there was quite a difference between her undergraduate and graduate school experiences. When discussing her undergraduate experience, which she recalled as a positive experience, Leila commented, "all of my professors knew me by my first name" (40:1). Leila identified several positive instructor-student relationships in her undergraduate years and one of the connecting pieces is that the instructors knew who Leila was. However, in Leila's graduate studies she discussed an instructor she had for three semesters. "He never said my name. When I'd raise my hand in class, he'd be like 'Yeah, you'” (40:36). "That professor would only learn those two people's names, and he wouldn't know anyone else's name. So he would tell those people how smart they were" (40:32). Learning students' names is one way for instructors to demonstrate or express care and respect to students as both students and individuals (Nilson, 2010).

The other indicator for closeness in the instructor-student relationship was when instructors invited students to call them by their first name. In higher education, it is rather common practice for students to address their instructors with the use of a title, such as doctor or professor, followed by a surname. In her undergraduate years, Barbara had been invited by an instructor to call him by his first name, but she was uncomfortable at that point in her studies to do so. Barbara shared:

I was brought up in a household where anybody who was older than you, you had to respect and part of respect was to never saying their first name. So even friends of my parents who were not related to me were either Mrs. So-and-So or Uncle Somebody. There was always some kind of title with the name. (32:11)

Whereas Barbara was not ready for an instructor-student relationship on a first-name basis during her undergraduate years, her opinion changed during her doctoral studies. "Now at my doctorate level, I was pleased and excited that that happened 'oh please, call 
me by my first name' because I was seeking a more collegial relationship. I went in not wanting to be the subordinate" $(32: 12)$. Elizabeth shared a similar story about her mentor during her doctoral studies who invited her to call him by his first name. "I had a hard time with that, you know, because...he was my mentor... so I couldn't...but by the same token he...treated me like a colleague" (35:8).

When it comes to the issues involving power in the instructor-student relationship, Hirv touched on the issue. He said, "Is it power? You know what, it's the power of call me what you want. And to me shows you are not concerned about power" (37:14). "I think that because they know they have the power instead of abusing it they can say 'call me by my first name"' (37:17). What Hirv is alluding to here is that when it comes to addressing an instructor, whether it is a formal or informal address, the instructor remains in a position of power regardless of how the student addresses the instructor. By being on a first-name basis, students may feel that they are in a more collegial or less hierarchical relationship, which thereby softens the sensitivity or presence of the instructor's power. It is the instructor who first decides whether or not students have the option to be on a first-name basis with them. If the invitation is extended to a student to address the instructor by his/her first name, the student must still decide whether or not to accept the invitation. The circumstances under which a student will accept this invitation may vary from student to student.

\section{Degree of Student Participation in the Classroom}

The participants in this study frequently addressed the classroom structure that is characteristic of a participatory classroom. A participatory classroom is a space where students are enabled and encouraged to contribute their particular worldview to the 
learning experience (Sauvé, 2001). A participatory classroom seemed to be a matter of preference for some of the participants. "I like discussion classes better than like lectures" (Daniela 34:3). "I like the interaction. I like to listen to different people's viewpoints and...I don't like to listen to [the] professor non-stop" (Daniela 34:4). "She kept the class alive. It was more discussion based" (Sasuke 45:2).

Some of the participants shed light on why participation in a higher education classroom was more than simply a preference for a specific style of instruction. When participatory forms of instruction were used, participants felt that instructors used their power to validate other forms of knowledge/ways of knowing. As a result, participants perceived a less hierarchical relationship between him/herself and the instructor. "You release the intellectual capital in the class. He [the instructor] was not threatened by that at all" (Elizabeth 35:11). "He was just super enthusiastic and very happy, and he brought such positive energy to the classroom. He really got you participating" (Leila 40:19). Leila brought up the issue of student voice when she said, "I really like courses that they encourage student participation and more of an equal democratic experience so you feel that your voice is valuable and that a lot of people's voices are very valuable" (40:23).

Barbara commented that in her experience her courses in the field of education were generally more participatory than in other academic areas.

In education courses, the students take charge. Education professors usually relinquish control to their students. Most of the teaching is done by the students in most of the courses. Except, maybe, the very fundamental ones where there has to be a lot of dumping of information. You know you need to do all that foundational background, lot of lecture I guess, but once you get past that I usually don't find professors of education to have that attitude. (32:8) 
The attitude that she was referring to was her perception that some instructors consider themselves to be the sole source of knowledge in the classroom and, therefore, dominate the classroom dynamics through lectures. This unidirectional dumping of information from instructor to student is what is commonly referred to as a banking model of education (Freire, 2000). As Mariana said directly, "some professors like the gap to say 'I'm mister know-it-all and I got this PhD at the end of my name"' (41:3). When this distance was created, particularly through nonparticipatory forms of instruction such as lectures, the instructor refused to validate any knowledge or experience that is not his/her own and increased the distance participants perceived between themselves and the instructor. For example, Mariana commented, "If it's just a lecture...it's obvious the professor has all the power. He is there to teach you something. Tabula rasa. You don't know anything. Whatever you have to say is not that important" (41:17). This is what Freire (2000) refers to as a banking system of education in which instructors presume themselves to be the authority in the classroom and all previous knowledge students may have acquired is dismissed and ignored.

Because of the less hierarchical structure perceived by participants when they were in a highly participative and open classroom, participants placed less emphasis on the instructor's formal power and authority in the classroom. When instructors opted for a participatory classroom, participants used the arrangement as a cue on how to perceive the positioning of the power structures in the classroom.

\section{Connecting Power to Instructor Personality}

When participants discussed instructor power in a higher education classroom, they mostly reflected on perceived personality issues of the instructors as unique 
individuals, rather than on issues involving the instructors as agents of the higher education system. In essence, the exercises of power were perceived as indicators of instructors' traits.

\section{Focus on Personality Issues not System Issues}

When students perceived a consistency or pattern in their instructors' behaviors, students attributed those behaviors to the particular traits of their instructors. A trait is "an enduring personality characteristic that describes or determines an individual's behavior across a range of situations" (APA, 2009, p. 529). Referencing back to when Leila discussed how the instructor she had for three terms never learned her name, she said "honestly, I think he has early-onset Alzheimer's" (40:37). Even though it bothered her that the instructor did not acknowledge her, Leila attributed his behavior to the instructor's age and mental status, rather than to any assumptions regarding instructor power or systemic issues involving power.

Daniela spoke about one of her instructors and said, "his personality is very eccentric and very blunt. Some people find that offensive" (34:5). Daniela thought that the average opinion of anyone walking into the course, like friends or family, who might witness the behavior of the instructor would find him to be offensive, but because of her consistent contact and exposure to him in the class, she does not see the professor in that way. Daniela explained, "definitely anybody that would walk in would be like "what is this?' but we have been there and we understand that's how he is, so it's not really a power thing, but others might view it as a power thing" (34:16). "I think it's funny and a distraction from the difficult coursework" (34:5). "Maybe because it happens consistently" (34:17). She goes on to say: 
I assume that that's his personality just because that's always how he acts. I mean I could be wrong, but maybe if it is like just once or twice then you are like "okay, what's going on here?," like this is out of character. So it could still be power, but I am viewing it more as like his personality. (34:18)

Even in light of derogatory comments involving racism or sexism, some participants still attributed those behaviors to the instructor's personality traits or identity rather than seeing those behaviors as part of a larger pattern of racism or sexism permeating the academy. Judy shared a situation where a female classmate of hers pointed out to the instructor that he had made a mistake on a problem they were working on in class. Judy shared:

Instead of telling him it was a mistake, she was like, "I was wondering if maybe ..." He's like, "Very good job. That was very female-like of you to ask that the way you did instead of just pointing out that it was wrong because I have learned that is how females do things and say things and that if you have an idea you should ask a question rather than making a statement." He even gave an example. He said, "So if my wife wants me to feed the cat she doesn't say feed the cat. She says, 'Has the cat been fed yet? Do you think the cat needs to be fed?" And that's what he said in class after that. It was just like, whatever. (39:19)

Judy then shared this incident with a friend of hers outside of the classroom. "She [her friend] was like, 'He's racist and sexist.' I was like, 'I didn't know he's racist or sexist. I know he makes sexist comments"' (39:21). This was similar to how other participants (Barbara, Jessica, Leila, Roberto, Michael) were more likely to label the comments as being racist, sexist, homophobic, etc. rather than label the particular instructor as a racist, sexist, or homophobic. Participants brushed off the comments and then pegged the instructor as rude or attributed the comments to things such as the instructor's political party affiliations or viewpoints. Participants rationalized the behaviors as random and/or isolated incidents or displaced aggressions stemming from the instructor's flawed 
personality or personal life circumstances outside of the classroom rather than

overbearing systemic influences (McPherson \& Young, 2004).

\section{Unreasonable Demonstrations of Power}

Because an instructor is already instilled in a position of power, unreasonable exercises of power were considered a reflection of a personality flaw of the instructor. Sometimes the unreasonable exercises of power were explicit. Barbara recalled how one of her instructors never had anything really positive to say to anyone in class.

All the comments were highly critical with a negative bent to them.... Nobody understood what her point was except to make you feel as if you are not her colleague, that she was a step above or two or 20 steps above, however many steps she needed in her mind. (32:7)

Roberto spoke about an instructor who did not like it when Roberto brought up a counterpoint to a statement the instructor made regarding minorities in education. The instructor told Roberto in front of the class "remember that I am the teacher" (44:14). Roberto stood up and walked out of the room despite his instructor telling him to sit down.

Nicole was admonished in front of her classmates when she up went to the instructor at the front of the room to inquire about a decision the instructor made that Nicole thought was particularly unfair to her regarding extra credit opportunities in the two classes she was taking with the same instructor. Nicole said the instructor told her:

"I did not get a Ph.D. because I am an idiot. I know what I am doing and this is how it is. If you would like to continue accusing me of unfairness at this point I shouldn't bother giving you extra credit for neither class. So if I were you, I would sit down and leave it as is and accept the credit in the other class." (43:3) 
Despite the embarrassment and anger Nicole felt at that moment, she still held on to the perception that "there's a reason why that person is that way and that reason has nothing to do with me....It's their problem" (43:14).

Other times, the unreasonable demonstrations of power were more implicit in the classroom interactions between instructor and students. “Arrogance... condescending... 'There's no way you'll ever know as much as I know or read as much as I've read,' you know. Those kinds of attitudes" (Barbara 32:9). Instructors were seen as unreasonably demonstrating power when they dominated the classroom time to "brag the hell out of himself" (Elizabeth 35:31), "fall asleep in class" (Leila 40:28), or when they "pontificated for the entire 3 hours we were in class and focused a lot on himself, projects that he was working on, issues he had with the school [and] with the faculty" (Hirv 37:6).

Sometimes the unreasonable behaviors were a bit excessive. For Barbara, an unreasonable exercise of power involved cancelling class for non-emergency reasons. Barbara shared:

I'm talking about consistently "oh let's look at the schedule and you know I don't think we really need to come back for another three weeks..." That kind of cancelling. "Oh just keep working on your projects." Yeah I don't like that and I feel cheated, as if the person is exploiting their power. (32:27)

Gina remembered another:

But his approach was so negative. If you were a few seconds late, he'd shut the door and lock it. It was very intimidating and maybe he just wanted to be rigorous. Maybe that was his intention - to let people know that the attitude here it's business, and it's not playtime, since a lot of the students were young. But really when you look at it, honestly, the students in his class were into learning. It wasn't like they were playing around. It wasn't necessary for him to be like that. (35:5) 
Ted mentioned an instructor who frequently comes to class unprepared to teach:

That lady would sit at the front of the classroom and spend half an hour flipping through the textbook, deciding in the middle of class, "I do want this on the test. I don't want this on the test. This is what we're going to cover." (46:11)

In all of these situations where participants discussed instances they thought instructors used their power unreasonably, not one of the participants addressed the issue with their instructor. Because students have much to risk if they confront their instructors, participants communicated an ethos of passivity and little belief that anything they could have done would have made a difference in the instructors' behaviors. This passivity and learned acquiescence to instructor power is a common phenomenon for undergraduate and graduate students just as it is for students in lower levels of education (Jamieson \& Thomas, 1974).

\section{Learning to Navigate the Field of Higher Education}

As participants progressed from undergraduate to graduate studies, they perceived expertise in content or knowledge development as secondary to expertise in successfully navigating the field of higher education. Strategies participants used to navigate the field included: (a) evaluating instructor performance, (b) preserving the self, and (c) learning to play the game.

\section{Evaluating Instructor Performance}

The two forms of student evaluations discussed by participants were the formal student evaluations of teaching administered by institutions of higher education and the non-institutional sources of student evaluations via Internet websites. Participants discussed both formal and informal evaluations as part of the process of navigating the field of higher education. 
Barbara discussed the common practice of higher education institutions to require that instructors administer student evaluations of teaching at the end of each term. Barbara commented:

The only thing that it's interesting is that when you are sitting as a student toward the end of the semester and the professors put down the evaluation forms and then they leave the room, there's always a little bit of scuttlebutt among the students. "Oh should we really tell them? Should we really write what we think? Well you know we haven't gotten our grades yet, maybe we shouldn't." And so it's always interesting to me that the perceptions that the professor is still in the room, that the professor has walked out, the person is not physically there anymore, but present nonetheless. (32:16)

There are two ways to view this situation. If the student evaluations are administered before student grades are recorded, students may be reluctant to truly share their feedback about the instructor's effectiveness. However, if the evaluations are administered after grades are recorded, instructors may argue that students are emotionally reacting to the grades which they already received and may not have met their expectations. Barbara pointed out that if it is perceived "that those student evaluations really don't have any power" (32:17), students may not take them as seriously.

However, two participants in this study did speak about using the formal student evaluations of teaching as a way to express their discontent with instructors' behaviors, personality, or pedagogical approach. Elizabeth recalled a time when she and her classmates were very displeased with an instructor who spent most of the semester boasting about herself rather than teaching course content. When it came to completing the evaluations, Elizabeth shared, "we were in there for like an hour and she kept ducking in and saying 'are you all done yet?' We are like 'no.' We wrote dissertations about her" (35:30). The class took longer than the usual 10-15 minutes to complete the student 
evaluations. Daniela mentioned that when she finds instructors are not approachable, caring, or interested in her work, she "won't ever take a class with that professor again or will give him a negative evaluation" (34:2).

Regardless of student perceptions, the results from the formal student evaluations of teaching submitted by students are generally not made easily available or publicized to the student population at-large (Coladarci \& Kornfield, 2007). Although participants discussed student evaluations at the end of their courses, none of the participants provided any indication of using or accessing the results of institutional student evaluations to inform future decisions regarding their higher education.

Because of the inability to easily access institutional student evaluations of teaching, participants relied on non-institutional sources of student evaluations to gain insights on what to possibly expect when they entered a new instructor-student relationship. Participants reported using the Internet and specifically the website RateMyProfessors.com to find out information about their instructors.

Having access to non-institutional student evaluations helped participants navigate the field of higher education in two primary ways. The first is that publically accessible information about instructors provided participants insight as to which instructors they should enroll with for their courses based on the information other students provided. The other is that the information helped participants psychologically prepare themselves and anticipate particular dynamics of instructor behavior as described by other students. "Now we have all the social media and RateMyProfessors and there's more public information about the faculty now than there ever was" (Barbara 32:17). "I was curious so I went online and I went to see RateMyProfessors and I went to see what 
are the other students saying now... I felt that was right on...." (Nicole 43:11). And Michael shared that current students "have it easier than a lot of us had in the past with all this 'Rate the Professor' stuff. You can just Google and figure out some idea of what the professor's going to grade like" (42:6).

\section{Preserving the Self}

Self-preserving behaviors as discovered in this study are behaviors that enabled the participants to feel psychologically safe to persist through their educational experiences. For example, self-preservation took place on an intrapersonal level. "I want a grade but I will no longer sacrifice my self-esteem for a grade. That is something I will not do" (Nicole 43:20). In other words, on an intrapersonal level participants engaged in self-preservation by not letting the instructors harm or lessen their self-esteem or selfconcept. Instead, Nicole stated that students should not "take it personally because if they [instructors] were comfortable with themselves they wouldn't feel the need to...use their power to do anything that can be interpreted in the wrong way or harmful or actually be harmful to a student" (43:21). This is a process of rationalization used when "logical reasons are given to justify unacceptable behavior", particularly if it is in "defense against feelings of guilt, to maintain self-respect, and to protect from criticism" (APA, 2009, p. 421).

When faced with a negative exercise of instructor power, participants decided whether or not to continue in that instructor-student relationship. For example, Sasuke spoke about a geology class that was particularly confusing and difficult for him to understand. When he would raise his hand to ask a clarifying question, his instructor would tell him to go back to the book instead of offering more detailed information. 
I actually ended up dropping that class... and it was a late drop though, and I had to go to him to get a signature and he asked, "Why did you drop my class?" And I told him, "to tell you the truth," I told him a lie, "to tell you the truth I thought it was going to be an easy class." (45:7)

Five of the participants (Camilo, Gina, Judy, Sasuke, and Nicole) reported that they dropped a course because they could not continue to be in what they perceived to be a negative instructor-student relationship.

For Gina, the negative interactions with a math professor influenced her to completely change her major to one where she felt would be safer.

I was a biology major. I changed my major. I changed it to English. He was one of the reasons why. I had always been weak in math. Then I asked him a question. The way I would learn would be that I would ask a lot of questions. It would keep me awake and I could check to see if my thinking was right. He just embarrassed me in front of the whole class. It was a class full of males and there were only three females in the class. (36:1)

Sasuke and Nicole also changed their major of study altogether because of negative interactions with their instructors.

If a student chose to remain in an unfavorable instructor-student relationship rather than exit the relationship, the student engaged in self-preservation in the classroom. Participants shared that some ways to engage in self-preservation in the classroom include: stay quiet, brush off the things that bother you, do not always tell the truth, and make sure you do not get labeled as a trouble-maker. This finding is similar to the way Johnson-Bailey and Cervero (1996) discussed participants in their study responded to issues of power with silence as a coping strategy to feel psychologically safe internally and in the classroom environment. Michael shared this instance about silence in the classroom: 
There was a class with a woman from the Caribbean who was - it was one of these social sciences classes. We were talking about the region, and one of the students in the class brought up the plight of gay people and how there was homophobia over there. This person [instructor] automatically jumped into a rant about how gay people were destroying her home country because of sexual tourism....Even though it seemed very homophobic what she was saying right on the surface of it, a lot of people didn't say anything. I thought that was a display of power in that people didn't talk. (42:9)

However, Michael did not clarify whether the students chose to remain silent in order to protect themselves from possible consequences of confronting the instructor in an emotionally-charged situation or if it was the instructor's power in the classroom that silenced students from pushing a counterpoint. From Michael's perspective, it was more about choosing to remain silent and not risk the academic consequences. Similarly, when Judy's instructor made racist comments in class, she chose to remain silent. Judy stated, “for one, I don't know that if I said anything it would make a difference. I maybe shouldn't feel like that, but that's how I feel. I don't like to rock the boat with professors" (39:16).

Roberto, Mariana, Elizabeth, and Sasuke touched on how sometimes instructors label students negatively and even at times share those labels or perceptions with their colleagues. "I didn't want to [be] misperceived as a bad student and make it hard on me because another professor already knows about me" (Sasuke 45:6). Participants perceived it was important for them to maintain a positive image with instructors for two reasons. The first is that if instructors hold a student in a favorable light, they are more supportive of that student. The second reason to maintain a positive image with instructors is that instructors talk to other instructors about students, especially about 
those that they feel are trouble-makers. To survive in other courses, a good student reputation is needed.

Camilo and Mariana offered interesting metaphors to illustrate how they saw themselves surviving through the educational process. When he spoke about an instructor who seemed to be consistently negative towards him, Camilo shared he did not want to "give him the pleasure of let's say having a hit. If you throw a rock into a pig pen, the pig that squeals is the one that got hit" (33:6). In other words, Camilo felt it is better to not let instructors know they hit a nerve. Mariana shared that instances with negative exercises of instructor power helped her to have a keener sense of that power. She provided a more aggressive and animalistic metaphor:

You learn how to smell the bad power. And in Spanish you say you grow fangs for that. You grow a fang for that. I don't know how to translate that. The bad power grows you a fang. Some people get really pushed down. If [with] bad power you don't have the stamina to keep on going, you don't have the motivation, bad power closes the door for you and you start dropping out of school. (41:18)

In other words, Mariana felt that if she does not toughen up, she falls victim to the process.

However, participants also discussed how some instructors helped them persist through their educational experiences. For example, Nicole and Gina mentioned relationships where the positive relationships with their instructors actually motivated them to stay in school. For Gina, personal problems at home were overwhelming her and she was very close to dropping out. She spoke about going to her instructor and advisor:

He's very nice, very understanding. I think that they understand when you have pressures at home. I was about to drop out from the program. I was having trouble with my daughter rebelling. I went to [the instructor] and said, "I think I'm going to have to drop out because this is too overwhelming. It's too much." 
He persuaded me to stay. He said to just take a class at a time, and he was supportive. $(36: 20)$

Nicole faced similar support and encouragement from one of her instructors. Nicole, having entered higher education as a non-traditional college age student presented hurdles for her in terms of feeling inadequate or not fitting in. However, one of her instructors was really impressed by Nicole's writing skills and pulled her aside after class and told her "you know you should consider graduate school" and Nicole shared about that incident, "you know that was a huge shocker to me when that happened to me and that's what made me go to graduate school" (43:25). Nicole remembers and attributes that singular conversation with her instructor as the event that propelled her decision to seriously consider graduate school.

\section{Learning to Play the Game}

The perceived benefits of earning the educational credential outweighed the perceived consequences of having to endure an unfavorable student-instructor relationship. In general, higher education was seen as a way to secure upward socioeconomic mobility, particularly for participants who are from immigrant families. For example, Camilo pursued higher education to "have a job that pays a little better than say one would consider labor intensive jobs. It is more of the way you have a middle class lifestyle as opposed to working up through the system" (33:2). For participants whose parents had attained a college degree, higher education was an expectation. "College was never a choice... [as a] baby coming out of the baby boomer generation, there wasn't a choice. It wasn't if you go to college, it's when you go to college. So I never thought about not going" (Barbara 32:32). "I realize I had this notion that I'm 
doing it because it's what is expected of me and what's always been expected of me" (Ted 46:19).

However, despite the long-term goals for many of the participants, the immediate focus was on earning the specific credentials they needed for their chosen profession (Swartz, 1997). "My goal is to get out of school and get the degree and move my way through the obstacles that are presented to me to get to that goal" (Michael 42:13). As participants neared the end of their academic programs, the more likely they were to withstand unfavorable situations. "It was the last semester. I needed to be finished. I needed to have my degree. I needed to move on with my life" (Barbara 32:22). "I didn't really want to get into an argument with him on this. I'm there just to get a grade at that point" (Michael 54:54). Although participants placed some focus on earning good grades when they spoke about their graduate school experiences, the focus was more so on surviving the process.

Participants described their experiences in higher education as ultimately not about what new knowledge or skills they acquired; it was about learning how to play the game. The emphasis was on getting through the process of earning the degree.

You just play the game. I don't even see - I've gone through so much studies and so much coursework. I don't even think that getting a doctorate has made me that much smarter or had much more of a leg up compared to people who just went to college. I think it's more that I'm getting the credential that will give me power in society. I'm going to be Dr. So and So. (Leila 40:40)

Roberto spoke about how his higher education experience was not what he expected:

For me it was very harsh to get through there and understand finally how the system in the university works. That you were there. You had to learn what they tell you. Read what they tell you. Write what they expect from you and your point of view was not too welcomed. (44:3) 
Participants shared stories about how they went along with what the professor wanted, despite what they believed, just because that was required to get them through the process. Leila shared:

She's like, "No, you don't put the purpose statement before the problem statement. It has to be problem, then purpose." It's how the process is, but that's so nitpicky. Who cares? You play the game, and that's how I see getting a doctorate. $(40: 39)$

In other words, instructors "have the power over your grade if you don't say or do it or write the way the instructor wants" (Camilo 33:8). Playing the game is how participants have related their experiences to power.

The ability to play the game successfully is facilitated when there is consistency in the rules of the game. Michael and many of the participants alluded to a preference for consistency of instructor behavior over finding them to being caring, nurturing, or agreeable. Michael commented:

The worst teachers would be the ones that were maybe erratic. They weren't following what they said the first day of class. You realize it too late, and you're going through the semester going, "Oh my God. What's going to be on the test now?" I would probably have more hatred for that kind of teacher than I did let's say, somebody who happened to be pompous or had ideas that I disagree with. If they followed what they said they were going to do at the beginning of the semester, then I tended to be okay with it. And actually in graduate school, I've gone through a few teachers that I didn't like, but I've been able to - I know I can maneuver my way through the course and pass it. (42:3)

For one participant in particular, the rules of the game are different having travelled and studied in different countries. Roberto thought the instructors in the United States were generally closed-off to knowledge outside of the country or originating in languages foreign to them. Roberto shared: 
You just cannot anymore impose Western values. And don't try to say the only thing that is good, because you don't read or understand other languages, is just what the people from this part of the world wrote or comment. (44:21)

He thought instructors in the United States expected students, particularly in doctoral programs, to sit passively and "eat paper" (44:23). He further shared:

Our PhDs, in my opinion, do not have to be just a paper eater. They have to be a scholar, but just not a scholar with blinders, they have to take their head out and be secure and have an opinion and be even at a PhD level have an interlocking multicultural context, some relationship, because otherwise that is why our $\mathrm{PhDs}$ can't get a job besides teaching or maybe writing from time to time. That's the challenge. (44:24)

Although dismayed by his perception, Roberto does what is expected in order to meet his education goals and earn the credential. This appears to be the same for all of the participants in this study.

\section{Summary}

This chapter presented the findings of this hermeneutic phenomenological study on students' experiences involving instructor power in a higher education classroom. Data were analyzed using thematic reflection (van Manen, 1990). The three themes that emerged from this data analysis were: (a) structuring of instructor-student relationships, (b) connecting power to instructor personality, and (c) learning to navigate the field of higher education. A summary of the themes is presented in Table 2. These themes emphasize how in discussing instructor power with participants, their perceptions were connected to how participants viewed and understood instructor-student relationships in a higher education classroom. Chapter 5 will specifically answer the research questions of this study and discuss the implications of this study to the research and practice of teaching and learning in higher education. 
Table 2

Summary of Themes

Main Themes Description and Sub-Themes

Structuring of How interpersonal relationships were structured in a higher education Instructor- classroom shaped how participants perceived power in that higher education Student classroom.

Relationships

- Sub-theme 1: Participants described positive relationships with instructors when they perceived instructors valued them through demonstrations of caring and nurturing.

- Sub-theme 2: Participants used the metaphor of family to describe and understand their experiences in higher education.

- Sub-theme 3: When instructors used participatory forms of instruction in a higher education classroom, instructors used their power to validate other forms of knowledge/ways of knowing and participants perceived a less hierarchical relationship with the instructors.

Connecting

Power to

Participants consistently discussed exercises of instructor power as issues

Instructor

Personality relating to the personalities of their instructors rather than as issues involving the instructors as agents of the higher education system.

- Sub-theme 1: When participants perceived a consistency or pattern in their instructors' behaviors involving exercises of power, participants attributed those behaviors to the particular traits of their instructors.

- Sub-theme 2: Because an instructor is in a position of power, unreasonable exercises of power were considered unnecessary and a reflection of a personality flaw of the instructor.

Table 2 continues 
Table 2 (continued)

Summary of Themes

Main Themes Description and Sub-Themes

Learning to As participants progressed from undergraduate to graduate studies, they Navigate the

Field of Higher perceived expertise in content or knowledge development as secondary to

Education expertise in successfully navigating the field of higher education.

- Sub-theme 1: Participants relied on non-institutional sources of student evaluations of instructor performance to gain insights on what to possibly expect when they entered a new student-instructor relationship.

- Sub-theme 2: Participants engaged in self-preserving behaviors that enabled them to feel psychologically safe to persist through their educational experiences.

- Sub-theme 3: Because the perceived benefits of earning the educational credential outweighed the consequences of an unfavorable studentinstructor relationship, participants focused on surviving the process and learning how to play the game. 


\section{CHAPTER V}

\section{Discussion}

This chapter is divided into three sections that form the discussion based on the findings of this study. The first section addresses each of the research questions originally proposed in the study and how the findings relate to the research questions. The second section addresses the implications of this study for teaching in higher education and recommendations for further research. A summary section concludes this chapter.

\section{Responses to the Research Questions}

Responses to the research questions of this study are presented in this section. The primary research question of this study was as follows: What are students' understandings of their experiences with the power of their instructors in a higher education classroom? The following subsidiary questions also guided the study:

1. How do students become aware of the power of their instructors?

2. How do students relate their particular experiences to the power of their instructors?

3. What do students perceive as the consequences of the power of their instructors? The responses to each of the subsidiary research questions are provided first as scaffolding to understand the primary research question.

\section{Response to Subsidiary Question 1: How do students become aware of the power of their instructors?}

The findings from this study revealed that by the time participants enrolled in higher education, they were already aware of the power of their instructors. Their 
awareness of instructor power stems primarily from their prior learning experiences. All of the participants were able to speak in detail about significant experiences involving instructor power during their primary and secondary school experiences. These experiences, which were defining and memorable for them as learners, included both positive and negative experiences.

The primary source of socialization and influence for each participant, which is the family, emphasized the importance of instructors. The family was an important agent in legitimizing instructor power (Mortimer \& Simmons, 1978; Weidman, 1989). For those participants (Ted, Leila, and Jessica) whose parents had a college education, college was a family expectation for their children because the parents had achieved that socioeconomic distinction (Swartz, 1997). A bar for educational attainment was set. Participants (Sasuke, Camilo, Mariana, Daniela, Roberto, Michael, and Gina) from immigrant families placed an emphasis on earning a college degree in order to climb the socioeconomic ladder and secure a better life and future than did their parents (Buttaro, 2004; Zalaquett, 2006). In either instance, the instructor was perceived as a gatekeeper to the status or credentials sought in higher education (Swartz, 1997).

Learning experiences in primary and secondary schools were important in inculcating obedience to instructors as a source of authority (Macedo, 1994). By the time participants entered higher education, their sense of perceiving and discerning instructor power had already become tacit (Mortimer \& Simmons, 1978; Weidman, 1989). It was by taking cues from their emotional responses (or gut feelings) in the classroom that they were able to formulate either positive or negative perceptions about their instructors and the way the instructors used their power in the classroom (Boler, 1999). The emotional 
responses were triggered when participants received indications of possible impediments to them reaching the goals and benefits that they were seeking as part of their educational pursuit. This is supported by Rouse (1983) who found connections between low student satisfaction, morale, and overall mood when correlated with instructor exercise of social power that resulted in negative resources or punishment for the student.

Participants also became aware of the power of their instructors when they experienced cognitive dissonance when instructor behavior contradicted student expectations of instructor behavior (Harmon-Jones \& Mills, 1999). As a result of the cognitive dissonance, participants had to readjust and reconstitute their understanding of not only the instructor, but also the instructor-student relationship. Readjusting required revaluating the nature of the instructor-student relationship and also the strategies by which the participants used to reach their goals within the context of the newly defined relationship. For example, two expectations widely shared by participants were that instructors should exhibit caring and nurturing behaviors. When instructors violated those expectations, participants perceived the instructors behaved in ways that were not beneficial to them and, therefore, emotionally distanced themselves from the relationship. The strategies then adopted were focused on task and course completion rather than finding self-fulfillment in the course material, learning experience, or the instructorstudent relationship which are characteristics of a state of alienation (Mann, 2001; Seeman, 1983).

Overall, the values of caring and nurturing as described by participants succinctly coincide with Baptiste's (1998) definition of the ethic of caring. He stated that the ethic of caring can be defined in one of three ways. The first is improving the marketability of 
students (human capital formation; Baptiste, 1998). This was evident as participants shared examples when their instructors were instrumental in getting them to publish (Elizabeth), apply new skills in their own classrooms as teachers (Leila), or improve their writing skills (Sasuke). The second way to define the ethic of caring is supporting selfimprovement to promote positive change in the individual student (Baptiste, 1998). For example, both Gina and Nicole discussed in this study how their instructors were instrumental in getting them over personal hurdles and avoiding dropping out of school. The third way of defining the ethic of caring is empowering students to take action against oppression and to engage in emancipatory learning (Baptiste, 1998). Taking action against oppression and engaging in emancipatory learning requires that students first gain a critical consciousness of their sources of oppression (Freire, 2000). In this study, however, none of the participants discussed having benefitted from this form of caring by their instructors.

\section{Response to Subsidiary Question 2: How do students relate their particular} experiences to the power of their instructors?

Participants described the experiences involving the power of their instructors in a higher education classroom as playing the game. Learning to play the game is about learning how to acquire the cultural capital that is sought after and that is tied to the educational credential being earned. Playing the game involved learning "how to present oneself vis-à-vis relations of power" in order to earn the rewards that follow the cultural capital (Isserles \& Dalmage, 2000, p. 160). The rewards may include a job, entry to a profession, promotion, or acceptance at another educational institution. Entering into the 
field of higher education requires the implicit adherence of the rules of the game (Swartz, 1997).

There are several components that are implied in playing the game. The first is that there are a set of players in the game. The categories of players discussed in this study were the participants as students and the instructors they discussed. Sometimes the players appeared to be at odds or playing for different teams. At other times, they worked together to achieve mutual goals. Another implied component is that there is a set of rules by which to play the game (Isserles \& Dalmage, 2000). The higher education institution and other systemic sources determined some of the rules discussed by participants such as policies or procedures. Other rules for the classroom were determined by instructors such as syllabi and the norms created and maintained through classroom management. Lastly, for both students and instructors, playing the game has an emotional component that shapes cognitive processes such as the way information and experiences are perceived and the behavioral responses that are elicited (Clark \& Dirkx, 2008; Dirkx, 2001, 2006, 2008).

Playing the game can be primarily interpreted in two different ways. The first is from a negative perspective that connotes triviality of the higher education experience as something participants do not take seriously. This negative perspective of playing the game is dismissive of participants as students and detracts from the reality of instructor power in a higher education classroom. This negative perspective also places instructors and students in adversarial relationships and assumes conflicting goals and priorities.

The other way to interpret the concept of playing the game is from a positive perspective that frames playing the game as an adaptive approach for participants to 
navigate the field of higher education despite instructor power. Playing the game is a performative role participants have assumed in which they sought to preserve their sense of self while trying to maximize the possibility of positive outcomes in the relationship. This happened regardless of whether the participants viewed the nature of the instructorstudent relationship as being positive or negative because the structures that reinforced instructors' authority always remained (Romer \& Whipple, 1991).

\section{Response to Subsidiary Question 3: What do students perceive as the consequences} of the power of their instructors?

Participants in this study identified both negative and positive consequences of the power of their instructors. As Gina clearly stated in reference to power, "It's one of those things that's a double-edged sword. It can be something that's wonderful when used the right way; but when you don't use it the right way, it can have terrible consequences" (36:21).

The negative consequences were those perceived by participants to work against their best interests. Participants considered anything that was not in their best interests as a hindrance to them completing their educational goal. Although the negative consequences perceived by participants varied, the most frequently discussed consequence was receiving negative grades as a result of perceived unfair grading practices (Isserles \& Dalmage, 2000). Participants viewed the power of grading as power instructors had the most control over (Cranton, 2006). Some of the examples provided by participants of discretionary grading options that may lead to unfair grading include the element of subjectivity in grading, the use of participation points as part of a final grade, and providing opportunities for extra credit assignments. Although there is no doubt that 
students must earn their grades, what is questioned is the extent to which instructors' decision-making is influenced by subjectivity when evaluating student performance (Isserles \& Dalmage, 2000). This instructor power is discretionary and can be used to either support or hinder students in successfully completing a course or earning good grades.

Another negative consequence participants perceived was the ability for instructors to adversely influence participants' experiences in courses with other instructors. Participants discussed that they felt instructors spoke to each other and shared information about their students. There was a general concern participants expressed about gaining a bad reputation among instructors and that the reputation would precede them in any learning situation. For example, Sasuke shared, "I didn't want them to spread bad things about me to others or I didn't want to be misperceived as a bad student and make it hard on me because another professor already knows about me" (45:6). The fear was that a bad reputation would bias future instructors and make it increasingly difficult for participants to successfully work toward their educational goals. One of the participants pointed out that a possible negative consequence as a result of being disliked or labeled as a problem student by an instructor is the likelihood there will be difficulty in securing a recommendation letter. At times, a student may need a recommendation or reference letter from an instructor for "work and maybe to get into a $\mathrm{PhD}$ program, get into another university, [or] get a job" (Robert 44:26). The fear of being labeled as a problem student was a factor taken into account when participants considered whether or not to confront or challenge their instructors in the classroom. 
The positive consequences were those perceived by participants to work in their best interests. Participants considered anything that supported or motivated them toward their educational goal as a positive consequence of power. Some of the examples provided by participants included instructors being flexible to students' life demands outside of the classroom, access to resources and opportunities, exposure to new ideas, professional development, and a mentoring relationship that extended the instructorstudent relationship beyond the confines of the classroom. Individualized approaches that centered on participants' particular learning needs motivated and empowered them (Mandell \& Herman, 2009).

\section{Response to the Primary Research Question: What are students' understandings of their experiences with the power of their instructors in a higher education} classroom?

The findings of this study revealed that students understood their particular experiences with the power of their instructors in two basic ways. The first is from a systems perspective that recognizes the instructor as an agent of the higher education system (Brookfield \& Preskill, 2005; Merriam, Caffarella, \& Baumgartner, 2007; Wilson \& Cervero, 2001). The second is from an individual perspective where the instructor is seen as an individual and half of the dyadic instructor-student relationship (Aguinis, Nesler, Quigley, Lee Suk, \& Tedeschi, 1996). The findings from this study place more emphasis on the individual perspective even though both perspectives intersect in a higher education classroom.

The systems perspective of instructor power is primarily related to the role of the instructor (Cranton, 2006; Tisdell et al., 2000). In fulfilling the role of instructor, the 
higher education system grants a certain authority to instructors. From a systems perspective, the power perceived by participants relates to the power connected to the authority inherent in the instructor role. Power associated with the instructor's formal position includes control over rewards and punishments, choosing assignments, evaluations in the form of grades, providing recommendation or reference letters for students, deciding what information is included or excluded, and managing classroom dynamics (Cranton, 2006).

Participants in this study largely attributed the power of their instructors to their instructors' individual traits. Although instructors are bound by rules, institutional and public policy, institutional and professional expectations, and other forms of oversight, participants viewed instructors as having a lot of freedom over their work. Participants were inclined to perceive the variability that existed in the way instructors conducted their work as a reflection of each particular instructor's values and the pedagogical decisions they made within the scope of their work (Kelsey, Kearney, Plax, Allen, \& Ritter, 2004; McPherson \& Young, 2004). This tendency to emphasize the degree to which instructors' behaviors are determined by an internal personality trait is consistent with the fundamental attribution error and research involving aggressive instructor behavior in the classroom (Kelsey et al., 2004).

Flexibility exists within the realm of authority that is afforded to professors. Instructors can choose to be approachable and accessible or closed-off to students. They can choose to be flexible and understanding when particular life circumstances require scheduling accommodations for students or they can choose to remain rigid with the established deadlines they indicated on their syllabi. Instructors can choose to allow 
students to write a paper, which is graded and returned, or instructors can choose to require students to engage in peer review and then to revise and resubmit papers so that they learn how to improve their writing skills.

When it comes to exercises of power, participants perceived the exercises of power had a lot to do with their instructors and not them as students (Kelsey et al., 2004). Students perceived their instructors to be displacing issues relating to low self-esteem, personal problems, or identity issues in their own personal life or their role as an instructor (McPherson \& Young, 2004). Aggressive or competitive behaviors are expected when people are of relatively the same rank. This is done to illuminate the differences between individuals who are on the surface otherwise equals. Therefore, competitive behaviors are to be expected between instructors on a professional level. However, instructors and students are not equals in the higher education social hierarchy. When instructors engaged in aggressive or competitive behaviors against their students when they were clearly in a position of power, participants perceived there was something inherently wrong with those instructors. Participants attributed aggressive behavior to their instructors' life circumstances and personality issues (McPherson \& Young, 2004).

Students have few choices. They can either stay or get out. If they are going to stay, then they need to do what the professor says and learn how to navigate the system (Inglis, 1997). However, instructors have a lot of latitude within the domain of the classroom to shape the classroom experiences for their students (Cranton, 2006). For example, instructors have the ability to choose course materials, establish deadlines, or provide flexibility for students in the way assignments are completed. For participants in 
this study, the institutional or systemic bases of power were largely eclipsed by the individual bases of instructor power (Kelsey et al., 2004). Participants recognized the large range of decisions instructors are able to make and, therefore, placed an emphasis on this aspect of instructor power, particularly because they perceived themselves to benefit most from these kinds of decisions.

Participants also believed that as students they had the ability to mitigate the influence or impact of instructor power. How participants felt or viewed themselves could either magnify or lessen the impact of instructor power. The more participants perceived themselves to be confident, self-aware, and self-assured, the more likely they were to not internalize the negative expressions of instructor power (Aronson, Cohen, \& Nail, 1999). This finding is supported by Steward, Gennain, and Jackson (1992) who discussed that student alienation may have more to do with internalized processes rather than interactional factors. This finding may also be explained by the self-affirmation theory which posits that individuals are motivated to maintain integrity and a valued sense of self (Steele, 1988). In this study, participants who allowed their experiences involving negative expressions of instructor power to be internalized were more likely to have sought ways to escape the relationship by dropping the course or changing their major. Participants who discussed the importance of having a higher level of selfconfidence had an easier time brushing off the instances of instructor power and then just "play the game." According to the self-affirmation theory, as long as individuals are able to sustain their self-integrity and value of the self, they are better able to tolerate the threats to the self without having to resolve them (Aronson, Cohen, \& Nail, 1999). Participants found the more they progressed through higher education - from 
undergraduate to graduate studies - the better equipped they were to play the game. "I think the difference is that you are more mature, you are more focused, [and] you have more direction" (Camilo 33:12).

\section{Implications for Students and Instructors in Higher Education}

The findings from this study have implications for students in higher education and their ongoing efforts to secure positive outcomes in their relationships with their instructors. Because those involved in this study primarily viewed their relationships with their instructors on an interpersonal basis, other students can use these findings to focus on ways to promote the development of positive relationships with their own instructor in a classroom. For example, one way for students to exert their own social power in the instructor-student relationship is to use prosocial behavioral alteration techniques to gain compliance from instructors (Golish, 1990; Golish \& Olson, 2000). Examples of prosocial behavioral alteration techniques include: honesty-sincerity ("I was sick all week and just couldn't finish it."); flattery (“I got a lot out of this project, but I also thought we could change it up a bit."); group persuasion ("We were just talking before class and most of us don't feel like we are ready."); performance ("I have had consistently good grades all semester."); evidence of preparation/logic ("I followed the rubric you gave us to complete this project and covered each point thoroughly"), and utilitarian justice ("If you gave us another week we can improve our papers and you can grade our work next weekend"; Golish \& Olson, 2000). As students progress through higher education, they should learn to be more active about managing and shaping their interpersonal relationships with instructors so that they are more likely to obtain the outcomes they seek. 
Another way students can produce positive relationships with instructors is to collaborate with their instructors beyond the classroom. For example, graduate students can pursue opportunities to conduct research or engage in scholarly writing with their instructors. Students can also actively seek out opportunities for mentoring relationships that will extend beyond the term of the course to the entirety of their degree programs or even into their careers. A mentoring relationship can be a source of psychosocial, instrumental, and networking support for students (Tenenbaum, Crosby, \& Gliner, 2001). When students perceive their instructors beyond solely as gatekeepers to grades, students increase their chances of gaining additional capital such as letters of reference, connections to employment, or personal support.

Graduate students may use the findings of this study to engage other students in empowering and potentially transformative discussions of power from a systems perspective. These discussions, which can take place in or outside of the classroom, should center on the power dynamics in their learning experiences and how they serve to reproduce the dominant structures of power in society, resulting in alienation from their own learning experiences (Brookfield, 2005). As part of learning how to navigate the field of higher education, students should understand their particular institutional policies and procedures as it pertains to student rights and responsibilities. Students should also understand the resources available to them if they encounter conflict or have specific grievances with instructors. Ideally, students should not be afraid about being open or criticizing instructors about their behaviors, especially when instructors' behaviors are clearly discriminatory or unethical. Nevertheless, students should carefully consider the 
limits of their power and gauge the possible consequences of their discussions and decisions.

The findings from this study also have implications for instructors teaching in higher education. This study used a critical approach to understand and illuminate student experiences involving instructor power in a higher education classroom (Brookfield, 2000). This approach involved uncovering and discussing how participants perceived and responded to their instructors' power because the power instructors wield exists mostly unquestioned (Brookfield, 2000; Johnson-Bailey \& Cervero, 1996; Tisdell, 1993).

In this study, the process by which participants evaluated their experiences involving instructor power was an ongoing process. Participants turned to other classmates or the internet (by visiting social networking websites such as RateMyProfessors.com) to gather information about their instructors in order to best strategize how to understand and successfully work through the relationship with their instructors to meet their goals. They sought out information sources that would help them best navigate the field of higher education. This means that participants are not acquiring the information from their own instructors that will equip them to understand and succeed in the system in which they are expected to perform. This is the very same system in which instructors have succeeded and now have assumed a role in sustaining (Isserles \& Dalmage, 2000).

But how often are instructors assessing what students are experiencing and learning in their courses beyond course content? If instructors see no problem between the power differential existing between them and their students or if instructors have no 
personal stake in their students' success, then they may perceive that no action is needed and that it is up to students to figure out how to navigate the system on their own. But if instructors' espoused theories (Argyris \& Schön, 1974) place value on students on any level, then due diligence is required when putting those theories into use by seeking continuous feedback concerning their teaching from students throughout a course. Instructors should be cognizant of the difference in power between themselves and students, consider how their teaching practices may influence the difference in power, and work toward creating a democratic classroom (Tisdell, 2001). To foster growth and awareness, instructors should engage in critically reflective teaching about their profession and how they approach instructor-student relationships in the classroom. Being critically reflective involves focusing on the ways power influences educational transactions and how one's assumptions may impact the interest of both students and instructors (Brookfield, 1995). Regardless of instructors' views of power in the classroom, the participants in this study were all aware of their instructors' power regardless of whether they described their relationship with the instructors as positive or negative. As an example, one way for instructors to continuously ascertain the effects of their actions on students and learn about their emotional responses to learning in a higher education classroom is by using tools such as the critical-incident questionnaire (CIQ) on a regular basis (Brookfield, 1995). Tools such as the CIQ allow instructors to learn whether the effects of their actions on students is what they intended while progressing through the course. Alternatively, instructors can be explicit by acknowledging their position of power and involve students in deconstructing that power as a way to model a critical analysis of power (Brookfield, 2001). 
The findings from this study have implications for instructors interested in the practice of social justice education or instructors interested in promoting the central tenets of social justice education. Social justice education concerns the "full and equal participation of all groups in a society that is mutually shaped to meet their needs" (Bell, 1997, p. 3). Social justice education focuses on empowerment of individuals as valuable members of the community, particularly those individuals whose power and resources are shortchanged by existing social, political, and economic structures (Griffiths, 1998). Given their concern for individual empowerment and full participation in society, social justice educators share common principles in their teaching practice. These principles include the use of student-centered learning, attention to social relations in the classroom, and the value of personal growth, awareness, and change (Adams, 1997). These are all characteristics identified by participants in this study that were perceived as positive examples of instructor power in a higher education classroom regardless of demographic or socioeconomic background.

If participants describe their experiences involving instructor power in a higher education classroom as playing the game, how students learn to play the game should be an important consideration for instructors in higher education. The participants in this study discussed key experiences during their formative educational years that helped shape their perspectives regarding the nature and structure of instructor-student relationships. All of the experiences involved power. Their experiences in K-12 became the cognitive and emotional frameworks by which they approached and understood their experiences in higher education. Therefore, teaching and learning in higher education 
should not be viewed as a separate phenomenon from the educational experiences that precede it; rather, it should be seen as a continuation of earlier learning experiences.

To move students toward a critical awareness of the issues of power involved in a higher education classroom, students need to move beyond learning how to play the game to learning why the game is played. This is what Freire (2000) referred to as conscientization, which is the process by which students gain a critical consciousness of the social and political sources of oppression. This requires that instructors not only help students understand the sources of power and oppression, but also help students discover ways to take actions that will empower students to overcome them. Only by learning why the game is played are students then able to bring about changes in how they play the game.

This study provides a different perspective that captured and explored student experiences involving instructor power from the student perspective. Knowledge production in the form of research is primarily a scholarly practice performed by instructors in the academy. When academics conduct research on power in higher education, they typically approach the research from their own perspective and as agents of the social and cultural systems of power they reproduce. Therefore, the research conducted and then published through a peer-reviewed process serves the producers and gatekeepers of that knowledge production system. "Educated elites typically claim that only they are qualified to produce theory and believe that only they can interpret not only their own but everyone else's experiences. Moreover, educated elites often use this belief to uphold their own privilege" (Hill Collins, 2000, p. vii). This research contributes to understanding instructor power in a higher education classroom from a bottom-up 
perspective in the social hierarchy because the researcher and the participants are all students. This research was an exercise in identifying and engaging in the process of unmasking power (Brookfield, 2005). But if students, such as the participants in this study, are generally not able to understand and discuss power from a systems perspective, students may not be learning the tools of critical inquiry and language required to engage in research. The result is that students are not able to contribute their own perspectives to the field of legitimized knowledge in the form of scholarly research and writing. What is considered as scholarly knowledge then only serves and empowers those that create it.

But critical reflection without action prevents the development of critical thought and socially active students and citizens (Darder, 1995). What is needed is a critical pedagogy that places politics and ethics at the center of educational theory and practice by recognizing the role educational institutions play in the production of dominant societal identities and cultural practices (Giroux, 2006). When an instructor gives students the opportunity to learn within a culture of critical inquiry and engagement, the instructor, as an agent of the American higher education system, upholds "the knowledge, values, skills, and social relations required for producing individual and social agents capable of addressing the political, economic, and social injustices that diminish the reality and promise of a substantive democracy at home and abroad" (Giroux, 2006, p.2).

\section{Recommendations for Future Research}

Future research on power in the higher education classroom can build on the findings of this study or use the findings to raise related questions. Some recommendations are discussed below. 
This study raises new questions for areas of future study of higher education students. This study sought graduate students in the field of education to explore their experiences involving instructor power in a higher education classroom. The assumption was that participants, as students in the field of education, would be able to discuss their experiences more critically because the topic is within their area of study (King \& Kitchener, 2002). A concern raised in this research is the hesitancy for participants to label instructors as racist, sexist, and homophobic. Why is the emphasis on the individual and not the system, or both? In all instances, participants have shifted their language to labeling the behaviors, not the person. Are students generally not equipped with the language and the perspective to be critical even as graduate students? Or does the fact that they are still in the higher education system mean they must continue to play the game? In terms of "playing the game," future research can explore further the unspoken rules in higher education and whether they are consistent across all different types and sizes of institutions. Furthermore, how can students be empowered to break the rules of the game and question authority without sacrificing any prospects for upward social mobility, access to jobs, and other opportunities?

Future research may also explore different segments of student demographics to understand if there are any differences in the way instructor power is perceived and experienced. This may be conducted in a multitude of ways, using either qualitative or quantitative methods, by exploring possible differences in common demographic categories (e.g., age, race, gender, and ethnicity), courses of study (e.g., undergraduate, masters, and doctoral), or programs of study (e.g., liberal arts, engineering, and business). For example, student attributions about teacher behaviors involving power may be 
statistically compared for differences based on academic disciplines that are considered predominantly technical (physical sciences, mathematics, engineering, computer science) versus disciplines that are considered more practical or professional (education, psychology, liberal arts). Future research may explore additional insights from international students who may provide a foreigner's perspective to the dynamics of instructor power in a higher education classroom in the United States.

The prevalence of social networking media and its use among students was discussed by many participants in this study. The use of websites such as RateMyProfessors.com, Facebook, and other social networks provide new areas for exploration of students' experiences with instructor power and how these virtual spaces may be areas for resisting and contesting negative expressions of instructor power. How do students use the information on these social networks to navigate through the terrains of higher education? What information do they perceive as most beneficial? When are students most likely to provide feedback about an instructor? Are students hesitant just as the participants in this study to label their instructors as being sexist, racist, homophobic, etc.? Further understanding is needed on how and why students use these social networking media sites.

The study on instructor power can also be a springboard for specifically studying how students are alienated in the classroom. Students experience alienation when they perceive themselves to be in a relationship involving a power differential that is characterized by powerlessness, meaninglessness, normlessness, isolation, and/or selfestrangement (Seeman, 1959). Whereas previous research explored the effects of the institution on student alienation (Cooke et al., 1995; Huffman, 2001; Loo \& Rolison, 
1986; Mohr et al., 1998; Quarterman, 2008; Schram \& Lauver, 1988; Sellers et al., 1997; Steward et al., 1992; Steward et al., 1993; Steward et al., 1990; Suen, 1983; TomlinsonClarke \& Clarke, 1996), a narrow focus in the classroom may provide more specific and detailed information about the space where the primary transactions of power take place in higher education. How are students alienated by their instructors in a higher education classroom? Why do students perceive their experiences as alienating? How do students become aware they have been alienated? What do students perceive as the effects of being alienated in a higher education classroom? Answers to these questions may further illuminate the power transactions in a higher education classroom, particularly when the questions are used to uncover how traditionally underrepresented students (i.e., African Americans, Latinos) are marginalized despite gaining access to higher education. Findings from these studies may then be reshaped into theoretical propositions or hypotheses that may be tested for generalizability to larger student populations.

Research on instructors' self-perceptions regarding their power in a higher education classroom is also warranted. Instructors' approach to teaching in a higher education classroom is guided by both personal and professional values. However, as participants reported in this study, the theories and values espoused by instructors are not always perceived by students as being compatible with those theories put into practice. Why do these discrepancies take place? What are the factors that influence instructors' decisions to behave in ways incongruent with their espoused beliefs? How do these discrepancies shape the way instructor-student relationships are developed? Future inquiry on instructor power can also focus on the professionalization of instructors. This includes not only looking at how personal values shape professional practices or how 
instructors are trained, but also how professional practices are constrained by institutional and student expectations for performance.

In this study, only one of the participants (Gina) mentioned an experience involving her instructor who was also her academic advisor. If students expressed concerns about learning how to navigate the higher education system, there was an opportunity for each one of the students to have been assisted by their academic advisor. In traditional undergraduate settings, much of the academic advisement takes place with advisors whose sole function is to advise students on their course of study. According to the National Academic Advising Association (NACADA; 2006):

Academic advising is integral to fulfilling the teaching and learning mission of higher education. Through academic advising, students learn to become members of their higher education community, to think critically about their roles and responsibilities as students, and to prepare to be educated citizens of a democratic society and a global community. Academic advising engages students beyond their own world views, while acknowledging their individual characteristics, values, and motivations as they enter, move through, and exit the institution. (Preamble section, para. 1)

However, in graduate school it is common for faculty to not only serve as instructors in the classroom, but also as academic advisors to students. When participants in this study struggled with navigating the field of higher education, they mostly relied on their peers or past educational experiences to understand and succeed in higher education. The role of the instructor as an academic advisor was missing in this study. Additional research is merited in this area. How do instructors understand their roles as academic advisors? How do instructors perceive academic advising in relation to their roles in the classroom? Is there a place for academic advisement in the higher education classroom? And what 
do instructors perceive to be the impact of academic advisement on the success of their students?

Additional research on power in higher education classrooms is needed to increase understanding of students' collegiate experiences. However, research "should be transformative; that is, it should serve emancipatory efforts to resist oppression" by "creating possibilities from the margins of power" (Baez, 2002, p. 36). Although common topics of study such as student recruitment, admissions, retention, or institutional culture, contribute to the advancement of knowledge, policy, and practice in higher education, such research questions do not enhance the possibilities for transformation or create space for the voices of the marginalized and oppressed to emerge. Rather, research should seek to expose the oppressive underbelly of higher education that reproduces societal systems of power. Until researchers start asking the tough questions to elicit responses and critical thinking from students in higher education, greater understanding that can significantly challenge transformation and critical consciousness will not be achieved.

\section{Summary}

Chapter 5 concluded the study with responses to the research questions, implications for teaching and learning, and recommendation for future research. The purpose of this hermeneutic phenomenological study was to explore students' experiences with the power of their instructors in a higher education classroom. This study illuminated both positive and negative student perceptions of instructor power. Although participants acknowledged both system and interpersonal sources of power in the classroom, participants perceived instructor power as largely shaped by the 
personality dynamics of the instructors and the choices instructors make within the parameters of authority granted to them within a higher education classroom. Ultimately, participants described their experiences as "playing the game" which serves as a metaphor for describing the adaptive and strategizing approach required for students to successfully maneuver through their higher education experiences to meet their education, personal, and professional goals. 


\section{References}

Adams, M. (1997). Pedagogical frameworks for social justice education. In M. Adams, L. A. Bell \& P. Griffin (Eds.), Teaching for diversity and social justice (pp. 30-43). New York, NY: Routledge.

Aguinis, H., Nesler, M. S., Quigley, B. M., Lee Suk, J., \& Tedeschi, J. T. (1996). Power bases of faculty supervisors and educational outcomes for graduate students. Journal of Higher Education, 67(3), 267-297.

Ajjawi, R., \& Higgs, J. (2007). Using hermeneutic phenomenology to investigate how experienced practitioners learn to communicate clinical reasoning. The Qualitative Report, 12(4), 612-638.

American Psychological Association. (2009). APA concise dictionary of psychology.. Washington, DC: Author.

Argyris, C., \& Schön, D. A. (1974). Theory in practice: Increasing professional effectiveness. San Francisco, CA: Jossey-Bass.

Aronson, J., Cohen, G., \& Nail, P. R. (1999). Self-affirmation theory: An update and appraisal. In E. Harmon-Jones \& J. Mills (Eds.), Cognitive dissonance: Progress on a pivotal theory in social psychology (pp. 127-147). Washington, DC: American Psychological Association.

Asamen, J. K., \& Berry, G. L. (1987). Self-concept, alienation, and perceived prejudice: Implications for counseling Asian Americans. Journal of Multicultural Counseling and Development, 15, 146-160.

ATLAS.ti Scientific Software Development GmbH. (2009). ATLAS.ti (Version 6.1) [Computer software]. Berlin, Germany: ATLAS.ti Scientific Software Development GmbH.

Baez, B. (2002). Confidentiality in qualitative research: Reflections on secrets, power and agency. Qualitative Research in Psychology, 2(1), 35-58. doi: $10.1177 / 1468794102002001638$

Baptiste, I. I. E. (1998, May). Towards a pedagogy of ethical disempowerment. Paper presented at the Proceedings of the 39th Annual Adult Education Research Conference, San Antonio, TX.

Beder, H. (1989). Purposes and philosophies of adult education. In S. B. Merriam \& P. M. Cunningham (Eds.), Handbook of adult and continuing education (pp. 37-50). San Francisco, CA: Jossey-Bass. 
Bell, L. A. (1997). Theoretical foundations for social education. In M. Adams, L. A. Bell \& P. Griffin (Eds.), Teaching for diversity and social justice: A sourcebook (pp. 3-15). New York, NY: Routledge.

Bell, L. A., Washington, S., Weinstein, G., \& Love, B. (1997). Knowing ourselves as instructors. In M. Adams, L. A. Bell \& P. Griffin (Eds.), Teaching for diversity and social justice: A sourcebook (pp. 299-310). New York, NY: Routledge.

Bierema, L. L. (2010). Professional identity. In C. E. Kasworm, A. D. Rose \& J. M. Ross-Gordon (Eds.), Handbook of adult and continuing education (pp. 135-145). Washington, DC: Sage.

Blauner, B. (1964). Alienation and freedom: The factory worker and his industry. Chicago, IL: University of Chicago Press.

Boler, M. (1999). Feeling power: Emotions and education. New York, NY: Routledge.

Bounous, R. (2001). Teaching as political practice. In V. Sheared \& P. A. Sissel (Eds.), Making space: Merging theory and practice in adult education (pp. 195-207). Westport, CT: Bergin \& Garvey.

Bourdieu, P., \& Passeron, J. (1977). Reproduction in education, society and culture. London, England: Sage.

Bowen, H. R. (1999). Goals: The intended outcomes of higher education. In J. L. Bess \& D. S. Webster (Eds.), Foundations of American higher education (pp. 23-27). Boston, MA: Pearson.

Braun, V., \& Clarke, V. (2006). Using thematic analysis in psychology. Qualitative Research in Psychology, 3, 77-101. doi: 10.1191/1478088706qp063oa

Brookfield, S. (1995). Becoming a critically reflective teacher. San Francisco, CA: Jossey-Bass.

Brookfield, S. (2000). The concept of critically reflective practice. In A. L. Wilson \& E. R. Hayes (Eds.), Handbook of adult and continuing education (pp. 33-49). San Francisco, CA: Jossey-Bass.

Brookfield, S. (2001). A political analysis of discussion groups: Can the circle be unbroken? In R. M. Cervero \& A. L. Wilson (Eds.), Power in practice: Adult education and the struggle for knowledge and power in society (pp. 206-225). San Francisco, CA: Jossey-Bass.

Brookfield, S. (2002). Overcoming alienation as the practice of adult education: The contributions of Erich Fromm to a critical theory of adult learning and education. Adult Education Quarterly, 52(2), 96-111. doi: 10.1177/0741713602052002002 
Brookfield, S. (2005). The power of critical theory: Liberating adult learning and teaching. San Francisco, CA: Jossey-Bass.

Brookfield, S. (2006). Authenticity and power. New Directions for Adult and Continuing Education, 111, 5-16. doi: 10.1002/ace.223

Brookfield, S., \& Preskill, S. (2005). Discussion as a way of teaching: Tools and techniques for democratic classrooms (2nd ed.). San Francisco, CA: Jossey-Bass.

Burbach, H. J. (1972). The development of a contextual measure of alienation. The Pacific Sociological Review, 15(2), 225-234.

Buttaro, L. (2004). Second-language acquisition, culture shock, and language stress of adult female Latina students in New York. Journal of Hispanic Higher Education, $3(1), 21-49$.

Cabrera, A. F., \& Nora, A. (1994). College students' perceptions of prejudice and discrimination and their feelings of alienation: A construct validation approach. Review of Education/Pedagogy/Cultural Studies, 16(3-4), 387-409.

Caffarella, R. S. (1992). Psychosocial Development of Women: Linkages to Teaching and Leadership in Adult Education. Retrieved from http://eric.ed.gov/PDFS/ED354386.pdf

Callahan, J. L. (2004). Breaking the cult of rationality: Mindful awareness of emotion in the critical theory classroom. New Directions for Adult and Continuing Education(102), 75-83.

Case, J. (2008). Alienation and engagement: Development of an alternative theoretical framework for understanding student learning. Higher Education, 55(3), 321-332. doi: 10.1007/s10734-007-9057-5

Cervero, R. M., \& Wilson, A. L. (2001). At the heart of practice: The struggle for knowledge and power. In R. M. Cervero \& A. L. Wilson (Eds.), Power in practice: Adult education and the struggle for knowledge and power in society (pp. 1-20). San Francisco, CA: Jossey-Bass.

Clark, J. P. (1959). Measuring Alienation Within a Social System. American Sociological Review, 24(6), 849-852.

Clark, M. C., \& Dirkx, J. M. (2008). The emotional self in adult learning. New Directions for Adult and Continuing Education(120), 89-95.

Coladarci, T., \& Kornfield, I. (2007). RateMyProfessors. com versus formal in-class student evaluations of teaching. Practical Assessment, Research \& Evaluation, $12(6), 1-15$. 
Cooke, D. K., Sims, R. L., \& Peyrefite, J. (1995). The relationship between graduate student attitudes and attrition. Journal of Psychology, 129(6), 677. doi: $10.1080 / 00223980.1995 .9914938$

Cranton, P. (2006). Understanding and promoting transformative learning: A guide for educators of adults. San Francisco, CA: Jossey-Bass.

Creswell, J. W. (1998). Qualitative inquiry and research design: Choosing among five traditions. Thousand Oaks, CA: Sage.

Creswell, J. W. (2003). Research design: Qualitative, quantitative, and mixed methods approaches (2nd ed.). Thousand Oaks, CA: Sage.

Darder, A. (1995). Buscando America: The contributions of critical Latino educators to the academic development and empowerment of Latino students in the U.S. In C. E. Sleeter \& P. McLaren (Eds.), Multicultural education, critical pedagogy, and the politics of difference (pp. 319-348). Albany, NY: State University of New York Press.

Dean, D. G. (1961). Alienation: Its meaning and measurement. American Sociological Review, 26(5), 753-758.

Delphin, M. E., \& Rollock, D. (1995). University alienation and African American ethnic identity as predictors of attitudes toward, knowledge about, and likely use of psychological services. Journal of College Student Development, 36, 337-346.

Dirkx, J. M. (2001). The power of feelings: Emotion, imagination, and the construction of meaning in adult learning. New Directions for Adult and Continuing Education, 2001(89), 63-72. doi: 10.1002/ace.9

Dirkx, J. M. (2006). Engaging emotions in adult learning: A Jungian perspective on emotion and transformative learning. New Directions for Adult and Continuing Education, 2006(109), 15-26. doi: 10.1002/ace.204

Dirkx, J. M. (2008). The meaning and role of emotions in adult learning. New Directions for Adult and Continuing Education, 2008(120), 7-18. doi: 10.1002/ace.311

Flick, U. (2007a). Designing qualitative research. Los Angeles, CA: Sage.

Flick, U. (2007b). Managing quality in qualitative research. Thousand Oaks, CA: Sage.

Florida International University. (2011). About FIU. Retrieved February 20, 2012, from http://cmshared.fiu.edu/fiu-edu/_assets/files/pdf/rankings-facts/about-fiu.pdf

Foucault, M. (1980a). Prison talk (C. Gordon, Trans.). In C. Gordon (Ed.), Power/knowledge: Selected interviews and other writings, 1972-1977 (pp. 37-54). New York, NY: Pantheon Books. 
Foucault, M. (1980b). Two lectures (K. Soper, Trans.). In C. Gordon (Ed.), Power/knowledge: Selected interviews and other writings, 1972-1977 (pp. 78108). New York, NY: Pantheon Books.

Freire, P. (1998). Pedagogy of freedom: Ethics, democracy, and civic courage. Lanham, MD: Rowman \& Littlefield.

Freire, P. (2000). Pedagogy of the oppressed (30th anniversary ed.). New York, NY: Continuum.

French, J. R. P., Jr. , \& Raven, B. (1959). The bases of social power. In D. Cartwright (Ed.), Studies in social power (pp. 150-167). Ann Arbor, MI: Institute for Social Research, The University of Michigan.

Friese, S. (2011). ATLAS.ti 6 Concepts and Functions. Berlin, Germany: ATLAS.ti Scientific Software Development GmbH.

Fromm, E. (1955). The sane society. Greenwich, CT: Fawcett.

Fromm, E., \& Marx, K. (1966). Marx's concept of man. New York, NY: Frederick Ungar.

Gibbs, G. (2007). Analyzing qualitative data. Los Angeles, CA: Sage.

Giroux, H. A. (1988). Teachers as intellectuals: Toward a critical pedagogy of learning. Granby, MA: Bergin \& Garvey.

Giroux, H. A. (2006). Academic freedom under fire: The case for critical pedagogy. College Literature, 33(4), 1-42. doi: 10.1353/lit.2006.0051

Goleman, D. (2006). Emotional intelligence. New York, NY: Bantam.

Golish, T. D. (1999). Students' use of compliance gaining strategies with graduate teaching assistants: Examining the other end of the power spectrum. Communication Quarterly, 47(1), 12-32.

Golish, T. D., \& Olson, L. N. (2000). Students' use of power in the classroom: An investigation of student power, teacher power, and teacher immediacy. Communication Quarterly, 48(3), 293(218).

Goodley, D., Lawthom, R., Clough, P., \& Moore, M. (2004). Researching life stories: Method, theory, and analyses in a biographical age. New York, NY: Routledge.

Graf, W. E. (2001). Power and powerlessness: Experiencing liberatory pedagogy and liberation theology in a First World college classroom. Available from ProQuest Dissertations and Theses database. (UMI No. 3023734) 
Grenfell, M., \& James, D. (1998). Theory, practice and pedagogic research. In M. Grenfell \& D. James (Eds.), Bourdieu and education: Acts of practical theory (pp. 6-26). Bristol, PA: Falmer.

Griffiths, M. (1998). Educational research for social justice: Getting off the fence. Philadelphia, PA: Open University Press.

Guest, G., Bunce, A., \& Johnson, L. (2006). How many interviews are enough? An experiment with data saturation and variability. Field Methods, 18(1), 59-82. doi: $10.1177 / 1525822 \times 05279903$

Hackman, H. W. (2000). Power consciousness: Understanding and transforming educator classroom power. Available from ProQuest Dissertations and Theses database. (UMI No. 9988794)

Harmon-Jones, E., \& Mills, J. (1999). An introduction to cognitive dissonance theory and an overview of current perspectives on the theory. In E. Harmon-Jones \& J. Mills (Eds.), Cognitive dissonance: Progress on a pivotal theory in social psychology (pp. 3-21). Washington, DC: American Psychological Association.

Heinrich, K. T. (1991). Loving partnerships: Dealing with sexual attraction and power in doctoral advisement relationships. The Journal of Higher Education, 62(5), 514538 .

Hill Collins, P. (2000). Black feminist thought: Knowledge, consciousness, and the politics of empowerment (2nd ed.). New York: Routledge.

Huffman, T. (2001). Resistance theory and the transcultural hypothesis as explanations of college attrition and persistence among culturally traditional American Indian students. Journal of American Indian Education, 40(3), 1-23.

Inglis, T. (1997). Empowerment and emancipation. Adult Education Quarterly, 48(1), 317. doi: $10.1177 / 074171369704800102$

Isserles, R., \& Dalmage, H. (2000). Cultural capital as rules and resistance: Bringing it home in the introductory classroom. Teaching Sociology, 28(2), 160-165.

James, R. (1998). The perceived effects of social alienation on Black college students enrolled at a Caucasian southern university. College Student Journal, 32(2), 228.

Jamieson, D. W., \& Thomas, K. W. (1974). Power and Conflict in the Student-Teacher Relationship. The Journal of Applied Behavioral Science, 10(3), 321-336. doi: $10.1177 / 002188637401000304$ 
Johnson-Bailey, J. (2001). The power of race and gender: Black women's struggle and survival in higher education. In R. M. Cervero \& A. L. Wilson (Eds.), Power in practice: Adult education and the struggle for knowledge and power in society (pp. 126-144). San Francisco, CA: Jossey-Bass.

Johnson-Bailey, J., \& Cervero, R. M. (1996). An analysis of the educational narratives of reentry Black women. Adult Education Quarterly, 46(3), 142-157. doi: $10.1177 / 074171369604600302$

Johnson-Bailey, J., \& Cervero, R. M. (1998). Power dynamics in teaching and learning practices: An examination of two adult education classrooms. International Journal of Lifelong Education, 17(6), 389-399.

Kasworm, C. E. (2008). Emotional challenges of adult learners in higher education. New Directions for Adult and Continuing Education, 2008(120), 27-34. doi: $10.1002 /$ ace. 313

Kelsey, D. M., Kearney, P., Plax, T. G., Allen, T. H., \& Ritter, K. J. (2004). College students' attributions of teacher misbehaviors. Communication Education, 53(1), 40-55. doi: 10.10/0363452032000135760

King, P. M., \& Kitchener, K. S. (2002). The reflective judgment model: Twenty years of research on epistemic cognition. In B. K. Hofer \& P. R. Pintrich (Eds.), Personal epistemology: The psychology of beliefs about knowledge and knowing (pp. 3761). Hillsadale, NJ: Erlbaum.

Klomegah, R. Y. (2006). Social factors relating to alienation experienced by international students in the United States. College Student Journal, 40(2), 303-315.

Lane, E. J., \& Daugherty, T. K. (1999). Correlates of social alienation among college students. College Student Journal, 33(1), 7.

Laverty, S. M. (2003). Hermeneutic phenomenology and phenomenology: A comparison of historical and methodological considerations. International Journal of Qualitative Methods, 2(3), 21-35.

Loo, C. M., \& Rolison, G. (1986). Alienation of ethnic minority students at a predominantly White university. The Journal of Higher Education, 57, 58-77. doi: $10.2307 / 1981466$

Lukes, S. (2004). Power: A radical view (2nd ed.). New York, NY: Palgrave Macmillan.

Macedo, D. P. (1994). Literacies of power: What Americans are not allowed to know. Boulder, CO: Westview Press.

Macedo, D. P. (2006). Literacies of power: What Americans are not allowed to know. Boulder, CO: Westview Press. 
Mandell, A., \& Herman, L. (2009). Mentoring: When learners make the learning. In J. Mezirow, E. W. Taylor \& Associates (Eds.), Transformative learning in practice: Insights from community, workplace, and higher education (pp. 78-88). San Francisco, CA: Jossey-Bass.

Mann, S. J. (2001). Alternative perspectives on the student experience: Alienation and engagement. Studies in Higher Education, 26(1), 7-19. doi: 10.1080/03075070020030689

Marx, K. (1964). Economic and philosophic manuscripts of 1844. New York, NY: International Publishers.

Maxham-Kastrinos, A. (1998). Adult learners empowered in the writing classroom: Moving from alienation to activism. Available from ProQuest Dissertations and Theses database. (UMI No. 9914965)

McPherson, M. B., \& Young, S. L. (2004). What students think when teachers get upset: Fundamental attribution error and student-generated reasons for teacher anger. Communication Quarterly, 52(4), 357-369. doi: 10.1080/01463370409370206

Merriam, S. B. (2002). Assessing and evaluating qualitative research. In S. B. Merriam (Ed.), Qualitative research in practice: Examples for discussion and analysis (pp. 18-33). New York, NY: John Wiley \& Sons.

Merriam, S. B., Caffarella, R. S., \& Baumgartner, L. (2007). Learning in adulthood: A comprehensive guide (3rd ed.). San Francisco, CA: Jossey-Bass.

Mezirow, J. (2009). Transformative learning theory. In J. Mezirow, E. W. Taylor \& Associates (Eds.), Transformative learning in practice: Insights from community, workplace, and higher education (pp. 18-31). San Francisco, CA: Jossey-Bass.

Miller, D. C., \& Salkind, N. J. (2002). Handook of research design and social measurement (6th ed.). Thousand Oaks, CA: Sage.

Mohr, J. J., Eiche, K. D., \& Sedlacek, W. E. (1998). So close, yet so far: Predictors of attrition in college seniors. Journal of College Student Development, 39(4), 343354.

Mortimer, J. T., \& Simmons, R. G. (1978). Adult Socialization. Annual Review of Sociology, 4, 421-454.

Moustakas, C. E. (1994). Phenomenological research methods. Thousand Oaks, CA: Sage. 
National Academic Advising Association. (2006). NACADA concept of academic advising. Retrieved from

http://www.nacada.ksu.edu/Clearinghouse/AdvisingIssues/

Concept-Advising.htm

Nilson, L. B. (2010). Teaching at its best: A research-based resource for college instructors. San Francisco, CA: Jossey-Bass.

Nottingham, C. R., Rosen David, H., \& Parks, C. (1992). Psychological well-being among African American university students. Journal of College Student Development, 33, 356-362.

Olssen, M. (1999). Michel Foucault: Materialism and education. Westport, CT: Bergin \& Garvey.

Patton, M. Q. (2002). Qualitative research and evaluation methods (3rd ed.). Thousand Oaks, CA: Sage.

Peters, M. A., \& Burbules, N. C. (2004). Poststructuralism and educational research. Lanham, MD: Rowman \& Littlefield.

Popkewitz, T. S. (1999). Critical traditions, modernisms, and the "posts". In T. S. Popkewitz \& L. Fendler (Eds.), Changing terrains of knowledge and politics (pp. 1-16). New York, NY: Routledge.

Quarterman, J. (2008). An assessment of barriers and strategies for recruitment and retention of a diverse graduate student population. College Student Journal, 42(4), 947-967.

Reinharz, S. (1994). Toward an ethnography of "voice" and "silence". In E. J. Trickett, R. J. Watts \& D. Birman (Eds.), Human diversity: Perspectives on people in context (pp. 178-200). San Francisco, CA: Jossey-Bass.

Richards, L., \& Morse, J. M. (2007). Readme first for a user's guide to qualitative methods (2nd ed.). Thousand Oaks, CA: Sage.

Rocco, T. S., \& West, G. W. (1998). Deconstructing privilege: An examination of privilege in adult education. Adult Education Quarterly, 48(3), 171-184. doi: $10.1177 / 074171369804800304$

Romer, K. T., \& Whipple, W. R. (1991). Collaboration across the power line. College Teaching, 39(2), 66-70.

Rouse, L. P. (1983). Social power in the college classroom: The impact of instructor resource manipulation and student dependence on graduate students' mood and morale. American Educational Research Journal, 20(3), 375-383. doi: $10.3102 / 00028312020003375$ 
Rubenson, K. (1989). The sociology of adult education. In S. B. Merriam \& P. M. Cunningham (Eds.), Handbook of adult and continuing education (pp. 51-69). San Francisco, CA: Jossey-Bass.

Rubin, H. J., \& Rubin, I. S. (2005). Qualitative interviewing: The art of hearing data (2nd ed.). Thousand Oaks, CA: Sage.

Russell, B. (1986). The forms of power. In S. Lukes (Ed.), Power (pp. 19-27). New York, NY: New York University Press.

Sauvé, V. L. (2001). A personal journey into participatory education. In P. Campbell \& B. Burnaby (Eds.), Participatory practices in adult education (pp. 15-30). Mahwah, NJ: Lawrence Erlbaum.

Schram, J. L., \& Lauver, P. J. (1988). Alienation in international students. Journal of College Student Development, 29, 146-150.

Seeman, M. (1959). On the meaning of alienation. American Sociological Review, 24(6), 783-791. doi: $10.2307 / 2088565$

Seeman, M. (1983). Alienation motifs in contemporary theorizing: The hidden continuity of the classic themes. Social Psychology Quarterly, 46(3), 171-184. doi: $10.2307 / 3033789$

Sellers, R. M., Kuperminc, G. P., \& Damas, A., Jr. (1997). The college life experiences of African American women athletes. American Journal of Community Psychology, 25, 699-721.

Sheared, V. (1999). Giving voice: Inclusion of African American students' polyrhythmic realities in adult basic education. New Directions for Adult and Continuing Education, 82, 33-48. doi: 10.1002/ace.8203

Sheared, V., \& Sissel, P. A. (2001). Making space: Merging theory and practice in adult education. Westport, CT: Bergin \& Garvey.

Shor, I. (1992). Empowering education: Critical teaching for social change. Chicago, IL: University of Chicago Press.

Smith, M. J. (2000). Caring, community, and transcendance-developing spirit to improve learning. Community College Review, 28(3), 57-74. doi: $10.1177 / 009155210002800304$

Spelman, D. (2010). Recognizing the centrality of emotion in diversity courses: Commentary on "Gender in the Management Education Classroom". Journal of Management Education, 34(6), 882-890. 
Steele, C. M. (1988). The psychology of self-affirmation: Sustaining the integrity of the self. Advances in Experimental Social Psychology, 21, 261-302.

Steward, R. J., Germain, S., \& Jackson, J. D. (1992). Alienation and interactional style: A study of successful Anglo, Asian, and Hispanic university students. Journal of College Student Development, 33, 149-156.

Steward, R. J., Jackson, J. D., \& Bartell, P. A. (1993). Black students' alienation: A study of world view. Journal of College Student Development, 34, 228-229.

Steward, R. J., Jackson, M. R., Sr., \& Jackson, J. D. (1990). Alienation and interactional styles in a predominantly white environment: A study of successful Black students. Journal of College Student Development, 31, 509-515.

Suarez, S. A., Fowers, B. J., Garwood, C. S., \& Szapocznik, J. (1997). Biculturalism, differentness, loneliness, and alienation in Hispanic college students. Hispanic Journal of Behavioral Sciences, 19, 489-496.

Suen, H. K. (1983). Alienation and attrition of Black college students on a predominantly White campus. Journal of College Student Personnel, 24, 117-121.

Swartz, D. (1997). Culture and power: The sociology of Pierre Bourdieu. Chicago, IL: University of Chicago Press.

Tai, B. (1999). The power to change minds: Toward an understanding of the nature of power in the teacher-student relationship. Available from ProQuest Dissertations and Theses database. (UMI No. 9933156)

Tenenbaum, H. R., Crosby, F. J., \& Gliner, N. D. (2001). Mentoring relationships in graduate school. Journal of Vocational Behavior, 59(3), 326-341. doi: 10.1006/jvbe.2001.1804

Tauber, R. T. (1985). French \& Raven's power bases: An appropriate focus for educational researchers and practitioners. British Education Research Association. University of Stirling. Stirling, Scotland. Retrieved from http://www.eric.ed.gov/ERICWebPortal/detail?accno=ED258962

Teddlie, C., \& Tashakkori, A. (2009). Foundations of mixed methods research: Integrating quantitative and qualitative approaches in the social and behavioral sciences. Los Angeles, CA: Sage.

Tinto, V. (1997). Classrooms as communities: Exploring the educational character of student persistence. The Journal of Higher Education, 68, 599-623. doi: $10.2307 / 2959965$ 
Tisdell, E. J. (1992). Power relations in higher education classes of nontraditional-age adults: A comparative case study. Available from ProQuest Dissertations and Theses database. (UMI No. 9235493)

Tisdell, E. J. (1993). Interlocking systems of power, privilege, and oppression in adult higher education classes. Adult Education Quarterly, 43(4), 203-226. doi: 10.1177/0741713693043004001

Tisdell, E. J. (2001). The politics of positionality: Teaching for social change in higher education. In R. M. Cervero \& A. L. Wilson (Eds.), Power in practice: Adult education and the struggle for knowledge and power in society (pp. 145-163). San Francisco: Jossey-Bass.

Tisdell, E. J., Hanley, M. S., \& Taylor, E. W. (2000). Different perspectives on teaching for critical consciousness. In A. L. Wilson \& E. R. Hayes (Eds.), Handbook of adult and continuing education (pp. 132-146). San Francisco, CA: Jossey-Bass.

Tobacyk, J. J. (1985). Paranormal beliefs, alienation and anomie in college students. Psychological Reports, 57, 844-846.

Tomlinson-Clarke, S., \& Clarke, D. (1996). Institutional effects on alienation and student effort at three campus environments. Journal of College Student Development, 37, 60-67.

Toth, L. (1996). An examination of student achievement and select psychosocial factors in relation to the cluster course teaching method. Journal of Instructional Psychology, 23, 81-84.

van Manen, M. (1990). Researching lived experience: Human science for an action sensitive pedagogy. Albany, NY: State University of New York Press.

Warren, C. A. B. (2002). Qualitative interviewing. In J. F. Gubrium \& J. A. Holstein (Eds.), Handbook of interview research: Context \& method (pp. 83-102). Thousand Oaks, CA: Sage.

Weidman, J. (1989). Undergraduate socialization: A conceptual approach. Higher education: Handbook of theory and research, 5, 289-322.

Wells, J. W., \& Daly, A. (1992). University students' felt alienation and their attitudes toward African-Americans, women and homosexuals. Psychological Reports, 70, 623-626. doi: 10.2466/PR0.70.2.623-626

Wendling, A. E. (2009). Karl Marx on technology and alienation. New York, NY: Palgrave Macmillan.

Wilson, A. L., \& Cervero, R. M. (2001). Power in practice: Adult education and the struggle for knowledge and power in society. San Francisco, CA: Jossey-Bass. 
Wolfe, P. (2006). The role of meaning and emotion in learning. New Directions for Adult and Continuing Education, 110, 35-41.

Zalaquett, C. P. (2006). Study of successful Latina/o students. Journal of Hispanic Higher Education, 5(1), 35-47. 


\section{APPENDIX A}

Email Inviting Students to Participate in the Study

Dear College of Education Graduate Student,

I am a fellow student at Florida International University College of Education. I am conducting a study for my dissertation focusing on students' experiences with the power of an instructor in a higher education classroom. I am using a phenomenological method to explore and understand these experiences from the student point of view. My interest in this topic stems from my own experiences in higher education. I expect my research to provide a foundation for future empirical research on the dynamics of power in a higher education classroom.

I am seeking graduate students who are willing to speak with me about their particular experiences involving the power of an instructor in a higher education classroom. The experience may have taken place here at Florida International University or at another institution of higher education. Participation in this study will require about an hour of your time for an interview. Additionally, you will be asked to review and provide feedback on my initial research findings to confirm they resonate with the perceptions of your experience.

Please be assured that all information shared with me will be confidential. If you have an experience to share with me, please email me so that we may arrange a mutually convenient meeting.

Thank you for your time and consideration,

Tony Delgado

Doctoral Candidate, Adult Education \& Human Resource Development 


\section{APPENDIX B}

Interview Protocol

\section{Background Information}

- Tell me a little bit about yourself.

○ Where are you from?

○ How would you describe yourself as a person?

- Age

- Sociocultural background

- Tell me about your work experience.

- Tell me about your school experiences growing up.

○ Do any particular experiences, good or bad, stand out for you? What are they?

- Tell me about the teachers you liked.

- Tell me about the teachers you did not like.

- Tell me about your undergraduate experience.

Why did you decide to go to college for an undergraduate degree?

- Tell me about the instructors you liked.

- Tell me about the instructors you did not like.

\section{Higher Education Classroom Experiences}

- Tell me about a positive/negative experience involving an instructor in a higher education classroom.

○ How did the instructor behave towards you?

○ Why do you think the instructor behaved that way towards you?

o How did it feel at that moment in the classroom?

o What were your thoughts/reactions at the time?

- What did you do after?

- What were your discussions with your instructor?

- What were your discussions with other students?

- What were your discussions with people other than your instructor or fellow students?

- How would you describe the instructor?

○ What were you perceptions of the instructor before the experience? After the experience?

- What did you perceive to be the values of the instructor before the experience? After the experience?

- How did you come to your perceptions regarding your instructor's values?

○ How did the instructor's actions in the classroom correspond to your perceptions about the instructor's values?

\section{Power in the Classroom}

- What does power mean to you?

○ How would you define power?

- Tell me what power you think may exist in a higher education classroom. 
- Tell me about what power, if any, the instructor had in the experience you described. o How do you think your instructor used his/her power?

- Tell me how you think you were affected by the power of the instructor in the classroom.

○ How do you think this situation impacted your learning in that class?

o How do you think this situation has impacted other classes you may have had since then?

○ How do you think this experience has impacted your professional experiences?

o How do you think this experience has impacted you personally?

○ Would you handle the situation differently now looking back at the situation? If so, how?

- What powers do you have as a student in a higher education setting?

- How would you describe the role of power in your learning?

- Are there any additional experiences you would like to tell me about?

\section{Concluding Questions}

- Is there anything you would like to add about your experiences?

- Is there any question you think I should have asked, but did not? 


\section{APPENDIX C}

Consent to Participate in a Research Study

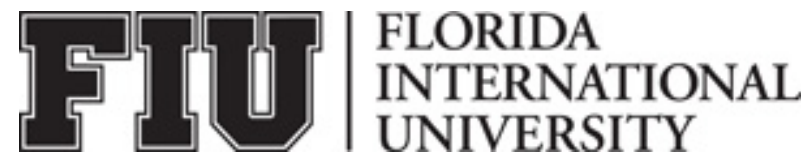

\section{ADULT CONSENT TO PARTICIPATE IN A RESEARCH STUDY A Hermeneutic Phenomenology of Students' Perceptions of Instructor Power in a Higher Education Classroom}

\section{PURPOSE OF THE STUDY}

You are being asked to be in a research study. The purpose of this study is to explore students' experiences with the power of their instructor in a higher education classroom. The objective of this research interview is gain a better understanding of how students perceive power in a higher education classroom, the ways in which this power manifests itself, and consequently how students perceive the consequences of the power of their instructors.

\section{NUMBER OF STUDY PARTICIPANTS}

If you decide to be in this study, you will be one of approximately 15 people in this research study.

\section{DURATION OF THE STUDY}

Your total participation in this study will require approximately $1-2$ hours of your time.

\section{PROCEDURES}

If you agree to be in the study, we will ask you to do the following things:

1. You will be asked to participate in an interview that will be audio recorded. A list of questions will be used as a guide for the interview. The interview will require approximately 1 hour of your time.

2. You will be emailed the preliminary findings of the study after all participants have been interviewed and all data have been analyzed. You will be asked to verify that the analysis reasonably describes or explains your experiences. Any feedback you provide will be used as additional data in the study. Review of the preliminary research findings and providing feedback will require no more than 1 hour of your time.

\section{RISKS AND/OR DISCOMFORTS}

There are no known risks associated with your participation in this study.

\section{BENEFITS}

There are no direct benefits associated with your participation in this study. 


\section{ALTERNATIVES}

There are no known alternatives available to you other than not taking part in this study. However, any significant new findings developed during the course of the research which may relate to your willingness to continue participation will be provided to you.

\section{CONFIDENTIALITY}

The records of this study will be kept private and will be protected to the fullest extent provided by law. In any sort of report we might publish, we will not include any information that will make it possible to identify a subject. Your responses will be identified by a pseudonym and not your name. Research records will be stored securely and only the researcher team will have access to the records.

\section{COMPENSATION \& COSTS}

There is no cost or payment to you for participation in this study.

\section{RIGHT TO DECLINE OR WITHDRAW}

Your participation in this study is voluntary. You are free to participate in the study or withdraw your consent at any time during the study. Your withdrawal or lack of participation will not affect any benefits to which you are otherwise entitled. The investigator reserves the right to remove you without your consent at such time that they feel it is in the best interest.

\section{RESEARCHER CONTACT INFORMATION}

If you have any questions about the purpose, procedures, or any other issues relating to this research study you may contact Antonio Delgado.

\section{IRB CONTACT INFORMATION}

If you would like to talk with someone about your rights of being a subject in this research study or about ethical issues with this research study you may contact Dr. Patricia Price, the Chairperson of the FIU Institutional Review Board (IRB) at 305-3482618 or 305-348-2494.

\section{PARTICIPANT AGREEMENT}

I have read the information in this consent form and agree to participate in this study. I have had a chance to ask any questions I have about this study, and they have been answered for me. I understand that I am entitled to a copy of this form after it has been read and signed.

Signature of Participant

$$
\text { Date }
$$

Printed Name of Participant

Signature of Person Obtaining Consent

Date 


\section{APPENDIX D}

\section{Sample Email for Member Checking}

\section{Dear Participant,}

Thank you for taking the time to meet with me several months ago for my dissertation study. Since we met, I have had the opportunity to meet and interview a total of 15 students, including you, who offered me many different perspectives regarding their experiences involving instructor power in a higher education classroom.

As I mentioned during our meeting, a second part of my study involves sending each participant a preliminary list of findings after I analyze all of the data as a form of member checking. The purpose of member checking is to gather your feedback on my findings and whether or not you feel they resonate with your experiences and our discussion.

Below you will find a list of three main themes that were obtained through my analysis of the interviews. Supporting themes follows each main theme. After each supporting theme, you will find some examples of quotes that support them. The quotes are selected from a variety of interviews.

Please send me your feedback, if any, via email. As a reminder, your participation is confidential and voluntary. If there are any questions I may answer, please let me know. I would greatly appreciate your feedback by Sunday, October $9^{\text {th }}, 2011$ so that I may incorporate any feedback into my analysis.

Thank you, Tony Delgado

Theme 1: The way interpersonal relationships were structured in a higher education classroom shaped how students perceived power in a higher education classroom.

Students used the metaphor of family to describe and understand their experiences in higher education.

"We had great instructors that we had for two or three different classes. They knew us and we knew them. It was like a big family, it really was. One of the things that I recall was that those instructors, those teachers, were very sincere at not letting us fail." "We were a close-knit family."

\section{Positive relationships with instructors were structured around a perceived ethic of caring and nurturing by the instructor.}

"It's the attitude and the essence of their teaching and their presence in the classroom that makes the student say this person cares for me." 
"He was very nurturing... of my intellect."

"If I sense that the professor is not approachable, not really caring, is not really interested, I generally won't either...won't ever take a class with that professor again or will give him a negative evaluation."

When instructors used participatory forms of instruction in a higher education classroom, instructors used their power to validate other forms of knowledge/ways of knowing.

"There were some students who were in the class and who did challenge him in class. He didn't shut them down."

"You just cannot anymore impose Western values and don't try to say the only thing that is good, because you don't read or understand other languages."

"Some professors like the gap to say I'm mister know-it-all and I got this $\mathrm{PhD}$ at the end of my name for a reason; whereas a warm professor in higher education is somebody that is a learner with you."

Theme 2: As participants were consistently exposed to exercises of instructor power in a higher education classroom, the more likely they were to attribute those exercises of power to particular instructor personality traits rather than systemic exercises of power.

Consistency or patterns of instructor behaviors were perceived as a trait of the instructor while the student-instructor relationship is maintained.

"I assume that that's his personality just because that's always how he acts, I mean I could be wrong...I think if you see it consistently it's like that's who that person is, you have to take it for what it is."

"Why would you never say someone's name if you know them? I think it was because he knows he's got memory problems."

When faced with a negative exercise of instructor power, students decided whether or not to continue in that student-instructor relationship. If a student chose to remain in that relationship, the student engaged in self-preservation.

"I actually ended up dropping that class, and I asked, and it was a late drop though, and I had to go to him to get a signature and he asked, why did you drop my class and I told him, to tell you the truth, I told him a lie, to tell you the truth I thought it was going to be an easy class."

"I was a biology major. I changed my major. I changed it to English. He was one of the reasons why. I had always been weak in math. Then I asked him a question. The way I would learn would be that I would ask a lot of questions....He just embarrassed me in front of the whole class. It was a class full of males and there were only three females in the class."

Because an instructor is in a position of power, unreasonable exercises of power were considered unnecessary and a reflection of a personality flaw of the instructor. 
"I think both of them were just miserable people. They had no clue how to teach." "Arrogance. Condescending. There's no way you'll ever know as much as I know or read as much as I've read, you know. Those kinds of attitudes."

"My professor now for the summer... is very eccentric and very blunt. Some people find that offensive; I think it's funny and a distraction from the difficult coursework." "I see it as that person's problem because I believe that people who feel the need to use their power in an environment where they are clearly the most powerful person, I believe there's a problem with that need....I don't take it personally because if they were comfortable with themselves they wouldn't feel the need to use their power to do anything that can be interpreted in the wrong way or harmful or actually be harmful to a student."

Theme 3: As participants progressed from undergraduate to graduate studies, they perceived expertise in content or knowledge development as secondary to expertise in successfully navigating the social, cultural, political, and interpersonal terrains of higher education.

Students relied on non-institutional sources of student evaluation to gain insights on what to possibly expect when they entered a new student-instructor relationship. "Now we have all the social media and Rate My Professor and there's more public information about the faculty now than there ever was. Most students don't think that it really has any impact on position in terms of a tenured professor. That those student evaluations really don't have any power."

"That's why I think a lot of kids have it easier than a lot of us had in the past with all this Rate the Professor stuff. You can just Google and figure out some idea of what the professor's going to grade like."

The perceived benefits of earning the educational credential outweighed the perceived consequences of having to endure an unfavorable student-instructor relationship. "I didn't really want to get into an argument with him on this. I'm there just to get a grade at that point."

"It was the last semester. I needed to be finished. I needed to have my degree. I needed to move on with my life."

It is not about what you know; it is about learning how to play the game.

"You just play the game....I don't even think that getting a doctorate has made me that much smarter or had much more of a leg up compared to people who just went to college. I think it's more that I'm getting the credential that will give me power in society. I'm going to be Dr. So and So."

"The worst teachers would be the ones that were maybe erratic. They weren't following what they said the first day of class. You realize it too late, and you're going through the semester going, "Oh my God. What's going to be on the test now?" I would probably have more hatred for that kind of teacher than I did, let's say, somebody who happened to be pompous or had ideas that I disagree with. If they followed what they said they were 
going to do at the beginning of the semester, then I tended to be okay with it. And actually in graduate school, I've gone through a few teachers that I didn't like, but I've been able to - I know I can maneuver my way through the course and pass it." 
VITA

\section{ANTONIO DELGADO}

1993-1997

B.A., Psychology

Florida International University

Miami, Florida

1997-1999

M.Ed., College Student Affairs Administration

University of Georgia

Athens, Georgia

2001-2002

M.A., Human Performance Systems

Marymount University

Arlington, Virginia

\section{PUBLICATIONS AND PRESENTATIONS}

Delgado, A. (2006). Better Spanish, better English: Native language literacy and adult education. In M. S. Plakhotnik \& S. M. Nielsen (Eds.), Proceedings of the Fifth Annual College of Education Research Conference: Urban and International Education Section (pp. 13-18). Miami, FL: Florida International University. http://coeweb.fiu.edu/research_conference/

Delgado, A. (2007). [Review of the book Teaching Defiance]. Adult Education Quarterly, 57(1), 178-182.

Delgado, A. (2008). Speaking up: A phenomenological study of student perceptions of being silenced in their higher education classrooms. In M.S. Plakhotnik \& S. M. Nielsen (Eds.), Proceedings of the Seventh Annual College of Education Research Conference (pp. 19-24). Miami, FL: Florida International University. http://coeweb.fiu.edu/research_conference/

Delgado, A., Rios, S. J., \& Roberts N. (2006). [Review of the book: Philosophical foundations of adult education]. New Horizons in Adult Education and Human Resource Development, 20(3), 43-46. http://education.fiu.edu/newhorizons

Delgado, A., \& Rocco, T. S. (2007). Framing the issue/framing the question: Inquiry, inclusion, advocacy, or hostility? In R. J. Hill (Ed.), Proceedings 2007 Adult Education Research Conference/Canadian Association for the Study of Adult Education, Lesbian, Gay, Bisexual, Transgender, Queer, \& Allies (LGBTQ\&A) Pre-Conference, Challenging Homophobia and Heterosexism: Lesbian, Gay, Bisexual, Transgender, and Queer Issues in Organizational Settings (pp. 33-39). Halifax, Nova Scotia, Canada: Mount Saint Vincent University. 
Delgado, A., \& Rocco, T. S. (2008). "But to impose, we must." Two views on educational imposition [Editorial]. New Horizons in Adult Education and Human Resource Development, 22(2), 2-5. http://education.fiu.edu/newhorizons

Plakhotnik, M. S., Delgado, A., \& Seepersad, R. (2006). Autobiographical exploration of selves as adult learners and adult educators. In E. P Isaac (Ed.), Proceedings of the $25^{\text {th }}$ Midwest Research-to-Practice Conference in Adult, Continuing, and Community Education (pp. 163-168). St. Louis, MO: University of Missouri.

Plakhotnik, M. S., \& Delgado, A. (2008). [Review of the book Identity and Violence: The Illusion of Destiny]. Adult Education Quarterly, 58(4), 337-342.

Rocco, T. S., \& Delgado, A. (2011). Shifting lenses: A critical examination of disability in adult education. New Directions for Adult and Continuing Education, 2011(132), 3-12. doi: 10.1002/ace.426

Rocco, T. S., Delgado, A., \& Landorf, H. (2008). Framing the issue/framing the question: How are sexual minority issues included in diversity initiatives? In T. J. Chermack (Ed.), Proceedings of the Academy of Human Resource Development 2008 Annual Conference (pp. 201-208). Panama City, FL: AHRD.

Rocco, T. S., Landorf, H. \& Delgado, A. (2009). Framing the issue/Framing the question: A proposed framework for organizational perspectives on sexual minorities. In $\mathrm{T}$. S. Rocco, J. Gedro, and M. Kormanik (Eds.), GLBT issues in HRD: Balancing inquiry and advocacy. Advances in Developing Human Resources, 11(1), 7-23. 